\title{
TAFONOMÍA DE LOS MICROVERTEBRADOS DEL SITIO ARQUEOLÓGICO CUEVA TIXI (PLEISTOCENO TARDÍO-HOLOCENO TARDÍO), TANDILIA ORIENTAL (PROVINCIA DE BUENOS AIRES, ARGENTINA)
}

\author{
CARLOS A. QUINTANA
}

Laboratorio de Arqueología Regional Bonaerense, Universidad Nacional de Mar del Plata, J. B. Justo 2550, 7600 Mar del Plata, provincia de Buenos Aires, Argentina.

Recibido: 22 de Octubre de 2015 - Aceptado: 6 de Abril de 2016

Para citar este artículo: Carlos A. Quintana (2016). Tafonomía de los microvertebrados del sitio arqueológico Cueva Tixi (Pleistoceno tardío-Holoceno tardío), Tandilia Oriental (provincia de Buenos Aires, Argentina). Publicación Electrónica de la Asociación Paleontológica Argentina 16 (1): 14-51.

Link a este artículo: http://dx.doi.org/10.5710/PEAPA.06.04.2016.87

DESPLAZARSE HACIA ABAJO PARA ACCEDER AL ARTÍCULO

Asociación Paleontológica Argentina Maipú $6451^{\circ}$ piso, C1006ACG, Buenos Aires República Argentina Tel/Fax (54-11) 4326-7563 Web: www.apaleontologica.org.ar

Otros artículos en Publicación Electrónica de la APA 15(1):

\section{Herrera}

METRIORHYNCHIDAE (CROCODYLOMORPHA: THALATTOSUCHIA) FROM UPPER JURASSIC-LOWER CRETACEOUS OF NEUQUÉN BASIN (ARGENTINA), WITH COMMENTS ON THE NATURAL CASTS OF THE BRAIN.

\section{Otero \& Salgado}

EL REGISTRO DE SAUROPODOMORPHA (DINOSAURIA) DE LA ARGENTINA.
Fernández \& Campos

OPHTHALMOSAURIDS (ICHTHYOSAURIA: THUNNOSAURIA): ALPHA TAXONOMY, CLADES AND NAMES. 


\title{
TAFONOMÍA DE LOS MICROVERTEBRADOS DEL SITIO ARQUEOLÓGICO CUEVA TIXI (PLEISTOCENO TARDÍO-HOLOCENO TARDIO), TANDILIA ORIENTAL (PROVINCIA DE BUENOS AIRES, ARGENTINA)
}

\author{
CARLOS A. QUINTANA
}

Laboratorio de Arqueología Regional Bonaerense, Universidad Nacional de Mar del Plata, J. B. Justo 2550, 7600 Mar del Plata, provincia de Buenos Aires, Argentina. quintanamdp@gmail.com

\begin{abstract}
Resumen. Se analizaron los atributos tafonómicos de una muestra de microvertebrados constituida por 67805 restos esqueléticos del sitio arqueológico Cueva Tixi (Tandilia oriental, provincia de Buenos Aires, Argentina). Se registraron restos asignados a mamíferos, aves, anuros, ofidios y peces, todos con alteraciones, en una secuencia de 11000 años (Pleistoceno Tardío-Holoceno tardío). La mayor proporción de la muestra compuesta por roedores, marsupiales didélfidos, aves, anuros y algunos peces presenta trazas de digestión y proporciones esqueléticas que indican que fue depositada por aves rapaces nocturnas. Se trata de acumulaciones de huesos con alteraciones muy homogéneas en toda la secuencia estratigráfica. En el caso de los restos de ofidios, su depósito se habría producido por muerte en el sitio durante el letargo. Los restos de roedores cávidos del Holoceno tardío final tienen marcas de corte de artefactos y una preservación del esqueleto que demuestran su manipulación antrópica. Las alteraciones posdepositacionales más frecuentes fueron las fracturas. Las marcas de raíces o las adherencias de minerales presentaron tendencias de aumento o disminución de sus frecuencias en la secuencia.
\end{abstract}

Palabras clave. Alteraciones óseas. Egagrópilas. Preservación esquelética.

\begin{abstract}
MICROVERTEBRATE TAPHONOMY OF THE ARCHAEOLOGICAL SITE CUEVA TIXI (LATE PLEISTOCENE-LATE HOLOCENE) EASTERN TANDILIA (BUENOS AIRES PROVINCE, ARGENTINA). The taphonomic attributes of a sample of microvertebrates composed by 67805 remains, from the archaeological site Cueva Tixi (Eastern Tandilia, Buenos Aires Province, Argentina), were analyzed. Mammals, birds, frogs, snakes and fish were recorded with natural or anthropogenic modifications in a sequence of 11000 years (Late Pleistocene-late Holocene). The largest proportion of the sample including rodents, didelphid marsupials, birds, frogs and some fish has traces of gastric digestion and skeletal proportions that suggests that it was deposited by nocturnal prey birds. These accumulations of bones have very homogeneous alterations throughout the stratigraphic sequence. The accumulation of snakes would have occurred by circumstantial death on the cave. The skeletal remains of cavid rodents, from the latest Holocene, have cut marks of artifacts and a skeletal preservation which demonstrate its anthropogenic manipulation. The most frequent alterations were post-depositional breakage. Roots marks and mineral deposits presented increasing or decreasing trends in its frequencies in the sequence.
\end{abstract}

Key words. Bone modifications. Owl pellets. Skeletal preservation.

CUEVA TIXI puede ser interpretada como un sitio arqueológico y paleontológico a la vez. Se ubica en el extremo este de las sierras de Tandilia, provincia de Buenos Aires, Argentina (Fig. 1). Tiene una secuencia arqueológica que representa una cronología extensa, desde el poblamiento de la región Pampeana hasta tiempos pre conquista (Mazzanti, 1997a). Su registro fósil, asignado al lapso Pleistoceno Tardío-Holoceno tardío, es ilustrativo de la diversidad de vertebrados de Tandilia, mientras que el uso antrópico de su fauna per- mitió conocer la composición y variabilidad de las estrategias de subsistencia indígena regional (Quintana y Mazzanti, 2001, 2010, 2011).

Este sitio presenta uno de los registros fósiles de microvertebrados más numeroso y taxonómicamente diverso de América del Sur lo que, junto a su contexto estratigráfico y cronológico, conforma un caso atractivo para la indagación paleontológica y zooarqueológica. La fauna contenida en sus estratos cuenta con decenas de miles de restos óseos de es- 
pecies de pequeño tamaño, como los ratones de campo, o grandes como los guanacos y los venados (Quintana, 2001a).

La posición en el paisaje de Cueva Tixi, en lo alto de un sector protegido de la pendiente serrana y su propia condición de refugio rocoso resultaron ser atributos que favorecieron la preservación de la secuencia sedimentaria y de su contenido arqueológico y paleontológico. La escasa perturbación de los depósitos y la acumulación continua de restos óseos ocasionaron que los esqueletos de animales grandes, incorporados para la subsistencia humana, y los de microvertebrados, depositados por depredadores, se dispongan en conjunto. Los análisis efectuados para resolver ese palimpsesto permitieron discriminar preliminarmente los distintos orígenes de las especies depositadas y reconocer causas múltiples de la acumulación de los vertebrados más pequeños (Quintana, 2005, 2015a). Estos aportes estuvieron enfocados principalmente en los roedores cávidos, ya que durante el Holoceno tardío final los grupos humanos ampliaron el espectro de presas que consumían incorporando a especies de micromamíferos, lo que fue interpretado como un emergente de cambio social (Quintana y Mazzanti, 2014).

La discriminación de los agentes tafonómicos de modo más preciso en todos los taxones de microvertebrados es trascendente para comprender cuáles agentes naturales de acumulación intervinieron y si fueron variables a través del
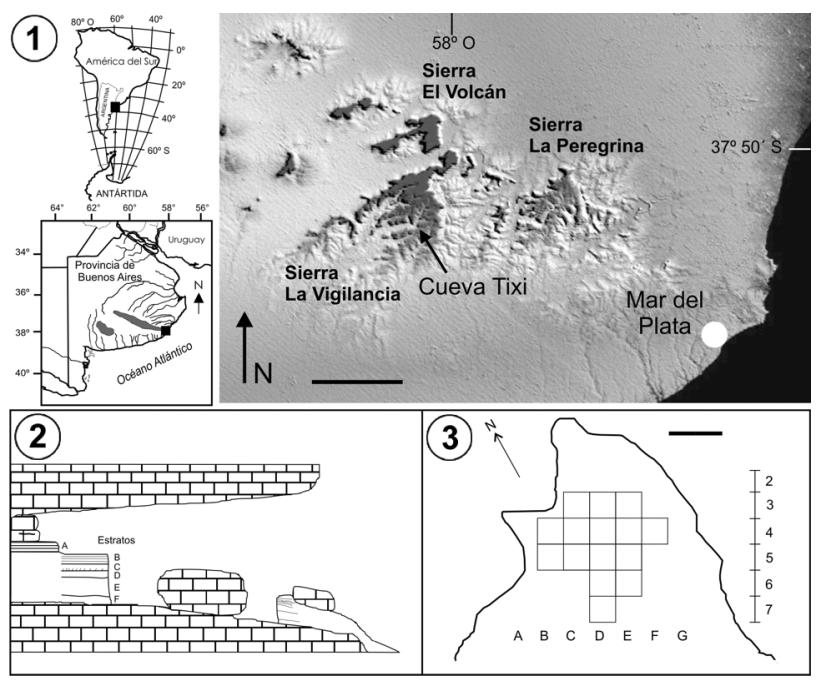

Figura 1. Cueva Tixi. 1, Ubicación geográfica, escala= 10 km; 2, corte lateral; 3, planta, escala $=2 \mathrm{~m}$. tiempo. En este contexto resulta crítico determinar si otras especies de microvertebrados fueron parte de la subsistencia de los cazadores-recolectores serranos y precisar qué tipos de depredadores ocasionaron esas acumulaciones.

La excavación, la clasificación anatómica, la identificación taxonómica y la determinación de los atributos tafonómicos de los microvertebrados de este refugio rocoso pasaron por etapas de análisis con enfoques y grados de resolución diversos. La causa principal de este proceso es la diversidad cronológica y el gran tamaño de la muestra que, en principio, aparentaba ser insondable y caótica. En este contexto, resultó inexorable la perspectiva multidisciplinaria con un pie en la paleontología, otro en la zooarqueología y otro más en la biología de los depredadores actuales. Interconectando esa red de enfoques, el análisis tafonómico se comportó como un tamiz que tradujo a los interrogantes iniciales, planteados a partir de un desorden aparente del registro fósil, en una nueva etapa de un modelo que permite vislumbrar a ese registro como un proceso explicable y ordenado. El objetivo de esta contribución es determinar y cuantificar las variables tafonómicas de las acumulaciones de microvertebrados de Cueva Tixi.

\section{EL SITIO ARQUEOLÓGICO CUEVA TIXI}

Cueva Tixi es un refugio rocoso que se encuentra en sierra La Vigilancia, provincia de Buenos Aires, a una cota de 190 msnm y se dispone sobre un valle pequeño que tributa al valle principal del arroyo San Pedro (Fig. 1). Esta sierra pertenece al Sistema de Tandilia, que constituye una serie de cerros alargados de una altura máxima 300 msnm, con cumbres chatas producto del fallamiento y erosión de los mantos subhorizontales de ortocuarcitas (Martínez y Osterrieth, 2001). El área cubierta de Cueva Tixi es de unos 40 m2 con una altura media de 1,80 m (Fig. 1). La boca de la cueva está orientada hacia el suroeste y protegida por la pendiente opuesta del valle. En primavera la línea de insolación penetra en todo el recinto durante la tarde.

La secuencia sedimentaria de este refugio rocoso se compone de seis unidades estratigráficas $(A, B, C, D, E$ y $F)$ (Figini et al., 1985; Mazzanti, 1993) descriptas detalladamente por Martínez y Osterrieth (2001) (Fig. 2). La unidad A es una capa de carbonato de calcio sin restos faunísticos ni culturales, que cubre la parte posterior de la cueva a modo 
de zócalo, por lo que no se encuentra incluida en la matriz sedimentaria excavada (Figini et al., 1985; Mazzanti, 1993; Martínez y Osterrieth, 2001; Mazzanti y Quintana, 2002). Las demás unidades se caracterizan por el tamaño de grano creciente hacia la base, de limos arcillosos a limos arenosos gruesos. Los restos de fauna se disponen en cuatro estratos ( $B, C, D$ y $E$ ) de los cuales el más antiguo fue separado en $E$ inferior (Pleistoceno Tardío) y E superior (Holoceno medio) por su cronología, contenido arqueológico y faunístico (Mazzanti, 2001; Quintana, 2001a) (Fig. 2). La cronología absoluta se estableció con seis fechados radiocarbónicos sobre muestras de carbón vegetal proveniente de fogones indígenas (Mazzanti, 1993, 1997a,b) (Fig. 2). Estas muestras se procesaron en el laboratorio NSF Arizona AMS Facility de la Universidad de Arizona (EEUU) utilizando un acelerador de espectrometría de masas (AMS).

Los estratos geológicos descriptos contienen cuatro niveles arqueológicos (Mazzanti, 1993, 1994, 1995-1996, 1997a-c; Mazzanti y Quintana, 1997, 2002; Mazzanti y Valverde, 2001; Valverde, 2003; Mazzanti et al., 2012; Mazzanti y Bonnat, 2013). Cueva Tixi fue excavada a través de niveles naturales usando la metodología de decapados. Los espesores fueron variables dependiendo de cómo estaban dispuestos los materiales arqueológicos y paleontológicos. Los materiales más conspicuos fueron relevados en tres dimensiones en planta y los más pequeños se recuperaron bajo agua con el uso de cernidores de $2 \mathrm{~mm}$ de malla. Los aspectos metodológicos de las excavaciones de Cueva Tixi y las técnicas de relevamiento de datos fueron expuestos en Mazzanti (1993, 1994, 1995-1996, 1997 a-c) y en Mazzanti y Quintana (2002).

El contenido faunístico ha sido objeto de diversas contribuciones sobre la diversidad taxonómica (Prado et al., 1985; Tonni et al., 1988; Quintana y Mazzanti, 1996; Albino, 2001; Cione y Barla, 2001; Goin, 2001; Laza, 2001; Quintana, 2001a,c, 2004a,b; Albino et al., 2002), la tafonomía (Quintana, 2001b, 2004c, 2007, 2015a) y la subsistencia humana (Mazzanti y Quintana, 1997, 2001; Valverde, 2001; Mazzanti y Valverde, 2001; Quintana et al., 2002, 2004; Quintana, 2005; Quintana y Mazzanti, 2010, 2011, 2014). Otras publicaciones que tratan algunos temas relacionados con el registro fósil de Cueva Tixi (Pardiñas, 1995, 1999a,b, 2000) no son considerados como antecedentes por los mo- tivos discutidos en Mazzanti y Quintana (2001, 2002).

Otros aportes relacionados con este sitio comprenden estudios geológicos y paleoambientales (Figini et. al., 1985; Martínez et al., 1999, 2013; Martínez y Osterrieth, 2001, 2004; Martínez, 2007; Mazzanti et al., 2012), paleobotánicos (Zucol et al., 2008; Brea y Mazzanti, 2014) y arqueométricos (Mazzanti y Porto López, 2007; Porto López y Mazzanti, 2009, 2010).

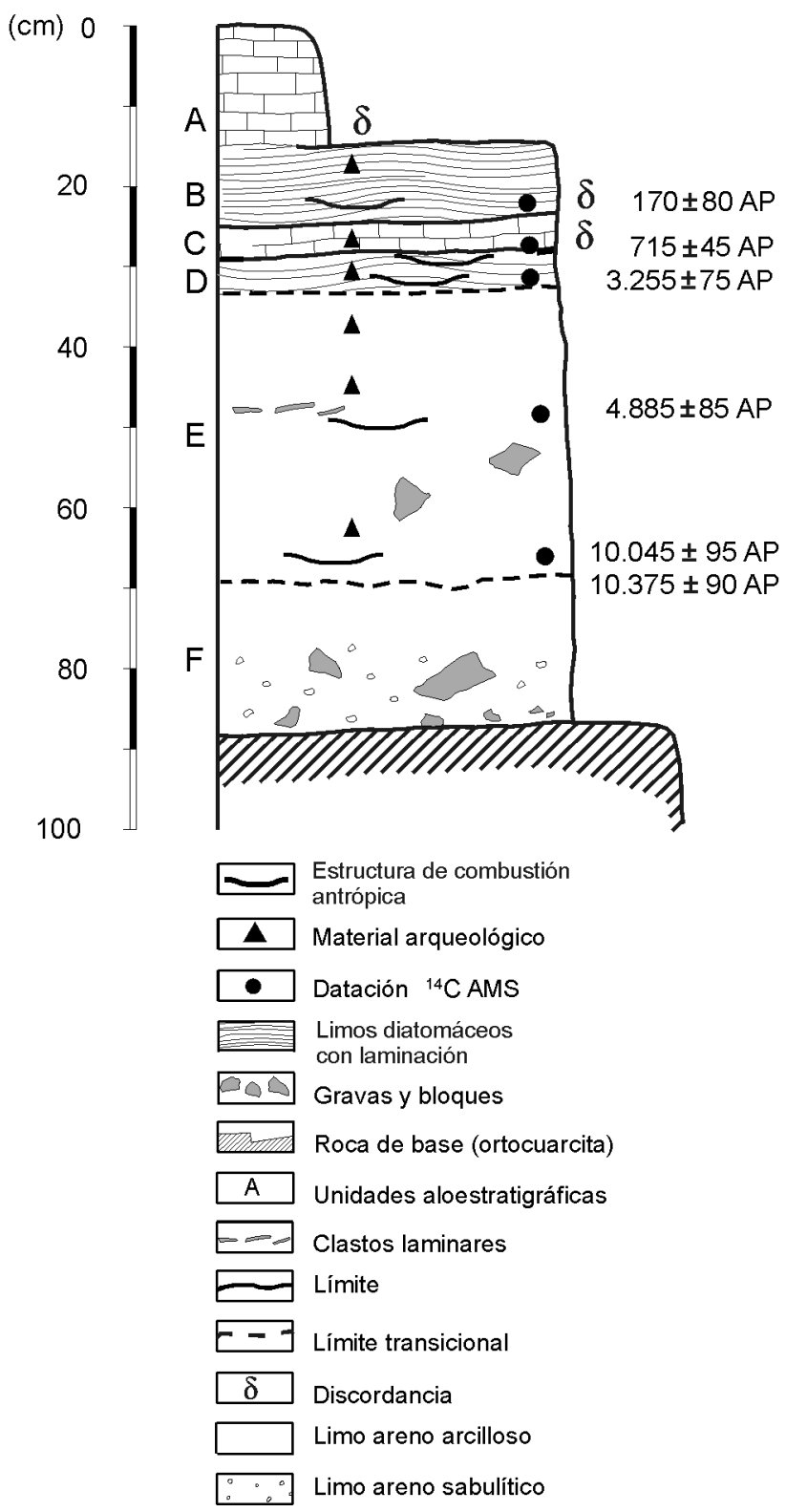

Figura 2. Perfil estratigráfico y fechados radicarbónicos (AMS) de toda la secuencia de Cueva Tixi, tomado de Martínez y Osterrieth (2001). 


\section{MATERIALES Y MÉTODOS}

En esta contribución se considera como microvertebrado a las especies con masa corporal menor a $1000 \mathrm{gr}$ (Quintana, 2005; Quintana y Mazzanti, 2010). Este criterio surge de análisis zooarqueológicos en los que las presas con ese rango de masa, fueron cazadas solamente en contextos de intensificación de la subsistencia indígena (Quintana y Mazzanti, 2014). En consecuencia esos tamaños de presas son indicadores de cambios significativos en la relación sociedad-naturaleza. A su vez, este concepto de microvertebrado comprende a las presas más comunes de los depredadores locales, tanto aves como mamíferos (Quintana y Mazzanti, 2001; Quintana, 2004c).

La muestra de Cueva Tixi está depositada en la colección científica del Laboratorio de Arqueología Regional Bonaerense (LARQ) de la Universidad Nacional de Mar del Plata. Debido a su gran volumen, las colecciones de sitios arqueológicos del LARQ, se registran por sitio y se identifican como lotes, rotulados individualmente con su procedencia geográfica y estratigráfica (sitio, nivel estratigráfico, decapado y ubicación tridimensional). Los microvertebrados de Cueva Tixi tienen un Número de Especímenes Identificados por Taxón (NEIT; Payne, 1975) de 72116, de los cuales 67805 fueron incorporados a este estudio. El 6\% restante (4311) no fue incluido debido a que proviene de cuadrículas cercanas a la línea de goteo, con menor calidad de definición de los estratos que los contenían.

En este análisis se realizó una revisión minuciosa de toda la muestra con el fin de evaluar restos craneanos y poscraneanos que fueron excluidos del estudio inicial de la fauna de este sitio (Quintana, 2001a, 2005) por ser caracterizados como no identificables o por no haber sido detectados debido a su tamaño minúsculo. En consecuencia se amplió significativamente la cantidad de elementos analizados al incorporar numerosos restos de mamíferos, aves, ofidios y peces. Los huesos de microvertebrados se presentaron en concentraciones, pero disgregados de la egagrópila, por lo que estuvieron más expuestos a los factores que pudieron alterarlos tanto en superficie como dentro de la matriz sedimentaria.

Se cuenta con antecedentes que caracterizaron a los micromamíferos incorporados a la subsistencia humana (roedores cávidos) (Quintana, 2005, 2015a; Quintana y
Mazzanti, 2010) y análisis preliminares del resto de los microvertebrados concentrados por agentes naturales (Quintana, 2004c). Estos aportes permitieron optimizar la metodología aplicada separando la muestra en tres conjuntos:

Grupo 1: microvertebrados incorporados naturalmente (nueve especies de roedores cricétidos, cinco de marsupiales didélfidos y el roedor caviomorfo Ctenomys talarum Thomas, 1898 (Quintana, 2001b, 2004c).

Grupo 2: microvertebrados incorporados natural y antrópicamente (los roedores caviomorfos Galea tixiensis Quintana, 2001 y Cavia aperea Erxleben, 1777 (Quintana y Mazzanti, 2001; Quintana, 2004c, 2005).

Grupo 3: aves, ofidios, anuros y peces.

Este agrupamiento de taxones tiene una base metodológica. Los restos óseos de los tres grupos habrían sido incorporados al sitio principalmente por agentes naturales (Quintana, 2001b, 2004c), pero los del Grupo 2 presentan también evidencias de traslado y explotación por grupos indígenas (Quintana, 2005, 2015a). Debido a ello las variables que pueden ser emergentes del agente de acumulación se analizaron para cada grupo por separado: patrón de preservación esquelética, huellas de corte, corrosión digestiva, fracturas y alteración térmica. La cuantificación de los diversos rasgos se efectuó en el conjunto óseo de cada decapado por observación bajo lupa binocular de hasta 40 aumentos.

Si bien los agentes posdepositacionales actúan de modo homogéneo, la anatomía de cada taxón condiciona su expresión de modo diferente. Así, las alteraciones posdepositacionales de la muestra se analizaron conjuntamente en los integrantes de los Grupos 1 y 2 (mamíferos) y para cada taxón del Grupo 3 (aves, reptiles, peces y anuros) por separado.

Complementariamente se compararon los resultados obtenidos con una muestra actual de huesos dispersos de microvertebrados (NEIT 6017) provenientes de egagrópilas de Tyto alba (Scopoli, 1769) hallada en Sierra La Peregrina en un sector sin tránsito de animales ni de personas, depositada sobre la roca de caja y parcialmente atrapada en grietas (Quintana, 2015b). Esta muestra resulta relevante a fines comparativos con la de Cueva Tixi porque proviene del mismo ambiente serrano y porque fue afectada en etapas 
previas al enterramiento por factores ambientales equivalentes a los de ese refugio rocoso.

\section{Alteraciones pre y posdepositacionales}

Alteraciones antrópicas. Se siguieron los criterios sintetizados en Lyman (1994) para reconocer huellas de corte y de Medina et al. (2012) para patrones de exposición intencional al fuego.

La termoalteración se analizó según los criterios de Shipman et al. (1984). En los micromamíferos se estableció solamente en los huesos largos (húmero, ulna, radio, fémur y tibia) del Grupo 1 (NEIT estrato B: 3438; NEIT estrato C: 4859; NEIT estrato D: 3776; NEIT estrato E superior: 9146; NEIT estrato E inferior: 1097), del Grupo 2 (NEIT B: 329; NEIT C: 476; NEIT D: 470; NEIT E superior: 567; NEIT E inferior: 45) y en la muestra actual de referencia (NEIT: 1817). En el resto de los taxones la termoalteración se buscó en todos los elementos preservados.

Alteraciones no antrópicas. Se utilizaron las contribuciones de Quintana (2007) para identificar marcas de mordeduras de roedores, de Lyman (1994) para reconocer marcas de mordeduras de carnívoros y de Mikuláš (1999) para establecer la bioerosión producida por raíces. Se establecieron tres categorías para cuantificar las impresiones de ácidos radiculares según la densidad en la superficie ósea afectada y si la corrosión destruyó algún rasgo de la anatomía: Reducida: $<20 \%$ de la superficie con marcas de raíces; Amplia: $>20 \%$ de la superficie con marcas de raíces; Profunda: con destrucción del hueso (perforación de la masa ósea independientemente de la extensión de las marcas) (Fig. 3). También se consideró la extensión, es decir, si las trazas están impresas de un solo lado del elemento o sobre todo su perímetro. La combinación de las categorías de densidad y de superficies afectadas es una aproximación a la intensidad de la acción de las raíces. Se registró la presencia de trazas radiculares en los bordes y planos de fractura.

Para identificar la corrosión digestiva en mamíferos se usó el criterio de Andrews (1990); se cuantificó sobre la epífisis proximal del fémur y la epífisis distal del húmero en cada grupo de mamíferos por separado, con el fin de poner a prueba si los roedores cávidos tienen evidencias diferentes a las de los otros micromamíferos. En esta etapa no se analizó esta alteración sobre la dentición debido al gran ta- maño de la muestra. La corrosión digestiva de los restos de anfibios se evaluó según los criterios de Pinto Llona y Andrews (1999). En los elementos de aves esta alteración se analizó en todo el esqueleto, pero para caracterizar la muestra de cada estrato se cuantificaron los porcentajes de las epífisis afectadas del total de los huesos largos.

Las fracturas se determinaron en dos categorías según las propuestas de Lyman (1994) y de Alcántara García et al. (2006): en estado fresco (superficies de fractura lisas, de ángulos obtusos o agudos y con bordes lineales) y en estado seco (superficies de fractura rugosas, de ángulos rectos y con bordes irregulares, quebrados o almenados). Las fracturas en estado fresco se interpretaron como predepositacionales y mayormente causadas durante la captura y el consumo. Aquellas ocasionadas sobre el hueso en estado seco, se interpretaron como posdepositacionales, ya sea en superficie o durante el enterramiento.

Las modificaciones posteriores al enterramiento comprendieron impregnación de óxidos de manganeso, depósitos y cristalizaciones de carbonatos, marcas de ácidos radiculares y fracturas. Los hoyos de disolución química, las descamaciones, las rayas de pisoteo, las alteraciones superficiales indeterminadas y las producidas por agentes meteóricos se incorporaron en la categoría denominada "otras" debido a su poca frecuencia.
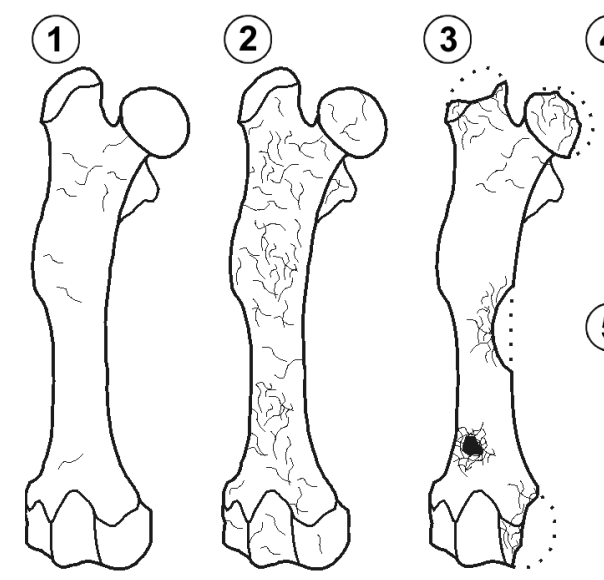

(4)

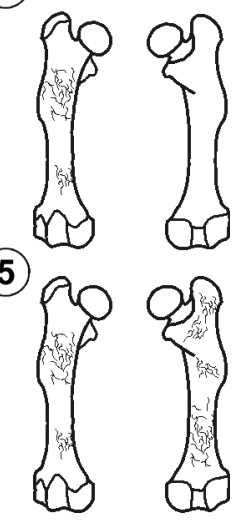

Figura 3. Categorías de impacto de acción radicular. 1, Reducida: <20\% de la superficie con marcas de raíces; 2 , amplia: $>20 \%$ de la superficie con marcas de raíces; 3, profunda: con destrucción o perforación del hueso; 4, marcas de un solo lado; 5, marcas sobre todo el perímetro. 
Para el caso de los mamíferos (Grupos 1 y 2) las alteraciones posdepositacionales se determinaron en conjunto y solo en los fémures debido al gran tamaño de la muestra.

Para los representantes del Grupo 3, cuya muestra es menor, se analizaron todos los elementos registrados para caracterizar las alteraciones pre y posdepositacionales con los mismos criterios usados para los mamíferos, cuando fue posible aplicarlos. En el caso de los ofidios las alteraciones se cuantificaron en cada rasgo anatómico de las vértebras.

Patologías. Las patologías óseas pueden ser una fuente de alteración y pérdida de la anatomía, por lo que fueron cuantificadas como alteraciones pre depositacionales.

\section{Preservación esquelética}

Índices de abundancia taxonómica y anatómica. Los índices utilizados fueron:

1) Número de Especímenes Identificados por Taxón (NEIT) (Payne, 1975). Se calculó para cada hueso entero o fragmentado identificado.

2) Número Mínimo de Individuos (NMI) (Withe, 1953). En esta contribución el NMI para cada taxón por separado se calculó en cada estrato sobre la base de las ramas mandibulares, fémures y húmeros considerando la lateralidad. Los valores máximos de cada taxón fueron combinados para componer el NMI final. Para el caso de las aves también se analizó la variable etaria debido al pequeño tamaño de la muestra.

3) Número Mínimo de Elementos (NME) (Binford, 1984). Se calculó a partir de la fragmentación de los huesos largos (huesos enteros, epífisis y diáfisis) sin considerar la lateralidad.

4) Abundancia relativa (Ab. rel.). Se empleó el siguiente criterio Ab. rel.= $100 \times(\mathrm{NMEi} / \mathrm{NMI} \times \mathrm{Ei})$, siendo Ei la cantidad de veces que el elemento i está presente en el esqueleto. Para el cálculo de la abundancia relativa promedio no se cuantificaron los dientes debido a que la pérdida de los mismos genera sesgos amplios que no representan a la muestra en el momento de su depósito en superficie (Quintana, 2015b). Para el cálculo de las vértebras no se incorporaron las caudales porque su número varía entre los taxones involucrados. La frecuencia de costillas (C), vértebras (V), metapodios (M) y falanges (F) de los distintos taxones de micromamíferos se calculó considerando a la anatomía de Ctenomys tala- rum (C 26, V 27, M 40, F 56), de Oxymycterus rufus (Fischer, 1814) (C 26, V 27, M 40, F 56) como modelo de los roedores cricétidos y de Cavia aperea (C 26, V 27, M 28, F 40) para los roedores cávidos presentes en el sitio. Para los marsupiales no se realizaron cálculos por separado de esos elementos debido a que se asume que su baja frecuencia no modifica sustancialmente el valor final de las abundancias relativas.

5) Pérdida de molares e incisivos. Para conocer la conservación de dientes fuera de los alvéolos se calculó el parámetro de Andrews (1990) que compara los dientes recuperados sueltos con relación a los alvéolos vacíos: NEIT dientes sueltos x 100/total de alvéolos vacíos. Para conocer la conservación total de dientes se realizó el siguiente cálculo: NEIT dientes sueltos + NEIT dientes en alvéolos $\mathrm{x}$ 100/total de dientes esperados.

El total de dientes esperados se estimó en función de los maxilares, premaxilares y ramas mandibulares registradas. En el Grupo 1 este parámetro fue analizado en roedores cricétidos y en Ctenomys talarum por separado debido a que las fórmulas dentarias son distintas. Es de destacar que los dientes de las especies analizadas tienen morfologías distintas (braquidontes o hipsodontes) de modo que la forma de sus raíces influye en la magnitud de su pérdida.

Se han desarrollado diversos índices con el objetivo de medir la preservación relativa entre distintas partes del esqueleto de mamíferos, aves y anuros (Bramwell et al., 1987; Andrews, 1990; Pinto Llona y Andrews, 1999; Bochenski y Tornberg, 2003, entre otros). En esta contribución se tomaron índices de todos los tipos con el fin de presentar valores comparables a publicaciones de referencia, se han adaptado algunos para el caso de estudio y se construyeron otros para resolver alguna cuestión específica. La diversidad de propuestas también incorpora el uso del NEIT o del NME para la cuantificación, en estos casos se siguió el enfoque de los autores originales.

6) Relación entre elementos distales y proximales de los miembros (ED). Este índice mide la relación de elementos preservados del zeugopodio en relación con el estilopodio. En los Grupos 1 y 2 se calculó según el algoritmo propuesto por Andrews (1990): ED1= $100 \times$ (NME tibia + radio/NME fémur + húmero).

También se efectuó una segunda evaluación incorpo- 
rando las ulnas y corrigiendo la ecuación con un factor de 2/3 para compensar la diferencia de la cantidad de huesos entre ambas partes de los miembros:

ED2 = $100 \times($ NME tibia + radio + ulna) $\times 2$ /(NME fémur + húmero) $x 3$.

Para las aves esta relación se calculó según lo propuesto por Bochenski (2005): EDaves= 100 x (NEIT escápula + coracoides + húmero + fémur + tibiotarso)/(NEIT escápula + coracoides + húmero + fémur + tibiotarso) + (NEIT ulna + radio + carpometacarpo + tarsometatarso).

7) Relaciones entre elementos del cráneo y del poscráneo. Se basaron sobre dos algoritmos tomados de Andrews (1990):

PC-C1 = 100 x (NME fémur + húmero/NME maxilares + ramas mandibulares) y

PC-C2 = $100 \times$ (NME fémur + húmero + tibia + radio+ ulna) $\times 2 / N M E$ (maxilares + ramas mandibulares) $\times 5$.

Este último índice fue modificado de la formulación original en función de que la fórmula dentaria de los organismos estudiados difieren entre ellos y respecto de las especies analizadas por Andrews (1990), por lo que no es posible mantener el factor de corrección 16/10 utilizado por ese autor, ni uno alternativo que sea representativo para toda la muestra. Con el fin de obtener un índice que sea comparable para los estratos analizados se eliminó la variable dentaria y se fijó el cociente de $2 / 5$ solo referido a las piezas óseas.

8) Índice de preservación de miembros (IPM). Para evaluar si la preservación del miembro anterior está sesgada respecto del posterior se aplicó el siguiente índice en los Grupos 1 y 2: IPM: 100 x (NME húmero + radio + ulna + escápula) x 3/(NME (fémur + tibia + pelvis) $\times 4$.

La fíbula no fue incorporada porque es muy frágil para preservarse por su tamaño diminuto y porque está fusionada a la tibia en la mayoría de las especies analizadas. Para el caso de las aves se aplicó la propuesta de Ericson (1987): IPMaves: 100 x (NEIT húmero + ulna + carpometacarpo)/(NEIT húmero + ulna + carpometacarpo) + (NEIT fémur + tibiotarso + tarsometatarso).

9) Relación entre cinturas y elementos de los miembros (ICMaves). Este índice mide la preservación proporcional de los huesos de las cinturas escapular y pélvica respecto de los huesos largos de las aves (Bramwell et al., 1987):
ICMaves: 100 x (NEIT esternón + coracoides + escápula + pelvis)/(NEIT esternón + coracoides + escápula + pelvis) + (NEIT húmero + ulna + radio + carpometacarpo + fémur + tibiotarso + tarsometatarso).

Fragmentación. Se analizó sobre la base del NEIT\% de cada parte preservada (hueso entero, cada epífisis y diáfisis) de tibias, fémures, húmeros y ulnas (Andrews, 1990). Para el cráneo se cuantificaron los premaxilares, las ramas mandibulares y los maxilares. En el Grupo 1 la fragmentación del cráneo fue analizada para cada taxón por separado debido a su anatomía diferente. Para establecer la fragmentación de las ramas mandibulares se evaluaron las fracturas de la sínfisis, las del borde inferior del cuerpo mandibular y las de la rama ascendente (Andrews, 1990). Se consideró como "no fracturadas" a las ramas ascendentes que preservaron, al menos, el proceso coronoides o el proceso articular. La fragmentación de los maxilares de mamíferos fue evaluada sobre las fracturas de la zona alveolar del maxilar y las del arco cigomático. En este último caso se consideró solamente al proceso maxilar del arco cigomático ya que en esta muestra esta región del cráneo está fracturada casi en su totalidad a partir del yugal. Tanto en las ramas mandibulares como en los maxilares se cuantificaron, en cada estrato, los porcentajes del total de cada taxón. Para analizar la fragmentación de las aves se aplicaron los criterios descriptos por Bochenski y Tornberg (2003) y Bochenski (2005).

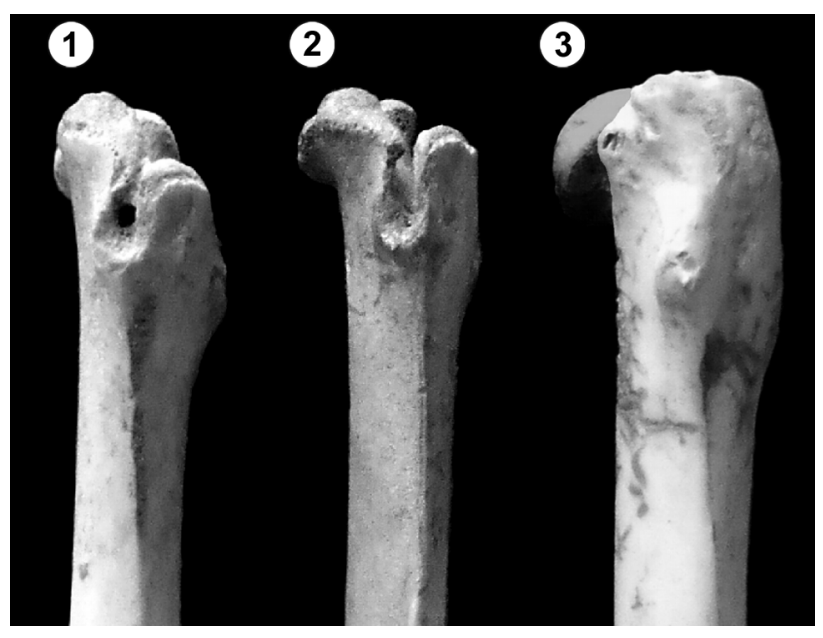

Figura 4. Criterios para determinar estadios etarios de roedores cávidos basado sobre sus fémures. 1-2, Superficie de la inserción muscular del trocánter mayor sin fusionar (juvenil); 3 , esa superficie totalmente osificada (adulto). 


\section{Otros criterios cuantitativos}

Para poner a prueba las relaciones de proporciones entre partes del esqueleto se aplicó el test de Chi cuadrado y para la heterogeneidad entre dos muestras se usó el test no paramétrico de Mann-Whitney. La conformación etaria de la muestra de roedores cávidos se estableció sobre dos estadios del fémur y de las ramas mandibulares. En los fémures se determinaron individuos adultos (superficie de in-

TABLA 1. Distribución estratigráfica de los taxones de microvertebrados identificados de Cueva Tixi.

\begin{tabular}{|c|c|c|c|c|c|}
\hline \multirow{2}{*}{ Taxones } & \multicolumn{5}{|c|}{ Estrato } \\
\hline & $B$ & $C$ & $D$ & Esup. & Einf. \\
\hline \multicolumn{6}{|l|}{ Marsupialia Didelphidae } \\
\hline Lutreolina crassicaudata & + & + & + & + & \\
\hline Lestodelphys halli & & & & + & + \\
\hline Monodelphis dimidiata & + & + & + & + & \\
\hline Monodelphis sp. nov. & & + & + & + & + \\
\hline Thylamys sp. & + & + & + & + & + \\
\hline \multicolumn{6}{|l|}{ Rodentia Cricetidae } \\
\hline Akodon azarae & + & + & + & + & + \\
\hline Bibimys torresi & + & + & & & \\
\hline Calomys sp. & + & + & + & + & + \\
\hline Holochilus brasiliensis & + & + & + & + & + \\
\hline Necromys sp. & + & + & + & + & + \\
\hline Oxymycterus rutilans & + & + & + & + & + \\
\hline Pseudoryzomys simplex & + & + & + & & \\
\hline Reithrodon auritus & + & + & + & + & + \\
\hline Scapteromys sp. & & & & & + \\
\hline \multicolumn{6}{|l|}{ Rodentia Caviomorpha } \\
\hline Ctenomys talarum & + & + & + & + & + \\
\hline Cavia aperea & + & + & + & + & + \\
\hline Galea tixiensis & + & + & + & + & + \\
\hline Chiroptera género y especie indet. & & & & + & \\
\hline Aves género y especie indet. & + & + & + & + & + \\
\hline \multicolumn{6}{|l|}{ Serpentes } \\
\hline Clelia rustica & + & + & & + & \\
\hline Bothrops alternatus & + & + & + & + & + \\
\hline Bothrops sp. & + & + & & + & \\
\hline Philodryas patagoniensis & + & + & & + & + \\
\hline Colubridae indet. & + & + & + & + & + \\
\hline Anura género y especie indet. & + & + & + & + & + \\
\hline \multicolumn{6}{|l|}{ Teleostei } \\
\hline Rhamdia cf. quelen & + & + & + & + & \\
\hline Corydoras $c f$. paleatus & + & & & & \\
\hline Teleostei género y especie indet. & + & + & + & + & + \\
\hline
\end{tabular}


serción muscular del trocánter mayor fusionada) y juveniles (esa superficie sin fusionar) (Fig. 4). Sobre las ramas mandibulares se identificaron como juveniles a aquellas con dientes de forma cónica y superficies óseas porosas. La cuantificación se expresó como NEIT adultos/NEIT juveniles.

\section{ABUNDANCIA Y DIVERSIDAD TAXONÓMICA}

La muestra analizada (NEIT 67805) se compone de 18 taxones de mamíferos [incluyendo a Scapteromys sp. que no había sido incluido en contribuciones anteriores (Quintana, 2001a)], cuatro de ofidios y dos de peces, mientras que la identificación de aves y anuros se encuentra en curso (Tab. 1).

\section{Grupo 1 (roedores cricétidos, Ctenomys talarum y didélfidos)}

Los restos asignados a este Grupo dominan cuantitativamente la muestra de microvertebrados (NEIT 61370, NEIT\% 90,51) (Fig. 5; Tab. 2). Se trata principalmente de restos de roedores cricétidos (NEIT 57139, NEIT\% 93,11), seguidos por los de Ctenomys talarum (NEIT 3892, NEIT\% 6,34) y mar-

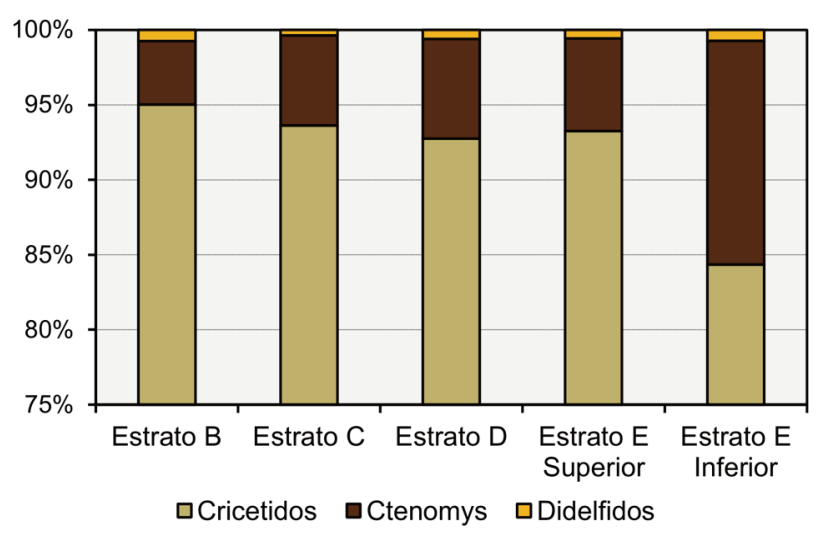

Figura 5. Frecuencia (NEIT\%) de los micromamíferos del Grupo 1 de Cueva Tixi. supiales didélfidos (NEIT 339, NEIT\% 0,55) (Fig. 5; Tab. 3).

\section{Grupo 2 (Cavia aperea y Galea tixiensis)}

Este grupo, integrado por restos de roedores cávidos, es el que sigue en abundancia (NEIT 5758, NEIT\% 8,49) (Tab. 2). La especie más numerosa en toda la secuencia, basado sobre datos craneanos, es Galea tixiensis (NEIT 866, NEIT\% $83,67 \%$ ), seguida por Cavia aperea (NEIT 169, NEIT\% 16,32) (Fig. 6). El esqueleto poscraneano presenta una morfología

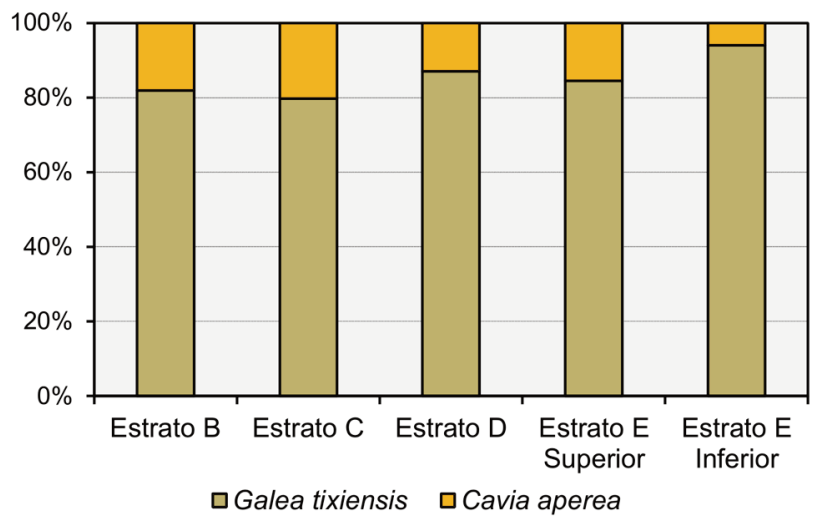

Figura 6. Frecuencia (NEIT\%) de los restos craneanos de los micromamíferos del Grupo 2 de Cueva Tixi.

TABLA 2. Abundancia (NEIT) de los tres grupos de microvertebrados analizados de Cueva Tixi.

\begin{tabular}{lcccc}
\hline Estrato & GRUPO 1 & GRUPO 2 & GRUPO 3 & Total \\
B & 8003 & 959 & 107 & 9069 \\
$C$ & 10662 & 1485 & 174 & 12321 \\
$D$ & 10164 & 1124 & 114 & 11402 \\
E sup. & 30025 & 2031 & 235 & 32291 \\
E inf. & 2516 & 159 & 47 & 2722 \\
Total & 61370 & 5758 & 677 & 67805 \\
\hline \hline
\end{tabular}

TABla 3. Abundancia de los micromamíferos de Cueva Tixi.

\begin{tabular}{llccccccc}
\hline \multirow{2}{*}{ Estrato } & \multicolumn{2}{c}{ Cricétidos } & \multicolumn{2}{c}{ C. talarum } & \multicolumn{2}{c}{ Didélfidos } & \multicolumn{2}{c}{ Cávidos } \\
& NEIT & NMI & NEIT & NMI & NEIT & NMI & NEIT & NMI \\
$B$ & 7606 & 484 & 339 & 22 & 58 & 24 & 959 & 62 \\
C & 9983 & 748 & 640 & 52 & 39 & 18 & 1485 & 107 \\
$D$ & 9428 & 566 & 677 & 58 & 59 & 24 & 1124 & 58 \\
E sup. & 28000 & 1269 & 1860 & 156 & 165 & 56 & 2031 & 120 \\
Einf. & 2122 & 155 & 376 & 57 & 18 & 12 & 159 & 14 \\
\hline \hline
\end{tabular}


muy similar entre ambas especies por lo que todavía no fue discriminado a ese nivel taxonómico (Quintana, 2001a, 2005). Incorporando a los elementos del poscráneo, este grupo presenta un NEIT total de 5758 (Tab. 2). EI NMI fue evaluado sobre cráneo y húmeros (Tab. 3). En todos los estratos el aporte del cráneo brindó los NMI más altos, incluso en el estrato $D$, donde los húmeros presentan una abundancia relativa más alta.

\section{Grupo 3 (aves, ofidios, peces y anuros)}

En este grupo (NEIT 677, NEIT\% 0,99) predominan las aves (NEIT\% 73,7) seguidas por los ofidios (NEIT\% 16,83), peces (NEIT\% 4,87) y anuros (NEIT\% 4,57) (Fig. 7; Tab. 2 y 4). Los quirópteros están representados por un único elemento (un húmero) que no fue incorporado al análisis.

Se registraron 499 elementos de aves de dimensiones pequeñas distribuidos en los cinco estratos del sitio. El NMI se calculó sobre los elementos más numerosos (fémur, ti-

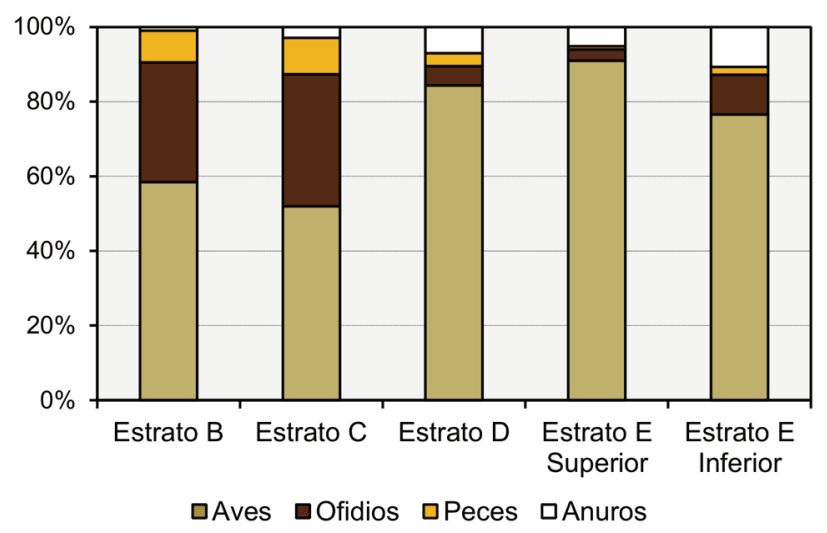

Figura 7. Frecuencia (NEIT\%) de los microvertebrados del Grupo 3 de Cueva Tixi. biotarso, tarsometatarso, húmero y ulna) (Tab. 4). Debido a que los taxones se encuentran en proceso de identificación, se reconoce que los NMI están subestimados.

Los ofidios se distribuyen en todos los estratos y fueron identificados cuatro taxones: Philodryas patagoniensis (Girard, 1858), Clelia rustica (Cope, 1878), Bothrops alternatus Duméril, Bibron y Duméril, 1854 y Bothrops sp., además de ejemplares indeterminados (Tab. 5) (Albino, 1999). La muestra es exigua (NEIT 115), aunque se trata de un registro relativamente numeroso para un mismo yacimiento que comprende desde el Pleistoceno Tardío hasta el Holoceno tardío. Los estratos con mayor cantidad de ejemplares son el B y el C. No se pudo establecer un criterio para calcular el NMI de estos reptiles sobre la base de la evidencia disponible, por lo que se considera al menos un ejemplar de cada taxón identificado.

En este sitio los restos de peces son muy escasos (NEIT 33), aunque se distribuyen en toda la secuencia (Tab. 6). En los tres estratos inferiores se encuentra la menor abundancia y el $78,78 \%$ se concentra en los estratos B y C. La mayoría (70\%) son taxones indeterminados debido a lo fragmentario del registro, el resto está dominado por Pimelodidae asignables a Rhamdia cf. R. quelen (Quoy y Gaimard, 1824) y un ejemplar de Corydoras cf. C. paleatus (Jenyns, 1842) (Callichthyidae) (Cione y Barla, 2001).

La muestra de anuros ocupa toda la secuencia aunque con muy pocos elementos registrados (NEIT 31). La identificación taxonómica está en proceso pero preliminarmente se advierten al menos tres taxones. El NMI se calculó considerando los elementos registrados y la diversidad tentativa identificada (Tab. 4).

TABLa 4. Abundancia de los microvertebrados del Grupo 3 de Cueva Tixi.

\begin{tabular}{|c|c|c|c|c|c|c|c|c|}
\hline \multirow{2}{*}{ Estrato } & \multicolumn{2}{|c|}{ Aves } & \multicolumn{2}{|c|}{ Ofidios } & \multicolumn{2}{|c|}{ Peces } & \multicolumn{2}{|c|}{ Anuros } \\
\hline & NEIT & $N M I$ & NEIT & $N M I$ & $N E I T$ & $N M I$ & NEIT & NMI \\
\hline$B$ & 62 & 4 & 34 & 4 & 10 & 2 & 1 & 1 \\
\hline$C$ & 91 & 7 & 62 & 4 & 16 & 1 & 5 & 2 \\
\hline$D$ & 97 & 7 & 5 & 2 & 4 & 1 & 8 & 2 \\
\hline E sup. & 213 & 16 & 8 & 4 & 2 & 1 & 12 & 4 \\
\hline E inf. & 36 & 3 & 5 & 2 & 1 & 1 & 5 & 2 \\
\hline Total & 499 & & 114 & & 33 & & 31 & \\
\hline
\end{tabular}




\begin{tabular}{lccccc}
\hline TABLA 5. Abundancia (NEIT) de ofidios de Cueva Tixi. \\
\hline Taxones & B & C & D & E sup. & E inf. \\
& 26 & 55 & 5 & 5 & 1 \\
Bothrops alternatus & 1 & & & 1 & 3 \\
Bothrops sp. & 2 & 1 & & 1 & \\
Clelia rustica & 1 & 2 & & 1 & 1 \\
Philodryas patagoniensis & 5 & 4 & & & \\
Colubridae indet. & 35 & 62 & 5 & 8 & 5 \\
Total & & & & & \\
\hline \hline
\end{tabular}

TABLA 6. Abundancia (NEIT) de peces de Cueva Tixi.

\begin{tabular}{lccccc}
\hline Taxones & \multicolumn{5}{c}{ Estrato } \\
& $B$ & $C$ & $D$ & Esup. Einf. \\
Rhamdia $c f$. R. quelen & 5 & 3 & 1 & 1 & \\
Corydoras $c f$. C. paleatus & 1 & & & & \\
Teleostei indet. & 4 & 13 & 3 & 1 & 1 \\
\hline \hline
\end{tabular}

\section{ALTERACIONES PRE Y POSDEPOSITACIONALES Alteraciones antrópicas}

Las dos especies de roedores cávidos de los estratos superiores C y B presentan huellas de filos líticos de las categorías cortes y raspados. Estas evidencias fueron descriptas y discutidas en Quintana (2005): 1) cortas y poco profundas, dispuestas oblicuas o transversales al eje de los huesos largos; 2) largas y longitudinales al eje del hueso; 3) un grupo de cortes juntos, de trazas paralelas y de poca longitud. Esta última categoría concuerda con la fisonomía de los raspados ya que provienen de un único gesto efectuado con el filo del instrumento dispuesto algo oblicuo, pero son muy cortas.

El procesamiento de distintas partes del cuerpo quedó registrado a través de huellas en ramas mandibulares, maxilares, húmeros, ulnas, radios, escápulas, fémures, tibias y ramas pélvicas (Fig. 8).

Solo se hallaron dos elementos del Grupo 1 con exposición térmica, uno en el estrato $D$ y otro en el E superior (Tab. 7). Entre los roedores del Grupo 2 las frecuencias fueron bajas (menores a 1,26\%) (Tab. 7). En estos roedores se identificaron, además, elementos quemados junto con mar-
TABLA 7. Frecuencia (NEIT\%) de huesos largos con termoalteraciones de los microvertebrados de Cueva Tixi y de la muestra actual producida por Tyto alba.

\begin{tabular}{lcc}
\hline Estrato & Grupo 1 & Grupo 2 \\
Actual & & \\
$B$ & & 0,6 \\
$C$ & 0,02 & 1,26 \\
$D$ & 0,01 & 0,63 \\
E sup. & & 1,05 \\
E inf. & & \\
\hline \hline
\end{tabular}

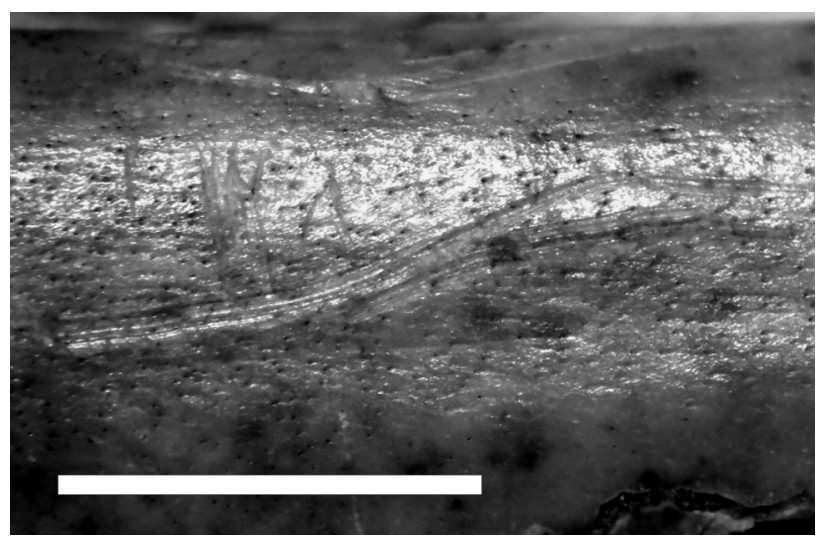

Figura 8. Huellas de corte realizadas con artefactos líticos en un fémur de cávido del estrato C. Escala= $5 \mathrm{~mm}$.

cas de corte en los estratos B y C. Entre los restos de aves, ofidios y de anuros (NEIT: 676) no hubo evidencias de exposición al fuego.

Los demás restos de micromamíferos, aves, ofidios y peces no tienen otros tipos de alteraciones antrópicas. Solo un resto de anuro presenta una fractura realizada en estado fresco por un agente indeterminado.

\section{Alteraciones no antrópicas}

Corrosión digestiva. En los fémures y húmeros del Grupo 1 se registró la acción de ácidos digestivos de bajo impacto en toda la secuencia, identificándose solo las categorías ligera y moderada (Fig. 9). En todos los estratos los fémures presentan menos trazas (hasta 13,53\%) que los húmeros (hasta 20,36\%) siendo estas diferencias significativas (Mann-Whitney $P<0,05$ ). Solo fueron afectadas las superficies articulares y, eventualmente, el área de inserción muscular del trocánter mayor o de los epicóndilos. En mu- 


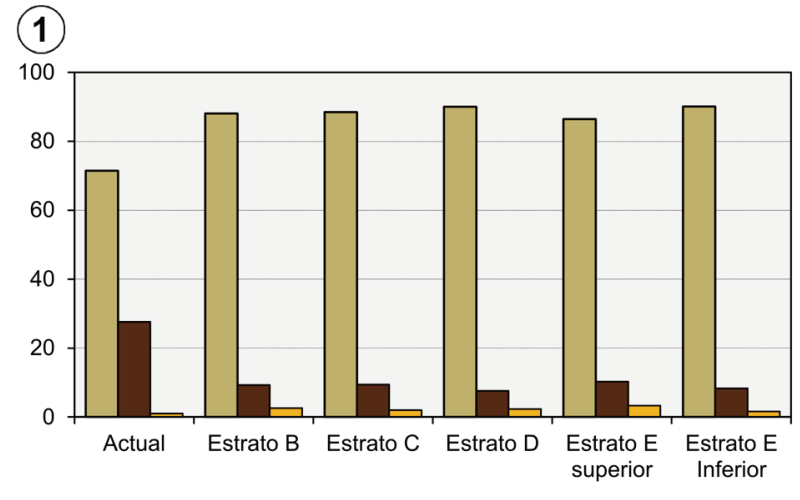

\section{(2)}

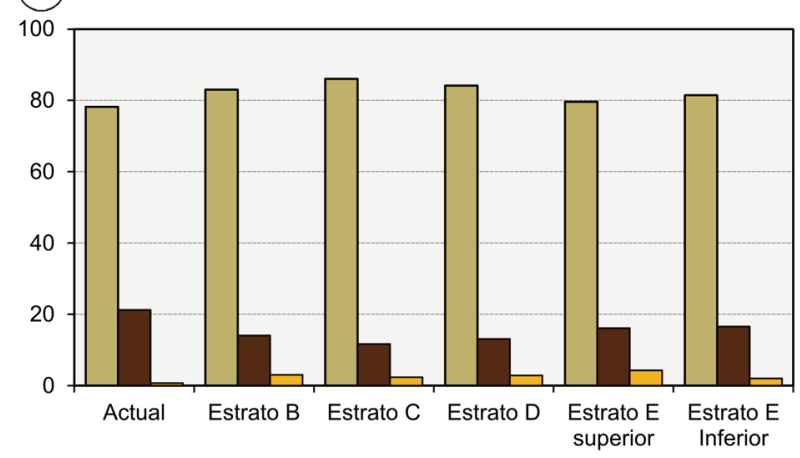

Figura 9. Corrosión por acción digestiva (NEIT\%) en elementos de micromamíferos del Grupo 1 de Cueva Tixi y de la muestra actual de referencia producida por Tyto alba. 1, Epífisis proximales de fémures; 2, epífisis distales de húmeros. (Inf. supl., Tab. 1).

chos casos se observó que la acción de los ácidos generó, además de adelgazamiento y perforación de la superficie ósea, una coloración gris translúcida característica y diferente a la del hueso no afectado. No se registraron fracturas redondeadas o adelgazadas por la acción digestiva.

En el Grupo 2 la corrosión digestiva, principalmente de la categoría ligera, solo afectó a los fémures (hasta el 29,4\%) y húmeros (hasta el 37,43\%) de los tres estratos inferiores (Fig. 10). Estos valores máximos son mayores que los del Grupo 1, pero están sesgados porque el estrato E inferior tiene solo 17 fémures y 16 húmeros analizados. Los otros dos estratos presentaron porcentajes más bajos de corrosión digestiva, entre 19,38\% y 29,41\% de fémures y húmeros, respectivamente.

EI NEIT de aves fue bajo y permitió analizar la muestra completa. Los elementos de los estratos B, C y E superior son los que presentan, proporcionalmente, más trazas de digestión, mientras que en el $\mathrm{E}$ inferior solo fue registrado un caso (Inf. supl., Tab. 3). Los huesos largos fueron los
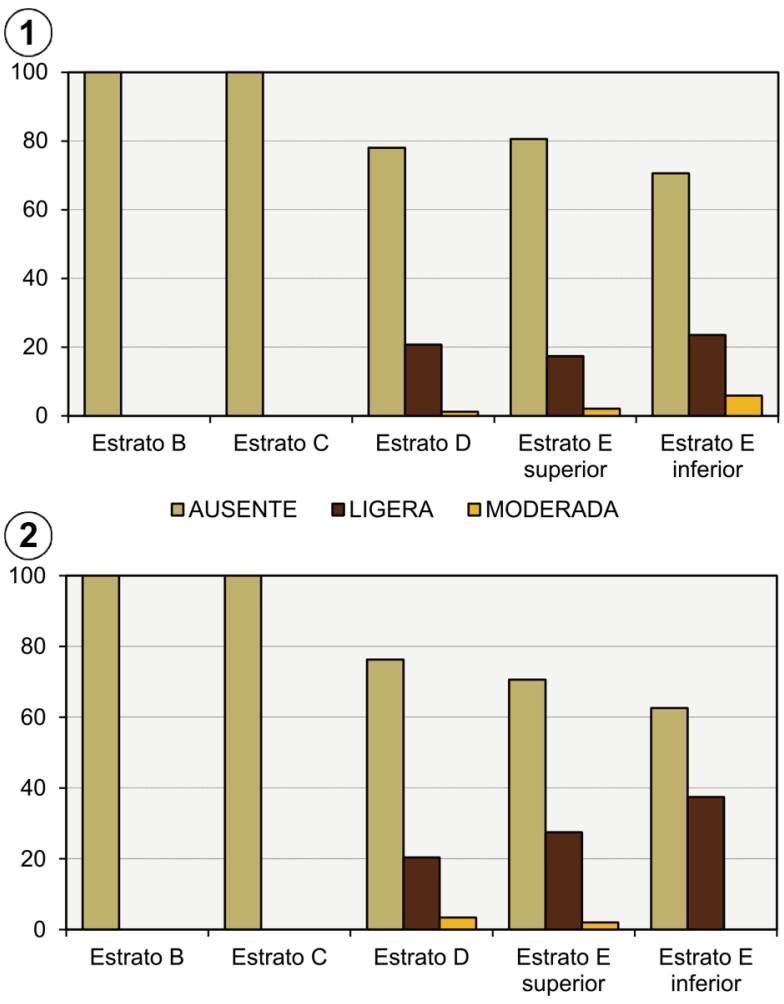

Figura 10. Corrosión por acción digestiva (NEIT\%) en elementos de micromamíferos del Grupo 2 (roedores cávidos) de Cueva Tixi. 1, Epífisis proximales de fémures; 2 , epífisis distales de húmeros. (Inf. supl., Tab. 2).

elementos más alterados. Un sinsacro del estrato $D$, una rama mandibular y una vértebra del estrato C, también presentan rasgos de digestión. En toda la secuencia la corrosión es ligera debido a que afectó solo a las epífisis con un bajo grado de daño, con la excepción de dos húmeros del estrato $E$ superior en los cuales las superficies de las epífisis están más afectadas alcanzando a parte de las diáfisis. Las fracturas corroídas por digestión (con bordes redondeados y adelgazados) son escasas.

La muestra actual de Sierra La Peregrina presenta las mismas categorías de digestión que los micromamíferos del Grupo 1 y de las aves, pero en mayor frecuencia.

En la muestra de peces solamente un elemento (epihial) de un Siluriformes asignable a Rhamdia cf. R. quelen, del estrato $\mathrm{E}$ superior, presenta trazas que pueden ser referidas preliminarmente a digestión. Se trata de perforaciones de bordes redondeados sobre una superficie plana con cambio de coloración hacia un gris translúcido sobre el área afectada (Fig. 11). 


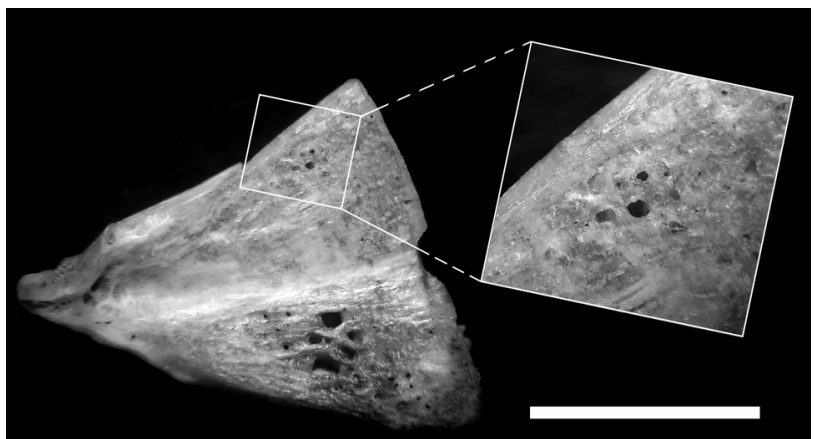

Figura 11. Epihial de pez Siluriformes del estrato E superior con trazas de digestión. Escala $=5 \mathrm{~mm}$ (detalle fuera de escala).

Los ofidios carecen de trazas de corrosión digestiva. Algunas vértebras de Bothrops sp. tienen las superficies de articulación con las costillas (sinapófisis) con perforaciones similares a la producida por corrosión digestiva, pero la ubicación específica de estas marcas y sus características anatómicas indican que se trata de la propia morfología de la superficie articular.

Pocos huesos largos de anuros presentan rasgos de corrosión digestiva. Estas son de las categorías ligeras (NEIT 5) y moderadas (NEIT 3) que afectaron a las epífisis distales de los húmeros (estratos B, C, D y E superior), un íleon (estrato C), un coracoides (estrato D) y una tibio-fíbula (estrato $E$ superior). Esta muestra carece de las alteraciones típicas (e.g., bordes colapsados, astillamientos, descamaciones o bordes de fractura adelgazados) detectadas en los restos de anuros recuperados de egagrópilas o de depósitos fósiles (Pinto Llona y Andrews, 1999; Montalvo y Tejerina, 2009). Debido al pequeño tamaño de la muestra esta alteración no se cuantificó como porcentaje.

Corrosión producida por el crecimiento de raíces. En el estrato B son abundantes los elementos de los Grupos 1 y 2 con este tipo de marcas. Son frecuentes los casos con todo el perímetro corroído y proporciones altas de daño profundo en la anatomía (Fig. 12). Los niveles con menos elementos afectados fueron los E superior e inferior. La proporción de huesos con trazas de raíces en todo el perfil fue variable, entre el $80,34 \%$ y el $19,12 \%$. La incidencia de esa bioerosión afectó poco a las superficies óseas, debido a que prevalecieron los fémures con la categoría reducida, mientras que la pérdida de masa ósea o la perforación fueron menores al 9,51\% (Fig. 12). Sin embargo, más de la mitad de los fému-

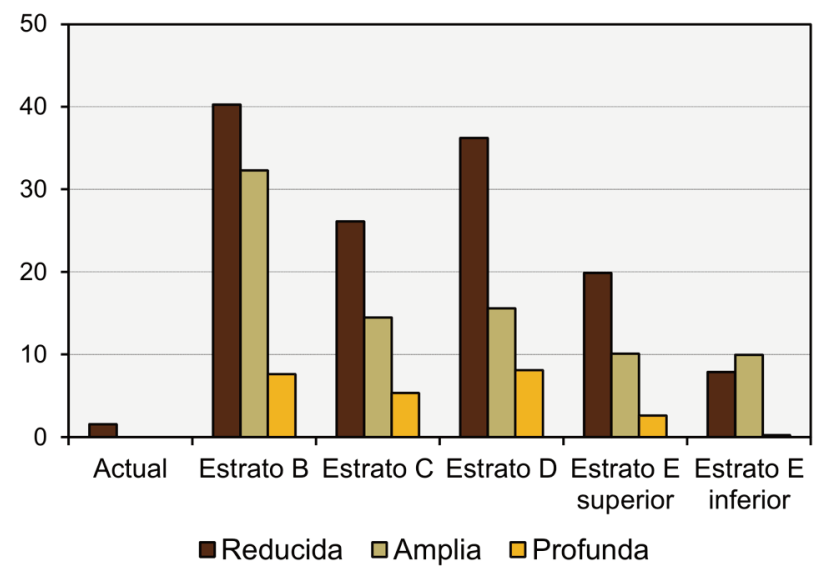

Figura 12. Corrosión por acción de raíces (NEIT\%) en fémures de micromamíferos de Cueva Tixi y de la muestra actual producida por Tyto alba. Ver categorías en la Figura 3. (Inf. supl., Tab. 5).

res presentan trazas en todo el perímetro superficial, indicando que las raíces incidieron sobre los huesos por tiempo prolongado. En el estrato E inferior la categoría amplia es levemente mayor, pero el total de fémures afectados fue muy bajo, por lo que puede tratarse de un sesgo del registro. En toda la secuencia las trazas son similares a las descriptas como Corrosichnia. No se hallaron marcas radiculares sobrepuestas a precipitaciones de minerales en la superficie del hueso.

En las aves las alteraciones ocasionadas por los ácidos radiculares fueron de bajo impacto (Fig. 13) y disminuyeron hacia los niveles inferiores, aunque en algunos estratos los elementos afectados por raíces superaron el 50\%, involucrando a toda la superficie cortical. En los estratos $D$ y $E$ superior e inferior prevalecieron los elementos con impresiones de un solo lado de su perímetro. A pesar de las pocas trazas identificadas, los casos de alteraciones profundas son proporcionalmente altos, incluso cuando fueron de baja densidad. Esta situación es particularmente notable en el estrato $D$, con el $13,4 \%$ de los elementos con perforaciones ocasionadas por raíces.

La mayoría de los restos de peces presenta marcas de raíces de bajo impacto.

Entre los elementos de ofidios se hallaron numerosos ejemplares con marcas de corrosión de raíces pero con poca densidad y bajo impacto; solo en tres vértebras se registraron alteraciones profundas (Fig. 14).

En los anuros las marcas de corrosión radicular fueron 


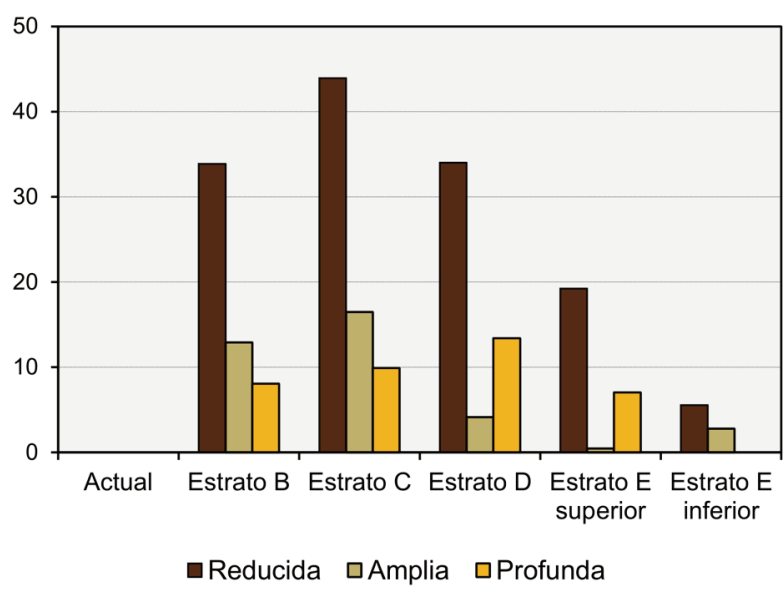

Figura 13. Corrosión por acción de raíces sobre elementos de las aves pequeñas de Cueva Tixi y de la muestra actual producida por Tyto alba. Ver categorías en la Figura 3. (Inf. supl., Tab. 6).

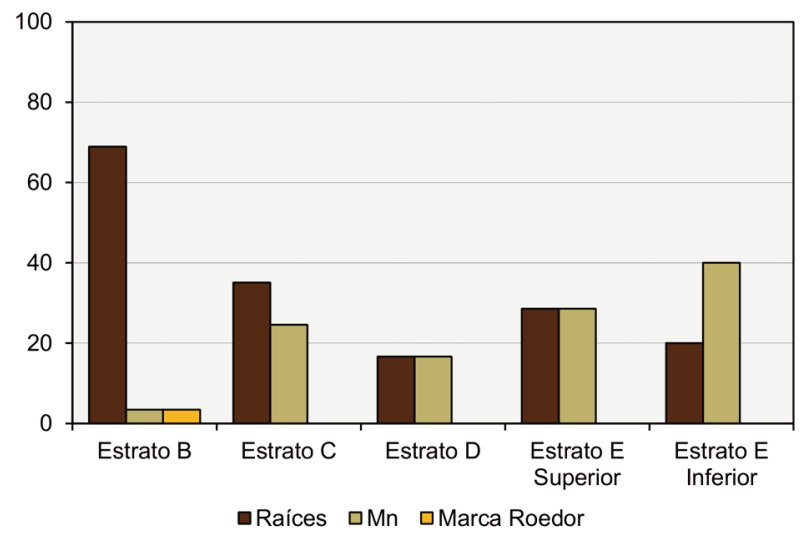

Figura 14. Alteraciones (NEIT\%) en los elementos de ofidios de Cueva Tixi. (Inf. supl., Tab. 7).

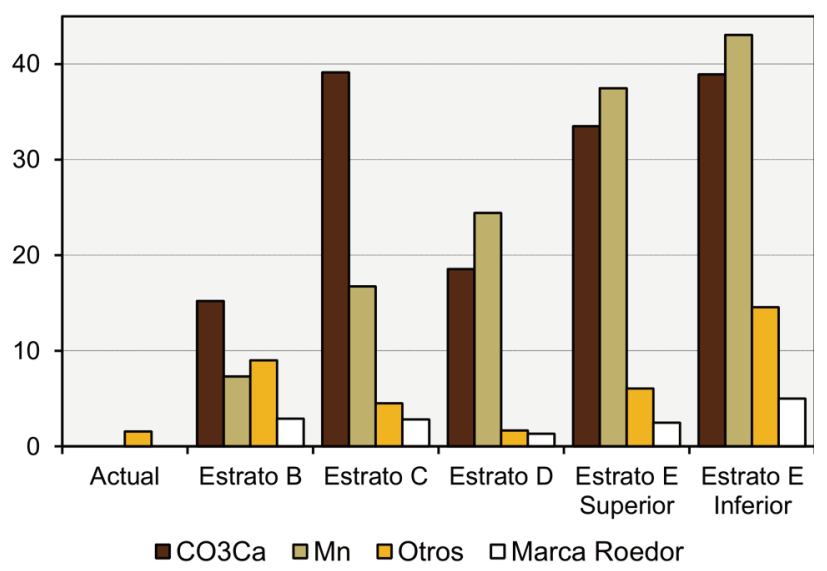

Figura 15. Impregnaciones de minerales, otras alteraciones posdepositacionales y mordeduras de roedores (NEIT\%) en fémures de micromamíferos de Cueva Tixi y de la muestra actual producida por Tyto alba. (Inf. supl., Tab. 9). escasas y no afectaron sustancialmente a las superficies óseas, en general se presentan apenas como puntos en sectores restringidos del elemento (Inf. sup. Tab. 8).

Las marcas de raíces en la muestra actual son escasas y de muy bajo impacto debido a que la misma estuvo parcialmente enterrada; consisten en cambios de coloración o trazas que se desvanecen con la manipulación (Quintana, 2015b).

Impregnaciones de minerales. Sobre y dentro de los huesos de micromamíferos (Grupos 1 y 2) los depósitos de carbonato de calcio aumentan proporcionalmente hacia los niveles inferiores, con un pico máximo en el estrato C (Fig. 15). El encostramiento se presenta como concreciones globulares blancas y duras, filtraciones laminares adheridas en el canal medular y depósitos superficiales grises que pueden atrapar granos de arena y cuarzo. En todos los casos reaccionan positivamente al ser expuestos a ácido clorhídrico diluido. Las filtraciones internas ocasionalmente pueden presentar cristalización intensa con crecimiento hacia afuera del hueso, lo que genera fracturas sagitales y transversales que destruyen la diáfisis (Fig. 16). En etapas iniciales de este proceso el propio carbonato mantiene unidos a todos los fragmentos. Algunos pocos ejemplos (NEIT 42) de este tipo se identificaron en los estratos D y E superior, representando el $2,15 \%$ y el $0,62 \%$ de los fémures analizados respectivamente.

Las impregnaciones de manganeso en elementos de micromamíferos también aumentan hacia abajo de la secuencia, generalmente están asociadas a la presencia de carbonatos (Fig. 15). El manganeso fue detectado como depósitos superficiales más o menos extendidos (manchas aisladas, puntos dispersos o láminas extensas y gruesas) o absorbido en el interior del hueso compacto.

En los restos de aves las precipitaciones de carbonatos se registraron hasta el 55\% del total pero afectaron escasamente su integridad ósea (Fig. 17). Solo un caso cubrió a toda la superficie del hueso. El crecimiento de cristales de carbonatos desde el canal medular generando grietas en la diáfisis se presentó solo en un húmero del estrato E superior. Las impregnaciones de manganeso aumentan proporcionalmente hacia la base de la secuencia sin cubrir grandes extensiones de la superficie de los huesos. Se manifestaron principalmente como inclusiones absorbidas en 


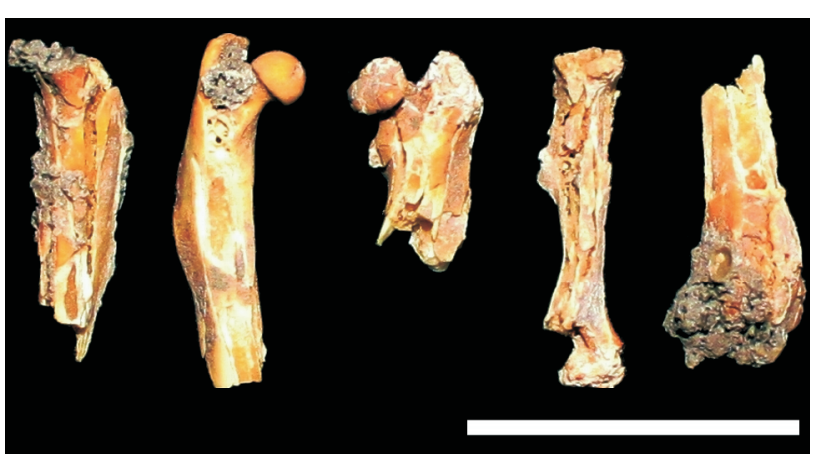

Figura 16. Elementos de roedores de Cueva Tixi (Estrato D) con carbonatos infiltrados en el canal medular que crecieron hacia afuera generando fracturas. Escala $=20 \mathrm{~mm}$.

la masa ósea a modo de puntos dispersos o de extensiones reducidas.

Entre los restos de anuros solo una tibio-fíbula del estrato D presenta cristales de carbonatos en el canal medular, mientras que las impregnaciones de manganeso fueron más numerosas (Inf. supl., Tab. 8).

La muestra de microvertebrados actuales carece de evidencias de precipitaciones de minerales (Quintana, 2015b). Otras alteraciones. Los huesos de micromamíferos presentan escasas evidencias de hoyos de disolución química, marcas de pisoteo y descamaciones, además no se identificó un patrón claro de distribución estratigráfica (Fig. 15). En los huesos de aves las evidencias de alteraciones producidas por meteorización se presentaron principalmente en

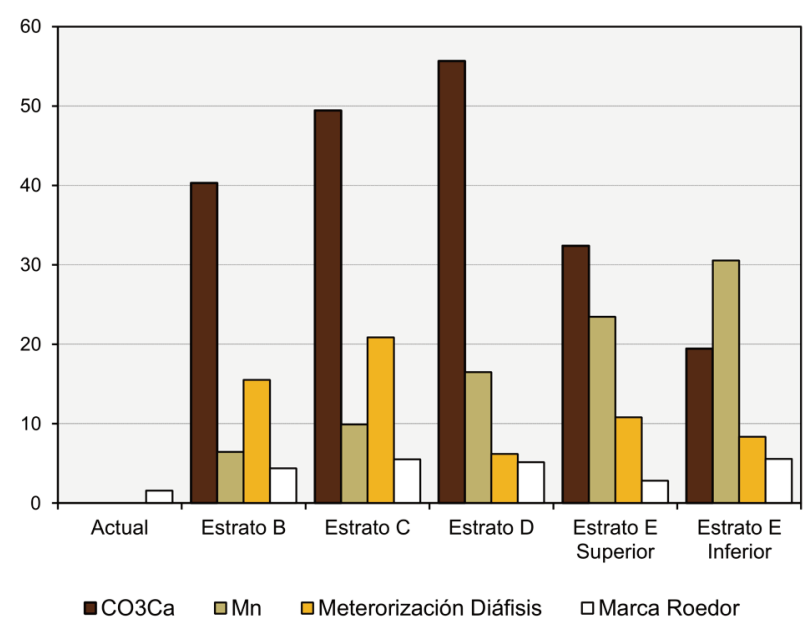

Figura 17. Impregnaciones de minerales, mordeduras de roedores y meteorización en las diáfisis (NEIT\%) sobre elementos de aves de Cueva Tixi y de la muestra actual producida por Tyto alba. (Inf. supl., Tab. 10). las diáfisis a modo de grietas, depresiones pequeñas o perforaciones de bordes filosos o redondeados en poca cantidad y que no alcanzaron a alterar sustancialmente la superficie ósea (Fig. 17).

Mordeduras. No se identificaron marcas de dientes de carnivoros y las marcas de roedores se distribuyeron en toda la secuencia con baja incidencia sobre elementos de mamíferos, aves y ofidios (Fig. 15). Se trata de marcas superficiales que no afectaron sustancialmente a la anatomía y que se presentaron como mordeduras aisladas o como conjuntos paralelos que incidieron en superficies planas, convexas o bordes. Solo un caso, un fémur de ave del estrato E inferior, tiene numerosas marcas sobre la diáfisis y en el borde de fractura (Fig. 17).

Patologías. En todos los estratos, excepto en el E inferior, se identificaron 17 especímenes de roedores y uno de ofidio con patologías (Fig. 18; Tab. 8). Las mismas corresponden a fracturas traumáticas con formación de callos óseos y alteración del eje del hueso, deformaciones de articulaciones con pérdida de masa ósea y otras no determinadas. Una vértebra de Bothrops sp. del estrato C tiene una patología no traumática y deformante que afectó a la poszigapófisis y al zigantro izquierdos. En la muestra actual solo dos tibias de roedor presentaron alteraciones patológicas no traumáticas.

Fracturas. Entre los fémures del Grupo 1, las fracturas afectaron entre el 31,08\% y el 50\% según el estrato (Fig. 19). Las generadas sobre el hueso en estado fresco son muy escasas (menos del 10\% en todos los niveles). Los planos y bordes de fracturas cuyas superficies resultaron afectadas por raíces fueron escasas (menos del 19\%). En algunos casos la superficie rota mostraba una coloración más clara que el resto del hueso, indicando una fractura muy tardía ocasionada posiblemente durante la excavación. No se identificaron fracturas con rasgos de corrosión digestiva. En la muestra actual fueron menos frecuentes, preponderando las efectuadas sobre el hueso fresco.

Entre los fémures del Grupo 2, las fracturas afectaron entre el $32 \%$ y el $71 \%$; la proporción aumenta hacia los niveles superiores $y$, en todos los estratos, las efectuadas sobre el hueso en estado seco superan a las registradas sobre el hueso en estado fresco (Fig. 20). Estas últimas aumentan significativamente en los dos estratos superiores. 
No se identificaron fracturas con rasgos de corrosión digestiva. Los planos y bordes de fractura cuya superficie resultó afectada por raíces fueron menos del 19,38\%.

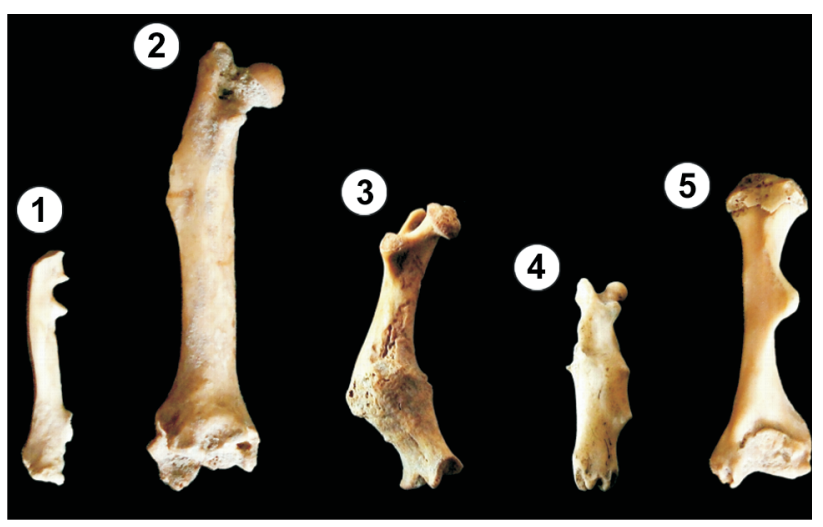

Figura 18. Patologías en elementos de micromamíferos de Cueva Tixi. 1-2, Estrato E superior; 3,5, estrato D; 4, estrato C.

TABLA 8. Patologías (NEIT) en elementos de roedores y de ofidios de Cueva Tixi y de la muestra actual producida por Tyto alba.

\begin{tabular}{lccc}
\hline Estrato & Fracturas & $\begin{array}{c}\text { Deformaciones } \\
\text { articulares }\end{array}$ & $\begin{array}{c}\text { Indeterminadas } \\
\text { Actual }\end{array}$ \\
$B$ & 1 & 4 & 2 \\
C & 1 & 1 & 2 \\
$D$ & 1 & 4 & 1 \\
Esup. & & & 3 \\
\hline \hline
\end{tabular}

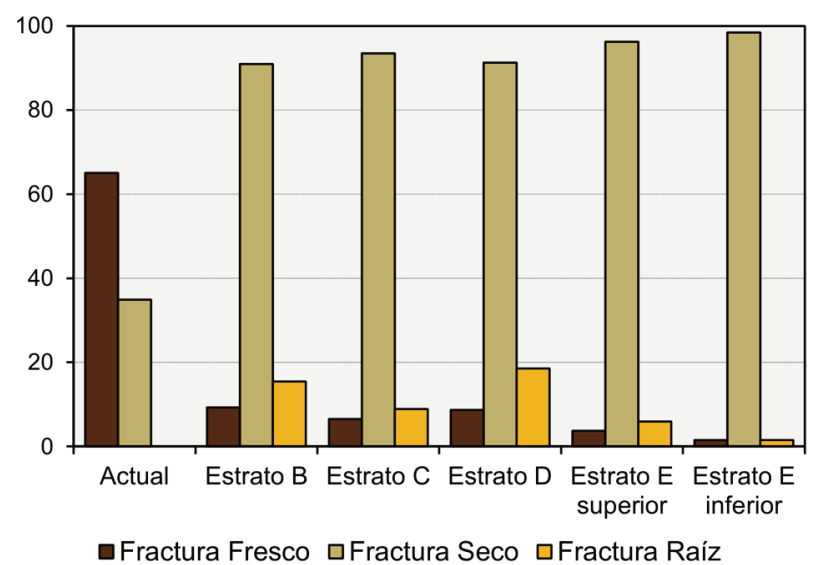

Figura 19. Tipos de fracturas (NEIT\%) en fémures de micromamíferos del Grupo 1 de Cueva Tixi y de la muestra actual producida por Tyto alba. Fractura Raíz, superficie de la fractura alterada por ácidos radiculares. (Inf. supl., Tab. 11).
Más del 63,38\% de los elementos de aves presentaban fracturas (Fig. 21). La mayoría se ocasionaron con el hueso en estado seco. Los planos de fractura fueron modificados por ácidos radiculares hasta un 20,51\%.

Las fracturas posdepositacionales afectan a más del $80 \%$ de las vértebras de ofidios en los estratos B y C (Inf. supl., Tab. 13). Se ubican en las hipoapófisis y las espinas neurales de Bothrops sp. Los cuerpos vertebrales fueron poco afectados, mientras que los cótilos fueron alterados ocasionalmente en su borde. Las costillas registradas están todas fracturadas y un pterigoides está entero pero conservó solo un diente.

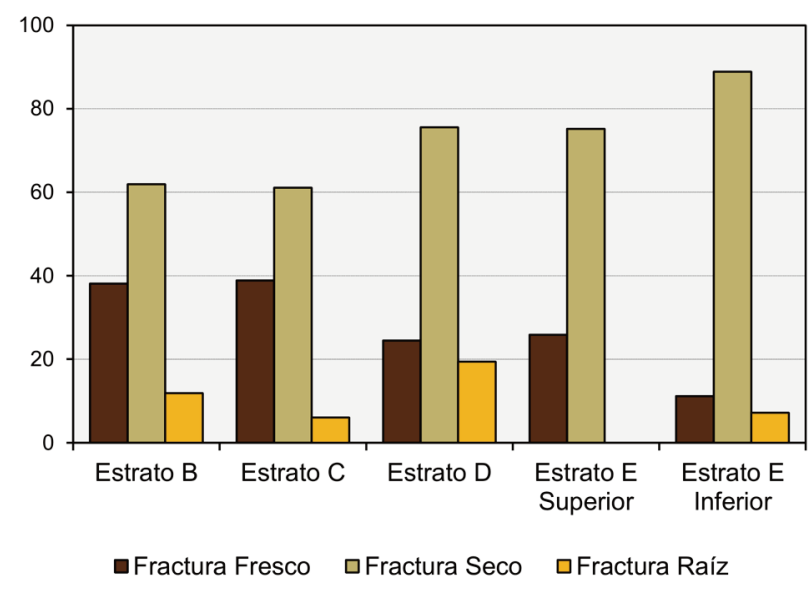

Figura 20. Tipos de fracturas (NEIT\%) en fémures de micromamíferos del Grupo 2 (roedores cávidos) de Cueva Tixi. Fractura Raíz, superficie de la fractura alterada por ácidos radiculares. (Inf. supl., Tab. 11).

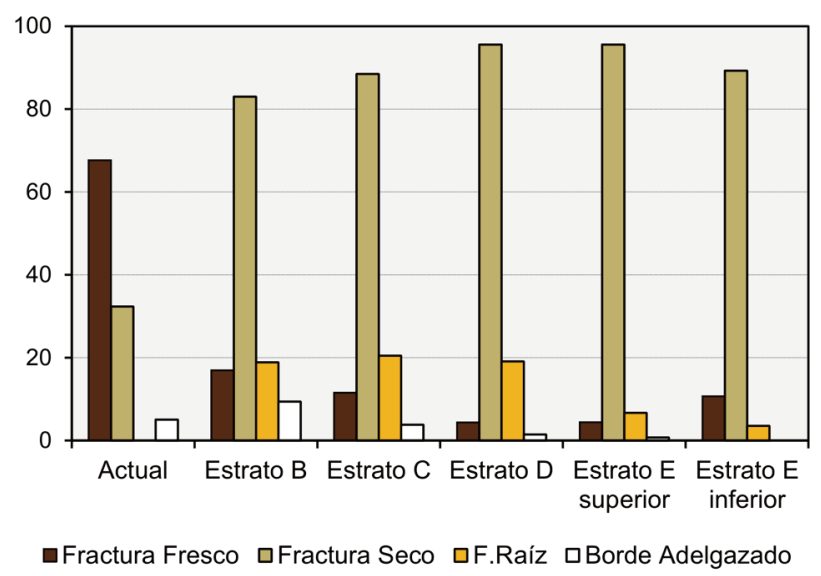

Figura 21. Tipos de fracturas (NEIT\%) y sus alteraciones sobre elementos de aves pequeñas de Cueva Tixi y de la muestra actual producida por Tyto alba. Borde Adelgazado, bordes de fracturas adelgazados por corrosión digestiva. Fractura Raíz, plano de fractura afectado por marcas de raíces. (Inf. supl., Tab. 12). 
Los restos de anuros presentan principalmente fracturas posdepositacionales; solo se registró un caso de fractura con el hueso en estado fresco (Inf. supl., Tab. 8). Finalmente, solo un elemento de pez (epihial de Siluriformes del E superior) estaba entero.

\section{PATRONES DE PRESERVACIÓN ESQUELÉTICA Grupo 1}

Abundancia relativa. La preservación del esqueleto en función de lo esperado por el NMI en los representantes del Grupo 1 es muy uniforme en toda la secuencia estratigráfica (Fig. 22). Los elementos del cráneo tienen una alta preservación en todos los estratos. Los fémures tienen abundancias relativas superiores al 87,64, seguido por valores altos de tibias, pelvis y húmeros. Los húmeros son los elementos más abundantes del miembro anterior en todos los estratos, seguidos por ulnas, radios y escápulas.

Los dientes fueron cuantificados como piezas fuera de los alvéolos, obteniendo valores muy dispares para los incisivos entre los estratos. Los incisivos recuperados fuera de los alvéolos tienen poca representación (Ab. rel. entre 16,51 y 42,45$)$. Mientras que los molares sueltos presentan valores muy bajos (Ab. rel. < 10). El resto del esqueleto poscraneano presenta porcentajes de supervivencia menores a 11, excepto las vértebras (Ab. rel.=15,06) y la escápula (Ab. rel.=17,35) del estrato E superior.

Los miembros están representados de modo desigual, con una clara preponderancia del miembro posterior en todos los estratos $(P<0,01)$ con índices entre $20,54 \mathrm{y}$ 41,58 (Tab. 9).
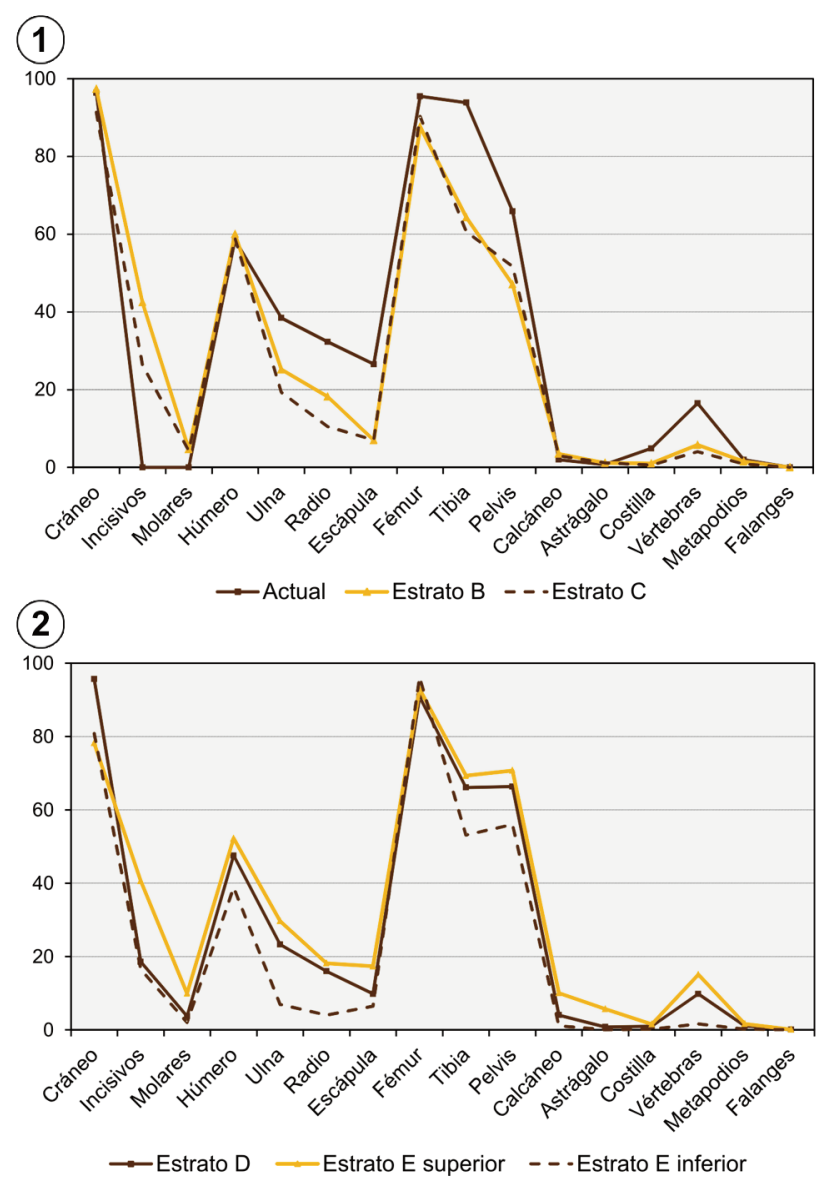

Figura 22. Abundancia relativa del esqueleto de micromamíferos del Grupo 1. 1, Muestra actual producida por Tyto alba y niveles superiores de Cueva Tixi; 2, niveles inferiores de Cueva Tixi. (Inf. supl., Tab. 14).

Las ramas mandibulares son más numerosas que los maxilares en los tres estratos superiores $(P<0,01)$, mientras que en el estrato E superior y E inferior sus valores son

TABLA 9. Parámetros analizados de los micromamíferos del Grupo 1 de Cueva Tixi y de la muestra actual producida por Tyto alba.

\begin{tabular}{lllllllll}
\hline Estrato & NEIT & NMI & $P C-C 1$ & $P C-C 2$ & $E D 1$ & $E D 2$ & IPM & Ab. rel. \\
Actual & 5657 & 277 & 85,72 & 70,95 & 81,84 & 70,27 & 45,67 & 41,11 \\
$B$ & 7997 & 530 & 111,8 & 77,39 & 55,91 & 48,64 & 41,58 & 29,97 \\
C & 10662 & 818 & 117,06 & 75,18 & 47,66 & 40,37 & 35,42 & 28,54 \\
$D$ & 10162 & 648 & 83,4 & 58,76 & 59,3 & 50,76 & 32,43 & 30,88 \\
Esup. & 30024 & 1481 & 93,54 & 67,6 & 60,22 & 53,78 & 37,79 & 33,05 \\
E inf. & 2516 & 224 & 87,55 & 51,63 & 42,31 & 31,62 & 20,54 & 24,67
\end{tabular}

NEIT, número de especímenes identificados por taxón; NMI, número mínimo de individuos; PC-C1 y PC-C2, índices poscráneo/cráneo; ED1 y ED2, indices de relación entre elementos distales y proximales de los miembros 1 y 2; IPM, índice de preservación de miembros; Ab. rel., abundancia relativa promedio. Para su descripción ver Materiales y Métodos. 
similares y no brindan diferencias significativas $(P>0,01)$. Los premaxilares son muy escasos en toda la secuencia.

Proporciones poscráneo-cráneo. La mejor preservación del poscráneo en los dos niveles superiores se aprecia a través del índice PC/C1 (Tab. 9) con diferencias altamente significativas $(P<0,01)$. Los cráneos están mejor representados que los fémures en los tres estratos superiores (Fig. 22) aunque solo en el estrato $B$ las diferencias son estadísticamente significativas $(P<0,05)$, mientras que en los dos estratos inferiores prevalecen los fémures (E superior $\mathrm{P}<0,01$; $E$ inferior $P<0,05)$. En los tres estratos inferiores preponderan los elementos craneanos ( $D$ y $E$ superior $P<0,01$; $E$ inferior $P<0,05)$. Al considerar otros elementos del poscráneo (índice PC/C2) las relaciones poscráneo-cráneo de las muestras de todos los estratos se ubican claramente $(P<0,01)$ en la zona de mayor preservación del poscráneo (Tab. 9).
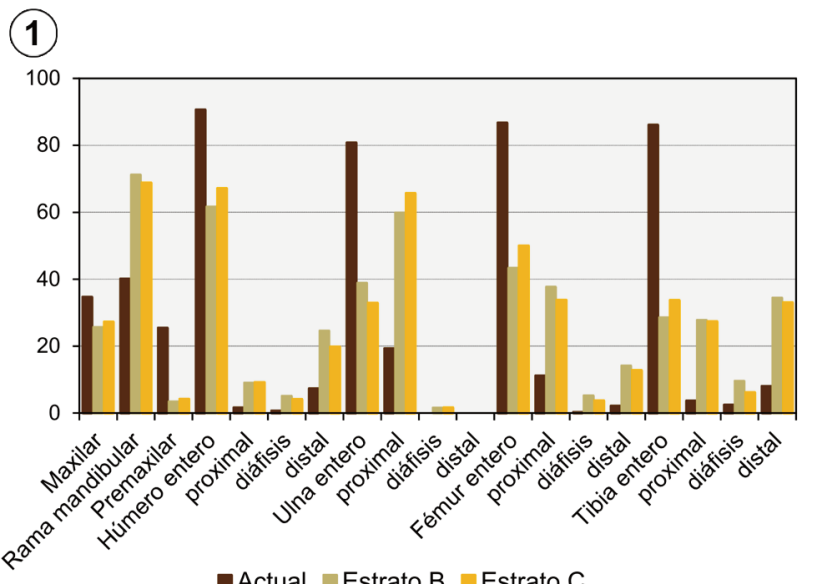

\section{(2)}

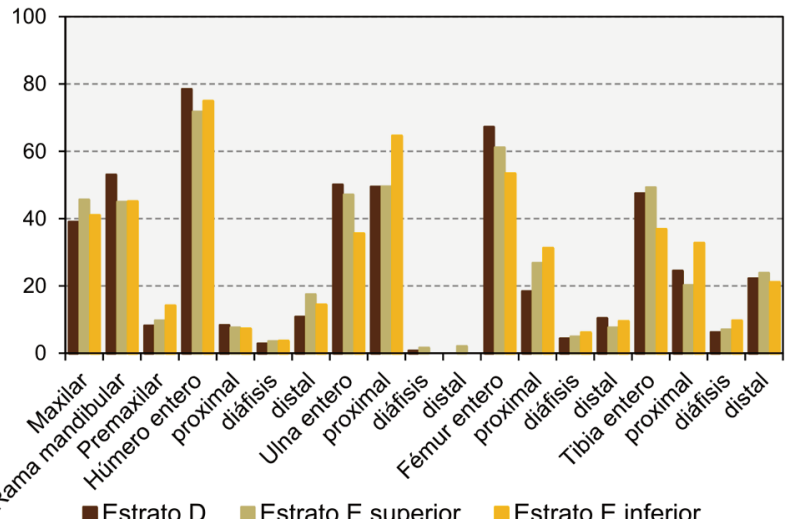

Figura 23. Fragmentación (NEIT\%) de micromamíferos del Grupo 1. 1, Muestra actual producida por Tyto alba y niveles superiores de Cueva Tixi; 2, niveles inferiores de Cueva Tixi. (Inf. supl., Tab. 15 y 16).
Conservación de elementos distales. En todos los estratos la relación entre el estilopodio y el zeugopodio indica una pobre preservación de los elementos distales, con índices entre 42 y 60 (Tab. 9). La incorporación de las ulnas al análisis deprime todavía más la relación a valores entre 31 y 53. Con ambos índices las diferencias son altamente significativas en todos los estratos $(P<0,01)$.

Fragmentación. La fragmentación del esqueleto poscraneano se caracteriza por la gran homogeneidad de sus parámetros en todos los estratos (Fig. 23). Los huesos largos presentan dos patrones: uno conformado por fémures, tibias y húmeros, y otro por las ulnas (Fig. 23). El primer grupo se caracteriza por una alta preservación de huesos completos (Fig. 24), siendo los húmeros los más enteros, seguido por los fémures y tibias. La baja tasa de fractura de los húmeros genera valores porcentuales más altos de piezas enteras que los fémures, a pesar de que es menos abundante en términos absolutos y como NME en todos los estratos (Inf. supl., Tab. 17). Las fracturas fueron más numerosas en las epífisis proximales de los fémures y en las distales de los húmeros, mientras que en las tibias fueron variables y con parámetros más parejos (Inf. supl., Tab. 18).

Las ulnas se caracterizan por una gran fragmentación con poca preservación de piezas enteras, mayor abundancia de epífisis proximales y casi ausencia de epífisis distales. Las

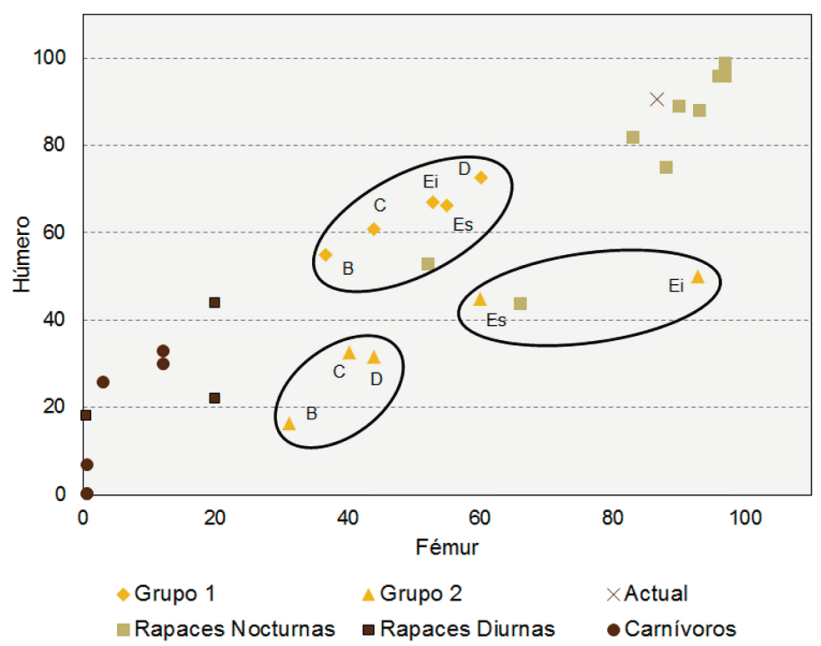

Figura 24. Relación entre el NEIT\% de húmeros y fémures enteros de micromamíferos del Grupo 1 y Grupo 2 de Cueva Tixi, comparado con la muestra actual producida por Tyto alba y datos de depredadores tomados de Andrews (1990). (Inf. supl., Tab. 16 y 22). 
diáfisis de las ulnas cuantificadas como cilindros sin epífisis son casi nulas. Esta preservación diferencial está vinculada a la mayor fragilidad de la epífisis distal, lo cual es consistente con sus valores bajos de abundancia relativa (Fig. 23).

Las diáfisis fracturadas de los huesos largos se preservaron mayormente asociadas a una epífisis que como cilindros sin epífisis, con relaciones entre 0,12 y 24,5 (Inf. supl., Tab. 19). Los valores más altos pertenecen a las ulnas y la única excepción son las diáfisis de fémures del estrato $\mathrm{E}$ inferior, donde los cilindros sin epífisis son más numerosos. En el mismo estrato no se recuperaron diáfisis de ulnas sin epífisis.

Fueron hallados muy pocos cráneos semi completos o con los maxilares y premaxilares articulados, casi la totalidad de la muestra craneana se compone de huesos aislados. Las ramas mandibulares de los roedores cricétidos y de Ctenomys talarum presentan el mismo patrón de fragmentación, caracterizado por porcentajes bajos de fracturas de la sínfisis, seguidos por la fractura del borde inferior de la mandíbula y por valores altos de fractura de las ramas ascendentes (Inf. supl., Tab. 20). Este patrón de fragmentación del cráneo es diferente a la muestra actual donde se registraron más partes del cráneo articuladas y ramas mandibulares más completas (Quintana, 2015b).

Las ramas mandibulares de los marsupiales sufrieron mayores eventos de fractura de la sínfisis, pero solamente casos excepcionales de rotura del borde inferior. Las ramas ascendentes están fracturadas con frecuencias similares a las de los roedores (Inf. sup. Tab. 20).

El cráneo de los roedores cricétidos se caracteriza por una pérdida muy alta de premaxilares. El arco cigomático está incompleto en todos los ejemplares. Las fracturas de

TABLA 10. Frecuencia (NEIT\%) de dientes sueltos conservados en función de los alvéolos vacíos de dos categorías de micromamíferos del Grupo 1 de Cueva Tixi.

\begin{tabular}{lcccc}
\hline Estrato & $\begin{array}{c}\text { Cricétidos } \\
\text { Molares }\end{array}$ & $\begin{array}{c}\text { Cricétidos } \\
\text { Incisivos }\end{array}$ & $\begin{array}{c}\text { C. talarum } \\
\text { Molares }\end{array}$ & $\begin{array}{c}\text { C. talarum } \\
\text { Incisivos }\end{array}$ \\
B & 11,84 & 112,2 & 31,57 & 595,65 \\
$C$ & 12,08 & 91,14 & 18,66 & 257 \\
$D$ & 8,54 & 40,39 & 9,45 & 227,11 \\
E sup. & 23,55 & 135,47 & 27,57 & 244,04 \\
E inf. & 3,97 & 43,33 & 6,68 & 159,61 \\
\hline \hline
\end{tabular}

la porción alveolar de los maxilares y del proceso maxilar del arco cigomático son más frecuentes en los estratos superiores ( $\mathrm{B}$ y C) mientras que en el resto de la secuencia presentan valores menores a $37 \%$ (Inf. supl., Tab. 20). En C. talarum el segmento más afectado fue el arco cigomático con valores mayores a $67 \%$. Todas las categorías presentan valores más altos en los estratos B y C, lo que es más acentuado en la pérdida de premaxilares. Los maxilares de los marsupiales didélfidos presentan una frecuencia de fragmentación mayor que los roedores, con pérdida total del arco cigomático y sin recuperación de premaxilares (Inf. supl., Tab. 20).

En los roedores cricétidos y C. talarum los molares recuperados sueltos son escasos pero, los incisivos presentan valores más altos (Tab. 10 y 11). En los cricétidos los índices de conservación de dientes son variables entre estratos. Los estratos D y E inferior muestran una pérdida importante de incisivos, mientras que en el C la preservación es cercana al equilibrio. Los estratos B y E superior tienen una sobrerrepresentación de incisivos lo que sugiere un déficit en la preservación de ramas mandibulares y principalmente de premaxilares (se recuperaron más incisivos sueltos que alvéolos vacíos). Los incisivos de C. talarum están sobrerrepresentados en todos los estratos, aunque la pérdida de premaxilares, medida en función de los maxilares recuperados, es algo menor que en el caso anterior. El cálculo de pérdida total de molares en función del total de molares esperados es superior al 50\% en los roedores cricétidos y menor al $45 \%$ en C. talarum. En el caso de los incisivos los valores obtenidos son consistentes a los calculados con el índice anterior.

TABLA 11. Frecuencia de conservación de dientes superiores e inferiores en relación con el total de dientes esperados de dos categorías de micromamíferos del Grupo 1 de Cueva Tixi.

\begin{tabular}{lcccc}
\hline Estrato & $\begin{array}{c}\text { Cricétidos } \\
\text { Molares }\end{array}$ & $\begin{array}{c}\text { Cricétidos } \\
\text { Incisivos }\end{array}$ & $\begin{array}{c}\text { C. talarum } \\
\text { Molares }\end{array}$ & $\begin{array}{c}\text { C. talarum } \\
\text { Incisivos }\end{array}$ \\
B & 51,73 & 108,25 & 44,51 & 435,29 \\
$C$ & 57,86 & 95,21 & 32,8 & 185,6 \\
$D$ & 54,92 & 58,13 & 39,51 & 161 \\
E sup. & 62,34 & 122,22 & 44,26 & 180,15 \\
E inf. & 52,28 & 74,7 & 42,29 & 132 \\
\hline \hline
\end{tabular}




\section{Grupo 2}

Abundancia relativa. La abundancia relativa promediada de cada estrato es menor y algo más heterogénea que en el Grupo 1, del cual también difiere en la preservación entre las distintas partes del esqueleto. Estas diferencias se manifiestan principalmente en la conservación de los miembros, lo cual está magnificado en el estrato $D$ con valores muy altos de todos los huesos largos (Fig. 25). Los estratos $B$ y C presentan valores bajos en el miembro posterior, mientras que el estrato $E$ inferior tiene magnitudes aun menores del miembro anterior.

Los huesos largos están mejor representados que el resto del esqueleto poscraneano, pero el cráneo cuenta con valores más altos que cualquier otro hueso (Ab. rel.> 71), con excepción de los húmeros del estrato D (Fig. 25). Los húmeros tienen los índices más altos del miembro anterior seguido, según el estrato, por las ulnas o los radios. Las
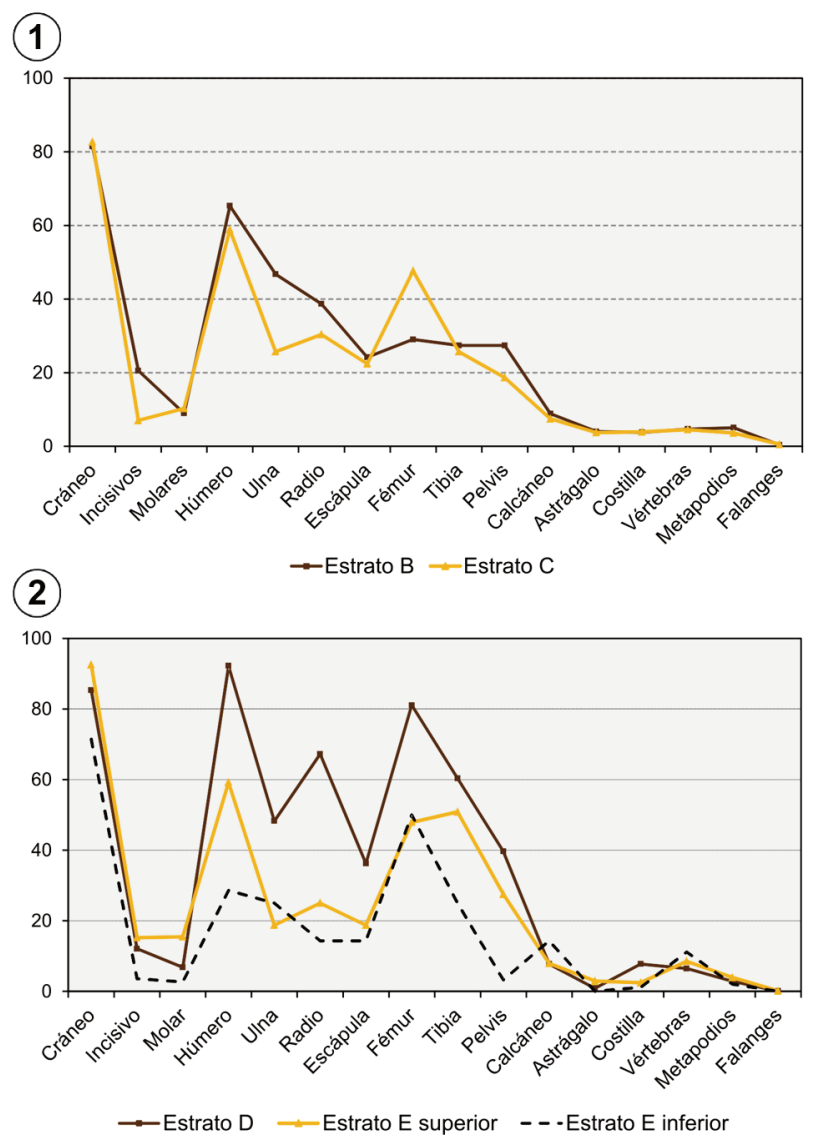

Figura 25. Abundancia relativa del esqueleto de micromamíferos del Grupo 2 (roedores cávidos) de Cueva Tixi. 1, Niveles superiores; 2, niveles inferiores. (Inf. supl., Tab. 21). escápulas presentan los valores más bajos de abundancia relativa.

En el miembro posterior, los mayores valores de abundancia relativa están en los fémures, aunque en el estrato $E$ superior las tibias apenas los superan, mientras que en el estrato B son muy parejos. Las pelvis son los huesos que menos se preservaron. Otros elementos óseos analizados y los dientes presentan valores muy bajos.

En los dos estratos inferiores el miembro posterior está mejor representado que el anterior ( $E$ superior $P<0,01$; $E$ inferior $P<0,05)$, como en el Grupo 1, aunque con una relación algo mayor (Fig. 26; Tab. 12). En el estrato D esta relación es cercana al equilibrio aunque sin diferencias significativas $(P>0,01)$ y continúa aumentando en los estratos $C$ y $B$ donde el miembro anterior es preponderante $(P<0,05)$ (Fig. 26; Tab. 12).

Las falanges de los roedores cávidos tienen una preservación diferencial, en los estratos superiores (B y C) son más numerosas que en los estratos inferiores, donde mantienen una frecuencia de falanges semejante a la de los micromamíferos del Grupo 1 (Fig. 27).

Proporciones poscráneo-cráneo. Las relaciones de conservación entre elementos del cráneo y poscráneo, a través del índice PC-C2, muestran preponderancia de estos últimos $(P<0,01)$, excepto en el estrato $D$ en el que las diferencias no son significativas. Considerando menos elementos poscraneanos (índice PC-C1) el estrato D y el E inferior presen-

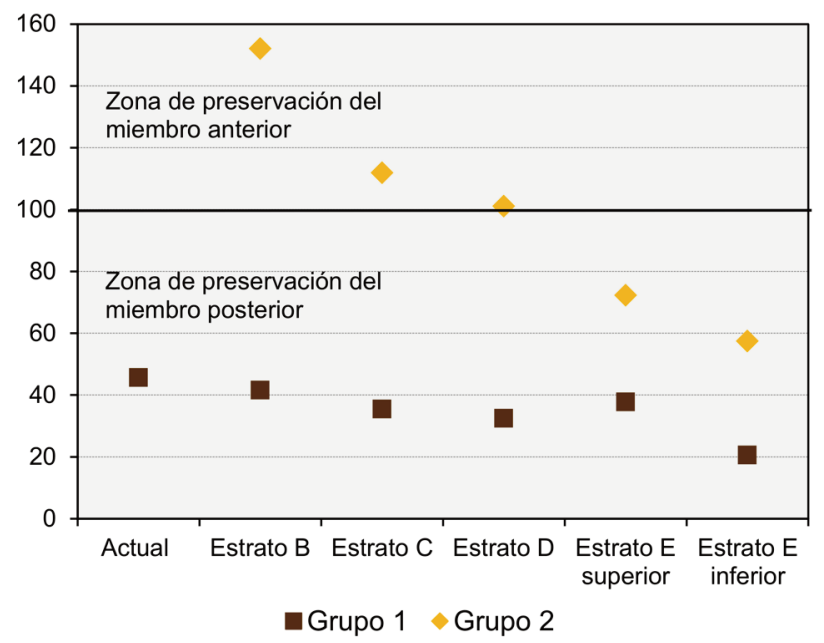

Figura 26. Preservación relativa entre el miembro anterior y posterior de los micromamíferos de Cueva Tixi y de la muestra actual producida por Tyto alba. (Tab. 9 y 12). 


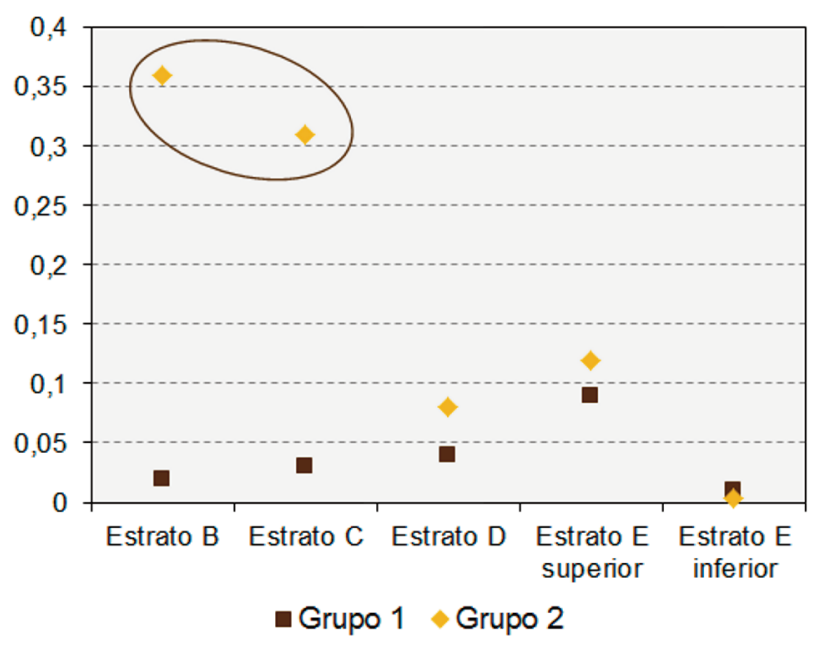

Figura 27. Abundancia relativa de falanges de las muestras de los roedores cávidos y de otros micromamíferos de Cueva Tixi. (Inf. supl., Tab. 8 y 21).

tan proporciones equilibradas $(P>0,01)$ mientras que en el resto de los estratos preponderan los craneanos ( $\mathrm{P} P<0,05$; $C P<0,01$; E superior $P<0,01$ ) (Tab. 12).

Conservación de elementos distales. La relación entre el estilopodio y el zeugopodio muestra una menor preservación de los elementos distales, con índices entre 50 y $73(P<0,05)$ (Tab. 12). Estos índices son mayores que en el Grupo 1, lo que indica una mejor representación del zeugopodio. La incorporación de las ulnas al análisis mantiene esta relación, aunque deprime los índices de los estratos E superior, D y C, y aumenta la de los estratos $E$ inferior y $B$.

Fragmentación. La fragmentación de los elementos de los roedores cávidos tiene un patrón parecido entre los estra- tos, pero es menos homogénea que la determinada para el Grupo 1 (Fig. 28). Esta mayor diversidad se manifiesta en coeficientes de correlación más bajos entre estratos que los del Grupo 1 (Inf. supl., Tab. 23). Entre los fémures, los enteros son los más abundantes proporcionalmente, a diferencia de lo que ocurre en el Grupo 1, seguidos por la epífisis proximal y la diáfisis (excepto en el Estrato E inferior) (Fig. 24 y 28). Las tibias sufrieron mayor fragmentación, las enteras preponderan en general, pero con magnitudes menores que los fémures. En los estratos $B$ y $C$ hay menos tibias enteras y más epífisis (distales y proximales) que en el resto de la secuencia (Inf. supl., Tab. 24).

La situación del miembro anterior es distinta, los húmeros muestran una mejor preservación de la epífisis distal y menor preservación de enteros y proximales (Fig. 28). Entre las ulnas, predominan las enteras y epífisis proximales, pero con variaciones importantes de proporción entre los estratos. En los estratos B y C esto último se magnifica al caer la proporción de ulnas enteras y aumentar la de epífisis proximales.

Las fracturas de las diáfisis de los huesos largos no son homogéneas como en el Grupo 1. Estas fueron registradas mayormente asociadas a una de las epífisis en las tibias, y en los estratos C, D y E superior a los húmeros y fémures. Esta relación se invierte en estos dos últimos huesos en el estrato $B$ en los que las diáfisis sin epífisis son más numerosas (Inf. supl., Tab. 25). Estas relaciones de conservación no pudieron ser evaluadas en las ulnas por su alta fragmentación.

Las ramas mandibulares están más dañadas en la rama

TABLA 12. Parámetros analizados de los micromamíferos del Grupo 2 de Cueva Tixi.

\begin{tabular}{|c|c|c|c|c|c|c|c|c|}
\hline Estrato & $N E I T$ & $N M I$ & $P C-C 1$ & $P C-C 2$ & ED1 & $E D 2$ & $I P M$ & Ab. rel. \\
\hline$B$ & 959 & 62 & 76,92 & 66,67 & 68,33 & 77,77 & 152,1 & 26,22 \\
\hline$C$ & 1485 & 107 & 77,02 & 54,45 & 52,63 & 51,16 & 111,92 & 23,99 \\
\hline$D$ & 1124 & 58 & 118,2 & 95,29 & 73,63 & 67,66 & 101,07 & 38,28 \\
\hline Esup. & 2031 & 120 & 60,61 & 45,66 & 70,81 & 58,88 & 72,27 & 26,15 \\
\hline E inf. & 159 & 14 & 62,85 & 45,71 & 50 & 54,54 & 57,5 & 18,59 \\
\hline
\end{tabular}


(1)

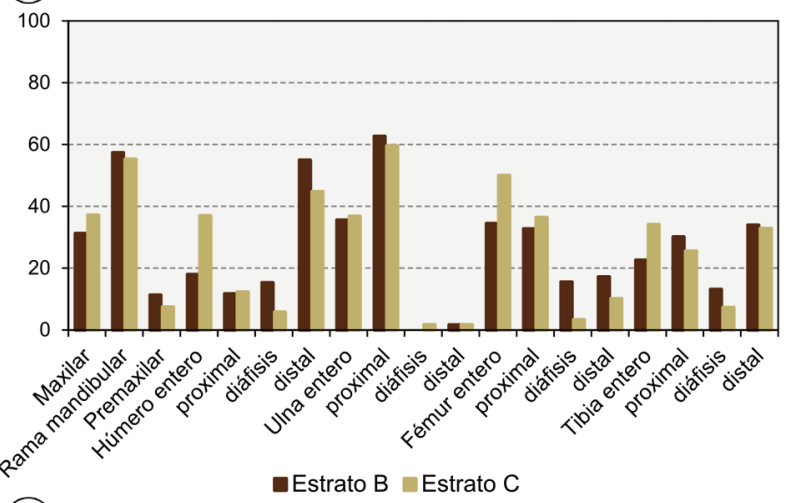

(2)

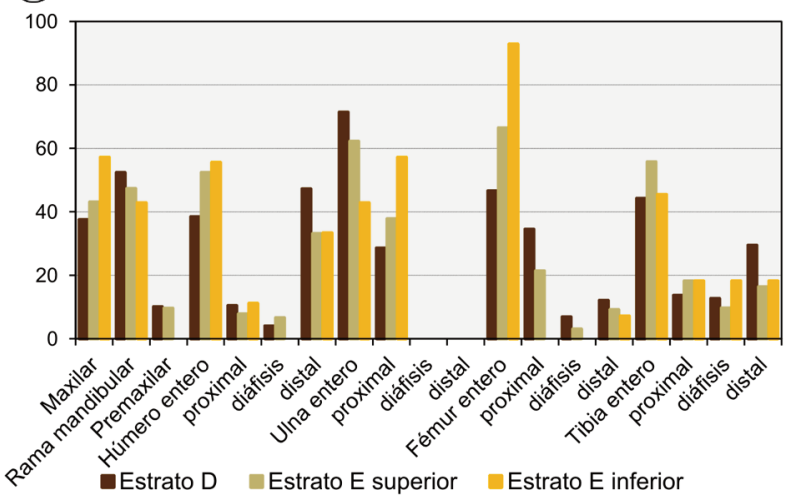

Figura 28. Fragmentación (NEIT\%) de micromamíferos del Grupo 2 (roedores cávidos) de Cueva Tixi. 1, Niveles superiores; 2, niveles inferiores. (Inf. supl., Tab. 22 a 24).

TABLA 13. Frecuencia (NEIT\%) de conservación de dientes del Grupo 2 de Cueva Tixi.

\begin{tabular}{lcccc}
\hline \multirow{2}{*}{ Estrato } & \multicolumn{2}{c}{$a$} & \multicolumn{2}{c}{$b$} \\
& Molares & Incisivos & Molares & Incisivos \\
B & 20,52 & 94,44 & 47,64 & 97,52 \\
$C$ & 21,3 & 35,71 & 45,1 & 73,13 \\
$D$ & 17,16 & 95 & 55,29 & 98,3 \\
E sup. & 27,5 & 52,89 & 53,83 & 75,65 \\
E inf. & 6,74 & 22,22 & 40,71 & 53,33
\end{tabular}

$a$, dientes sueltos conservados en función de los alvéolos vacíos; $b$, dientes superiores e inferiores en relación con el total de dientes esperados.

ascendente, seguidas por valores bajos de fracturas del borde mandibular inferior y de la sínfisis (Inf. supl., Tab. 26). Casi todos los maxilares carecen del arco cigomático com- pleto. Las fracturas de la porción maxilar del arco cigomático son mayores que las fracturas de la porción alveolar de los maxilares. Ambos tipos de fracturas aumentan progresivamente desde los estratos inferiores. El cráneo tiene una tendencia alta a la pérdida de premaxilares.

Los molares recuperados fuera de los alvéolos son escasos en relación con los molares faltantes de los alvéolos vacíos de los maxilares y de las ramas mandibulares (Tab. 13). Los incisivos presentan valores más diversos, cercanos al $100 \%$ en los estratos B y D, y menores al 53\% en el resto. La conservación total de molares varía entre el $40,71 \%$ y el $55,29 \%$, mientras que los incisivos se preservaron con valores más altos, excepto en el estrato $E$ inferior.

\section{Grupo 3}

Aves. Las abundancias relativas promediadas de las aves son similares a las de la muestra actual de aves depositada por Tyto alba (Quintana, 2015b) (Tab. 14), pero los elementos óseos de la muestra fósil están representados de modo diferente entre los distintos estratos (Fig. 29).

En los dos estratos inferiores y en la muestra actual prevalecen ligeramente los huesos de las alas (Tab. 14), mientras que a partir del estrato $D$ son más numerosos los huesos del miembro posterior, pero en todos los casos las diferencias no son significativas $(P>0,01)$. Los elementos proximales superan a los distales, particularmente en los estratos B y E inferior. En los estratos D y E superior y en la muestra actual los huesos proximales y distales se encuentran cercanos al equilibrio.

Los cráneos y mandíbulas de las aves tienen un grado alto de fragmentación y una preservación proporcional baja (Inf. supl., Tab. 28). Las partes mejor representadas son los picos (premaxilares y las partes distales de las ramas mandibulares). Solo se registraron tres fragmentos de la región posterior del cráneo en los niveles inferiores.

Las cinturas pélvicas están muy fragmentadas en todos los niveles y solamente se preservó la región que se dispone alrededor del acetábulo. Los sinsacros son más numerosos, en algunos casos se encuentran enteros, pero siempre con algún grado de alteración por fracturas pequeñas de los procesos vertebrales (Inf. supl., Tab. 28). En todos los niveles los esternones fueron recuperados fracturados, habiéndose preservado la región anterior que comprende al manubrio y 
TABLA 14. Parámetros analizados de las aves pequeñas de Cueva Tixi y de la muestra actual producida por Tyto alba.

\begin{tabular}{lcccccc}
\hline Estrato & NEIT & NMI & Miembro Ant/Post & EDaves & $\begin{array}{c}\text { Cinturas/Huesos } \\
\text { largos }\end{array}$ \\
Actual & 192 & 13 & 56,81 & 50 & 21,87 & 46,45 \\
$B$ & 62 & 4 & 41,02 & 70,45 & 18,75 & 44,64 \\
C & 91 & 7 & 40,9 & 57,14 & 9,87 & 31,63 \\
D & 97 & 7 & 43,28 & 53,33 & 10,38 & 45,4 \\
E sup. & 213 & 16 & 53,27 & 61,37 & 15,89 & 36,6 \\
E inf. & 36 & 3 & 54,54 & 70,37 & 24,13 & 39,28 \\
\hline
\end{tabular}

NEIT, número de especímenes identificados por taxón. NMI, número mínimo de individuos; Miembro Ant/Post, índice de preservación de miembros; EDaves, índice de relación entre elementos distales y proximales de los miembros; Cinturas/Huesos largos, índice de relación entre elementos de los miembros y cinturas; $\boldsymbol{A} b$. rel., abundancia relativa promedio. Para su descripción ver Materiales y Métodos.

las superficies articulares con los coracoides (Inf. supl., Tab. 28). Las cinturas están subrepresentadas hasta un $90 \%$ en relación con los huesos largos en todos los estratos, siendo todas diferencias altamente significativas $(P<0,01)$ (Tab. 14).

Las diáfisis sin epífisis fueron poco frecuentes. Pocos elementos enteros alcanzan $50 \%$ de preservación y algunos de ellos con NEIT muy bajos (e.g., el carpometacarpo o el radio). Los huesos mejor representados son los coracoides, húmeros, ulnas, carpometacarpos, sinsacros, fémures, tibiotarsos y tarsometatarsos (Fig. 30). Los elementos con poca fragmentación son los carpometacarpos, las escápulas y las vértebras.

Ofidios. Las partes del esqueleto mejor preservadas de los ofidios son las vértebras, seguidas por las costillas y un solo resto craneano en el estrato C (Inf. supl., Tab. 7).

Peces. Los restos de peces son muy fragmentarios como para proponer un patrón confiable. Se identificaron vértebras, espinas y partes del cráneo.

Anuros. Debido a que la muestra de anuros es muy pequeña (NEIT 31), solo se presentan los valores absolutos y no se calcularon índices. Se recuperaron elementos de los miembros y de las cinturas (Inf. supl., Tab. 30). Los huesos largos carecen de los extremos articulares, excepto las epífisis distales de los húmeros que presentan mayor desarrollo de la osificación. En la muestra actual de referencia los anuros están mejor representados anatómicamente y con pocas fracturas (Quintana, 2015b).
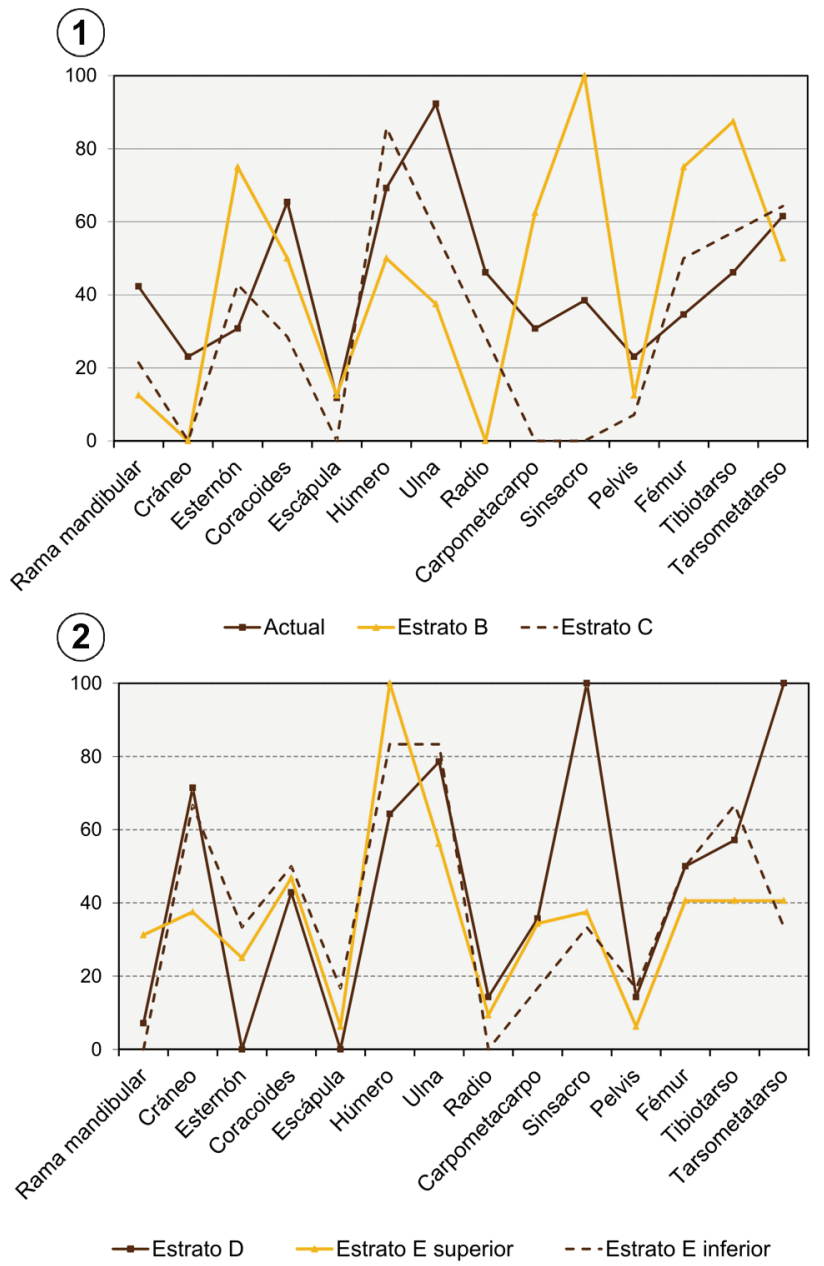

Figura 29. Abundancias relativas de aves pequeñas. 1, Muestra actual producida por Tyto alba y niveles superiores de Cueva Tixi; 2 , niveles inferiores de Cueva Tixi. (Inf. supl., Tab. 27). 

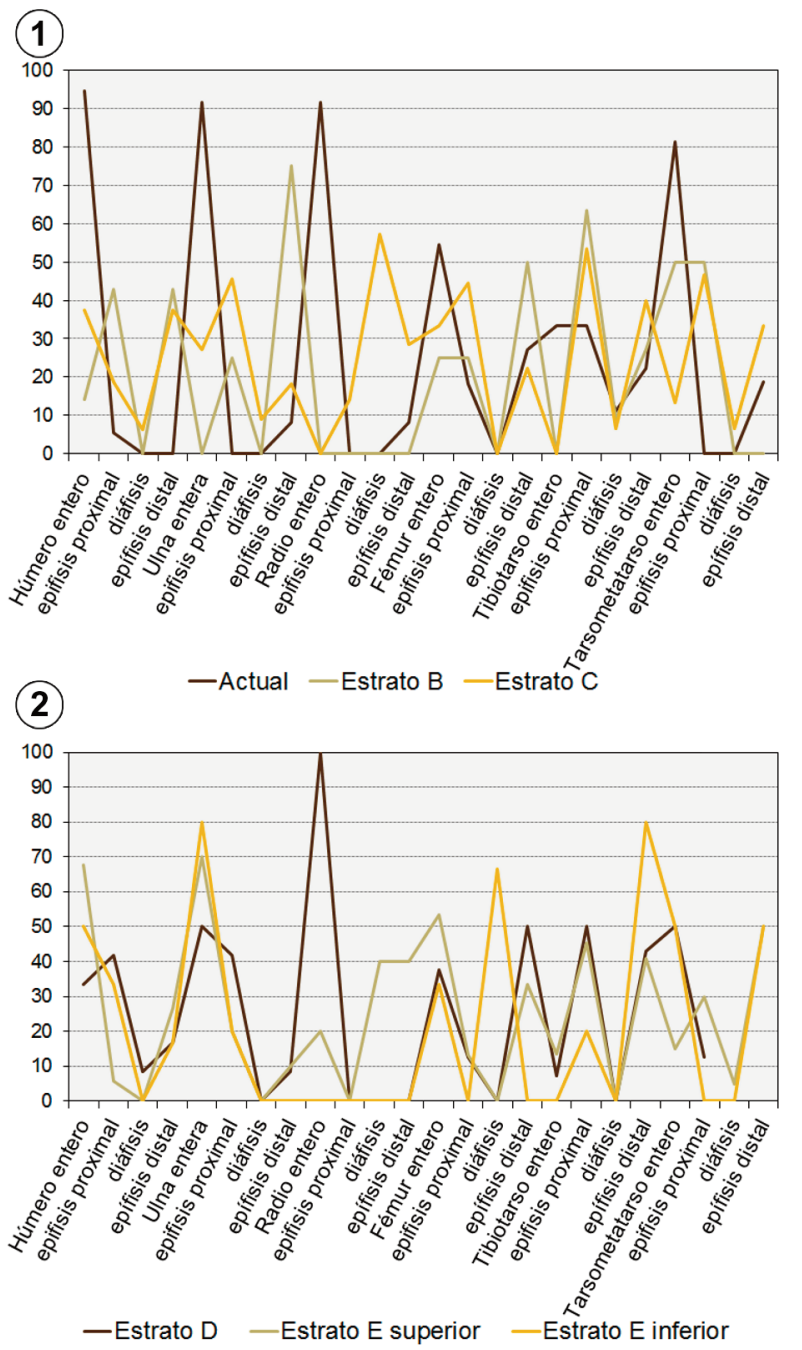

Figura 30. Fragmentación (NEIT\%) de los miembros de aves. 1, Muestra actual producida por Tyto alba y niveles superiores de Cueva Tixi; 2, niveles inferiores de Cueva Tixi. (Inf. supl., Tab. 29).

\section{DISCUSION}

\section{Abundancia y diversidad taxonómica}

La distribución y abundancia de cada taxón fue analizada en detalle en Quintana (2001a). Las poblaciones de la mayoría de los microvertebrados de Cueva Tixi se disponen actualmente en el área de estudio. Las especies Bibimys torresi Massoia, 1979, Pseudoryzomys simplex (Winge, 1887), Lestodelphys halli (Thomas, 1921), Scapteromys sp. y Ctenomys talarum en el presente no habitan en el área serrana, mientras que se extinguieron el marsupial didélfido Monodelphis sp. nov. (ver su descripción en Goin, 2001) y el roedor Caviinae Galea tixiensis (Quintana 2001c).
Durante el Pleistoceno tardío se registran asociaciones no análogas a las distribuciones de las poblaciones actuales, como en el caso de Lestodelphys halli, Monodelphis sp., Cavia aperea y Scapteromys sp. entre otros (Quintana, 2001a). La presencia de Scapteromys sp. es singular para este período y desaparece del registro de Tandilia oriental, aunque fue citada para inicios del Holoceno medio en el sitio arqueológico La Moderna (Tandilia occidental) (Politis y Gutiérrez, 1998) y para el Holoceno tardío del norte de la provincia de Buenos Aires (Martínez y Gutiérrez, 2004).

Los cambios más significativos en los ensambles de micromamíferos y otras asociaciones no análogas, ocurren al final de la secuencia y son más evidentes al ser comparados con el registro actual (Quintana, 2015b). Estos cambios fueron interpretados en relación con el desarrollo de la pequeña Edad de Hielo y, más tarde, con el impacto ambiental de los ecosistemas agrícolas (Quintana, 2001c).

\section{Patrones de preservación esquelética}

En el Grupo 1 los atributos de preservación esquelética están influenciados fuertemente por los datos de los roedores cricétidos (más del 93\% de los restos recuperados), aunque se pudieron determinar algunas diferencias respecto de Ctenomys talarum y de los didélfidos. La homogeneidad en la preservación y representación anatómica de las muestras de cada estrato indica que los restos incluidos en este grupo sufrieron los mismos procesos de alteración y que no fueron afectados por acciones muy destructivas. Particularmente la pérdida de molares es alta lo cual puede estar relacionado con las operaciones del tamizado y de su movilidad desde su acumulación en superficie. En la muestra actual se verificó que la pérdida de dientes ocurre en momentos muy tempranos previos al enterramiento y durante la manipulación del material (Quintana, 2015b). Los mayores valores de pérdida de molares de Ctenomys talarum, además, están influenciados por la forma tubular y abierta de las raíces que carecen de estructuras que faciliten el anclaje de los dientes. La preservación de incisivos está sobrerrepresentada indicando una pérdida importante de premaxilares, lo cual está corroborado por la relación entre premaxilares y maxilares registrados.

La mayor fragmentación de los maxilares de los marsupiales está relacionada con que el proceso maxilar del arco 
cigomático está muy reducido y el yugal adquiere mayor desarrollo. Debido a que el yugal no está fusionado al maxilar, se pierde con facilidad, por lo que ningún ejemplar conservó el arco cigomático; mientras que la menor fractura del borde inferior de las mandíbulas de los marsupiales se debe a su mayor robustez, en función de que ese borde carece del alvéolo del incisivo como en los roedores.

La homogeneidad en los valores de fragmentación y la proporción alta de fracturas sobre el hueso en estado seco de los integrantes del Grupo 1 muestra que el proceso que produjo las fracturas posdepositacionales afectó principalmente a los huesos más frágiles y a las áreas más frágiles de cada elemento. Así, se obtuvo una mejor preservación del miembro posterior que del anterior, los fémures y húmeros enteros fueron más abundantes que otros huesos largos, las ulnas estaban muy fracturadas, los elementos distales fueron escasos y las ramas mandibulares más numerosas y mejor preservadas que los maxilares.

El promedio de abundancia relativa de los elementos incluidos en el Grupo 1 es menor que en la muestra actual. La fragmentación presenta un patrón muy parecido, pero con menos huesos enteros en las muestras fósiles. Los demás parámetros son similares entre estas acumulaciones, pero en la muestra actual hay valores más cercanos al equilibrio en la pérdida de elementos distales.

La uniformidad a través de la secuencia sedimentaria de la preservación del esqueleto de los micromamíferos del Grupo 1 se caracteriza por la mejor conservación de los elementos del miembro posterior, principalmente los fémures; los húmeros resultaron poco fragmentados, en tanto las tibias fueron los huesos más afectados por fragmentación; los fémures, tibias y húmeros se preservaron mejor enteros, y las ulnas como epífisis proximales; las epífisis mejor preservadas fueron las distales de húmeros y las proximales de fémures y ulnas; en todos los huesos largos fracturados las diáfisis se preservaron mejor asociadas a una epífisis que como simples cilindros sin epífisis; los huesos distales están pobremente representados; los elementos poscraneanos están mejor preservados que los craneanos, particularmente en los dos estratos superiores; la pérdida de molares es mayor que la de incisivos en los roedores cricétidos y Ctenomys talarum. Esta especie presenta mayor pérdida de molares que los cricétidos y sus incisivos son más numerosos que los alvéolos preservados. Esto último también ocurre en los roedores cricétidos pero solo en los estratos B y E superior; las ramas ascendentes son las partes más afectadas de las ramas mandibulares; los arcos cigomáticos están rotos en casi todos los ejemplares y no se conservó en ningún didélfido. La región más alterada en Ctenomys talarum es el proceso maxilar del arco cigomático y en cricétidos los premaxilares. La anatomía de los didélfidos facilitó la pérdida de los premaxilares y que no se conserve el arco cigomático articulado a los maxilares. El porcentaje de premaxilares de roedores no recuperados es muy alto.

Dentro de este contexto se pueden señalar algunas variaciones sutiles. Los estratos $\mathrm{B}$ y $\mathrm{C}$ se agrupan a través de las relaciones PC/C más cercanas al equilibrio, influido por una mejor preservación de las ramas mandibulares. Estos estratos muestran una relación entre húmeros y fémures enteros más alta. Por su parte, las acumulaciones de los estratos D y E superior presentan una mayor proporción de ulnas enteras. La muestra del estrato $E$ inferior tiene, en general, los valores más bajos de todos los parámetros, posiblemente debido a una peor conservación posdepositacional de los huesos, más que a las condiciones del depósito original o a su agente de acumulación.

Entre los integrantes del Grupo 2, el patrón de preservación del esqueleto presenta parámetros menos uniformes que los del Grupo 1. Esta diversidad se manifiesta principalmente en el amplio rango de valores de la abundancia relativa o de la fragmentación entre los estratos. A su vez, algunos valores se invierten en la secuencia, por ejemplo el NEIT\% de las ulnas enteras es mayor que el de las epífisis proximales en los estratos $E$ superior y $D$, mientras que en los demás estratos la relación es opuesta. Situaciones similares ocurren con la abundancia relativa.

Las semejanzas respecto del Grupo 1 son la baja abundancia relativa de dientes sueltos, costillas, vértebras, falanges y metapodios, la menor preservación de elementos del zeugopodio y la buena representación de los huesos largos. Las principales diferencias con el Grupo 1, además de la dispersión de parámetros ya señalada, son la fragmentación más intensa de los huesos largos y la inversión de la preservación relativa de los miembros en los dos estratos superiores. La mejor representación del esqueleto apendi- 
cular también se manifiesta por los índices P/C que indican la preponderancia poscraneana, excepto en el estrato D.

A través de la secuencia, mientras aumenta el registro proporcional de huesos de los miembros del Grupo 2, disminuye el porcentaje de huesos largos enteros hacia los niveles superiores. Esta mayor fragmentación se puede caracterizar a través de las relaciones entre los fémures y los húmeros enteros, las cuales lo discriminan claramente respecto del Grupo 1. Los valores del estrato $E$ inferior están muy deprimidos, por lo que se supone que el sesgo debido al efecto del tamaño de la muestra (NMI 15, NEIT 153) altera la calidad de su registro.

Se pueden reconocer dos conjuntos de roedores cávidos en función de su preservación esquelética. La fragmentación de las muestras procedentes de los niveles superiores (estratos B y C) del Holoceno tardío final tiene índices de correlación más altos que los obtenidos en las muestras de los niveles inferiores (estratos D y E). Esto es consecuencia de que en las muestras más tardías existe una disminución proporcional de húmeros, ulnas, fémures y tibias enteros; la abundancia relativa de elementos del autopodio es hasta cuatro veces más alta y aumenta la frecuencia de las fracturas realizadas sobre el hueso en estado fresco. El cambio más significativo entre ambos conjuntos de roedores cávidos se determinó en la preservación relativa de los miembros, pasando de la preponderancia del miembro posterior en las muestras de los tres niveles inferiores a la del miembro anterior en las más tardías. Los cávidos de los niveles inferiores, además, presentan una preservación esquelética similar a la del Grupo 1 (Quintana, 2015a).

La preservación del esqueleto de las aves es heterogénea entre los distintos niveles estratigráficos de Cueva Tixi. Cráneos, mandíbulas, cinturas pélvicas, esternones y falanges son poco abundantes y con alta fragmentación. El resto de los elementos analizados son muy variables y con preservación dispar entre estratos. Los restos de aves de la muestra actual se diferencian por presentar menor fragmentación y mejor preservación de elementos del cráneo y de las cinturas (Quintana, 2015b). El parámetro más estable del registro de aves de los estratos de Cueva Tixi y de la muestra actual es la relación equilibrada entre el miembro anterior y el posterior, lo cual fue interpretado como típico de restos de aves en egagrópilas de rapaces nocturnas
(Bochenski, 1997) y hallado en otros conjuntos fósiles (Fernández et al., 2009). El bajo número registrado de algunos huesos de aves genera valores extremos de preservación, como el caso de radios y carpometacarpos. Estos últimos, además, presentan poca fragmentación en función de su alta densidad y pocas áreas frágiles. Por ello la zona correspondiente al tercer metacarpo es la más comúnmente dañada de este hueso.

La preservación de los ofidios coincide con otros registros fósiles caracterizados por la abundancia de vértebras y poca representación craneana (Albino, 1994; Quintana, en prensa). Por su parte, los anuros solo conservaron elementos del poscráneo, lo cual es una tendencia en otros registros de fósiles (Pinto Llona y Andrews, 1999). Sin embargo, en los contenidos de egagrópilas actuales los restos craneanos alcanzan mayor abundancia relativa que en las muestras de Cueva Tixi (Montalvo y Tejerina, 2009; Quintana, 2015b).

\section{Alteraciones antrópicas}

Se pueden discriminar dos conjuntos de roedores cávidos, el de los niveles inferiores ( $D, E$ superior y $E$ inferior) con marcas de corrosión digestiva y el de los dos estratos superiores (B y C) con huellas de filos líticos (Quintana et al., 2002; Quintana, 2005, 2015a; Quintana y Mazzanti, 2014).

Quintana (2005) indicó que las huellas de filos líticos se distribuyen con un patrón distintivo y no aleatorio que, complementado por la acción que habrían tenido esos cortes sobre la anatomía, permiten plantear una secuencia simple de faenamiento para el uso antrópico, sus productos para consumo y como materia prima. Las características diferenciales reconocidas en el patrón esquelético de la muestra de los cávidos usados en la subsistencia humana, pueden vincularse con el procesamiento carnicero. La técnica de despellejamiento aplicada a estos roedores comprendió el corte transversal de la piel en el zeugopodio anterior (Quintana, 2005), lo cual es consistente con la preponderancia del miembro anterior y la mayor preservación de elementos distales como las falanges. Esta técnica se diferencia del despellejamiento aplicado en el mismo sitio a roedores más grandes (vizcachas), actividad que generó la rotura de ulnas y radios y su salida del sitio adheridos a la piel (Quintana y Mazzanti, 2011). 
La mayor fragmentación de los maxilares, de la rama ascendente y de la porción maxilar del arco cigomático permiten proponer una posible intervención humana ya que el procesamiento del cráneo en estos estratos, indicado por huellas de corte, está caracterizado por la separación de la mandíbula (Quintana, 2005). Por otra parte, se observó el aumento de las fracturas sobre el hueso en estado fresco en la muestras de los niveles superiores.

Los cávidos explotados antrópicamente también presentan otros parámetros propios, como el aumento proporcional de la cantidad de ejemplares (Quintana, 2015a), la selección antrópica orientada a ejemplares adultos (más grandes) y la de aves rapaces hacia los cávidos juveniles (más pequeños) (Fig. 31).

Las sociedades que habitaron Cueva Tixi durante el Holoceno tardío final profundizaron la selección y caza de especies pequeñas, las cuales fueron obtenidas en mayor proporción que en tiempos anteriores. Este comportamiento económico se desarrolló en el contexto de una estrategia de subsistencia de intensificación y diversificación de la obtención de los recursos en la micro región, ya que el mismo patrón se verificó en los sitios Cueva El Abra y Lobería I, los cuales presentan cronologías similares a los estratos B y C de Cueva Tixi (Quintana y Mazzanti, 2001, 2014; Quintana, en prensa). La preponderancia de ejemplares adultos en el conjunto de cávidos explotados es consistente con esa estrategia de subsistencia, ya que la selección de los individuos más grandes optimiza la obtención de pieles y partes comestibles. El mismo patrón de explotación de cávidos se desarrolló en Cueva El Abra, que se encuentra a pocos kilómetros de Cueva Tixi (Quintana, 2015a, en prensa).

Los patrones esqueléticos obtenidos para las muestras de roedores cávidos del Holoceno tardío final de Cueva Tixi presentan algunas diferencias respecto de otras tafocenosis formadas por acción de depredadores poco destructivos como las aves rapaces estrigiformes (Andrews, 1990). Sin embargo las diferencias del patrón de preservación esquelética entre las dos muestras de cávidos resultaron sutiles, lo que dificulta la discriminación entre los conjuntos producidos por depredadores y por actividad antrópica (Quintana, 2015a). En este sitio la información procedente de los patrones esqueléticos considerada de modo aislado de otras

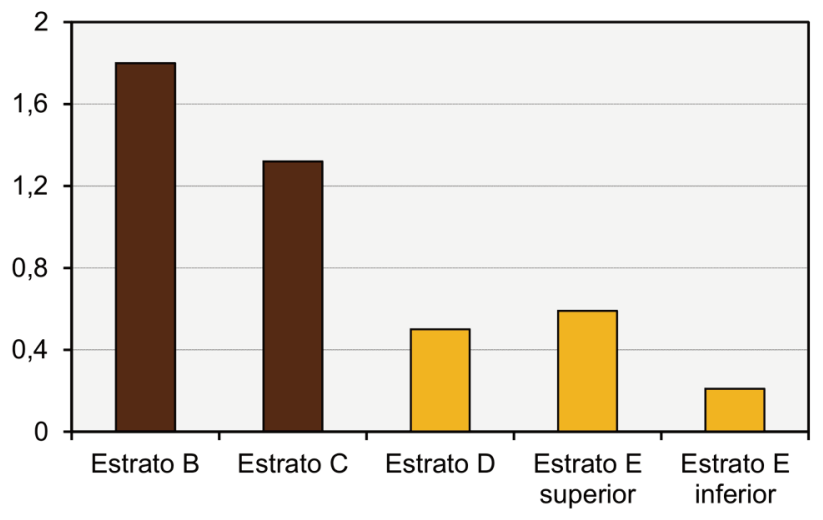

Figura 31. Relación de NEIT ejemplares adultos/NEIT ejemplares juveniles de los roedores cávidos de Cueva Tixi. En marrón: ejemplares cazados por sociedades indígenas. En naranja: ejemplares depredados por aves rapaces.

evidencias no resultó suficiente para discriminar concluyentemente el origen de las tafocenosis de roedores cávidos. Esas evidencias involucran a las huellas de corte, el procesamiento carnicero previamente establecido, la ausencia de marcas de digestión, el aumento proporcional de individuos y la selectividad sobre individuos adultos (Quintana, 2015a).

Las frecuencias de elementos con exposición al fuego son muy bajas como para reconocer patrones de termoalteración (Medina et al., 2011, 2012) que puedan ser atribuidos a la actividad antrópica de modo directo, ya sea en la muestra de roedores cávidos de los estratos donde fueron explotados o en el resto de la secuencia y de los taxones. Estas alteraciones térmicas son posteriores a las acumulaciones de microvertebrados debido a que provienen de los niveles infrayacentes a estructuras de combustión generadas por las sociedades indígenas que habitaron en el recinto.

El registro de los peces es escaso, en ningún espécimen se identificaron rasgos que puedan ser atribuidos a la manipulación antrópica. Sin embargo, el aumento de la cantidad de ejemplares en los dos estratos superiores, que corresponden a la última ocupación del sitio, coincide con la estrategia de intensificación de la subsistencia y con la incorporación de presas nuevas y pequeñas a la dieta (Quintana y Mazzanti, 2014). En este contexto se considera que los peces de esos niveles habrían sido producto de la pesca. 


\section{Alteraciones no antrópicas}

Se determinaron procesos naturales que modificaron el esqueleto de los microvertebrados analizados, tanto durante etapas previas a su depósito, como a fenómenos ocurridos en la superficie o durante el enterramiento (Tab. 15). Corrosión radicular. La cantidad proporcional de elementos afectados por ácidos radiculares es diversa, pero con una tendencia a la disminución de este agente hacia los niveles inferiores. La discriminación de la corrosión radicular por categorías permite advertir que si bien hubo porcentajes altos de elementos de micromamíferos con esta alteración, la misma no fue de gran extensión debido a que preponderó la baja densidad y la poca pérdida de masa ósea, aunque su distribución en todo el contorno de los fémures fue mayor. Estas trazas ocultan información tafonómica previa. Los depósitos del estrato B fueron los más dañados por raíces, lo cual podría estar relacionado con el mayor contenido orgánico y de humedad durante el Holoceno tardío final.

En las aves la proporción de huesos con daños profundos fue relativamente alta a pesar de la poca densidad de trazas, lo cual es consecuencia de que estos huesos tienen una estructura frágil, con espesores muy delgados que son fácilmente perforados por la corrosión radicular. En concordancia con la poca extensión de estas marcas, la mayoría de los elementos de aves con la categoría profunda son perforaciones pequeñas y raramente con pérdidas importantes de masa ósea.

La ausencia de esta bioerosión sobre las precipitaciones minerales indica que la actividad de las raíces afectó a los huesos durante un tiempo acotado y cuando estuvieron enterrados cercanos a la superficie.
Encostramientos e impregnaciones de minerales. Los depósitos de carbonatos sobre los huesos no afectaron profundamente a la muestra. El crecimiento de cristales desde el canal medular fue la variable más destructiva pero de muy baja frecuencia. Este tipo de filtración carbonática es similar a la descripta en mamíferos de estratos del Pleistoceno Superior del río Quequén Salado (Montalvo et al., 2012a). En los elementos de micromamíferos de Cueva Tixi, este mineral tiene un patrón claro de mayor incidencia hacia los niveles inferiores. El pico máximo de su precipitación sobre los huesos del estrato C es consistente con la formación de una capa carbonática espesa que sella este nivel y cementa huesos, clastos y materiales arqueológicos. La proporción de elementos con carbonatos de los restos de aves y de las vértebras de ofidios está sesgada por su fácil desprendimiento durante la manipulación y la limpieza durante su identificación taxonómica.

En los restos de mamíferos, aves y ofidios las precipitaciones de manganeso aumentan proporcionalmente hacia los niveles inferiores, lo cual está relacionado con la acumulación de humedad en contacto con la roca de caja. Particularmente la precipitación de los óxidos de manganeso es un indicador de la alternancia entre la saturación de humedad y períodos secos (Imbelloni y Zárate, 1983). Las concentraciones de carbonatos también dependen del hidromorfismo temporario, de hecho la formación del nivel de carbonato del estrato C fue relacionada con la anomalía climática seca denominada Pequeña Edad de Hielo (Martínez et al., 2000). Estos minerales se disponen en la superficie ósea por encima de otros rasgos pre y posdepositacionales como roídos, fracturas o corrosiones por raíces y por di-

TABLA 15. Síntesis de las alteraciones identificadas en los microvertebrados de Cueva Tixi.

\begin{tabular}{|c|c|c|c|}
\hline \multirow[t]{3}{*}{ ANTRÓPICAS } & \multicolumn{3}{|c|}{ NATURALES } \\
\hline & \multirow[t]{2}{*}{ Predepositacionales } & \multicolumn{2}{|c|}{ Posdepositacionales } \\
\hline & & Bioestratinómicas & Fosildiagenéticas \\
\hline $\begin{array}{l}\text { Huellas de corte } \\
\text { Termoalteración (por transferencia) }\end{array}$ & $\begin{array}{c}\text { Corrosión digestiva } \\
\text { Representación anatómica } \\
\text { Patologías } \\
\text { Fracturas }\end{array}$ & $\begin{array}{c}\text { Mordeduras de roedores } \\
\text { Fracturas }\end{array}$ & $\begin{array}{c}\text { Precipitación de minerales } \\
\text { Corrosión radicular } \\
\text { Fracturas }\end{array}$ \\
\hline
\end{tabular}


gestión. Esto indica que los minerales precipitan en la superficie de los huesos o se infiltran en su interior con posterioridad a esos procesos. Las precipitaciones de minerales sobre las superficies óseas solo fueron alteradas por fracturas posdepositacionales, pero no por marcas de raíces ni por agentes meteóricos, lo cual es un buen indicador de la estabilidad de los procesos posdepositacionales a lo largo de la secuencia.

Mordeduras. Las marcas de mordeduras de roedores fueron poco frecuentes y no ocasionaron daños importantes de la masa ósea ni resultaron un factor destructivo del conjunto analizado. La muestra de referencia actual también presenta pocos casos de marcas producidas por roedores (Quintana, 2015b).

Corrosión digestiva. Las categorías de digestión de los elementos del Grupo 1 y de los recuperados de los niveles inferiores del Grupo 2 son leves y moderadas (Andrews, 1990) y con frecuencias bajas. Los integrantes del Grupo 2 presentan frecuencias de trazas algo mayores que en los otros micromamíferos. Esta diferencia puede ser un sesgo derivado del tamaño de las muestras de huesos largos analizadas, en las que los cávidos son de un orden de magnitud menor ( $n=488$ ) que los demás micromamíferos ( $n=6876)$. La mayor incidencia sobre húmeros se presenta como un indicador de la estabilidad del tipo de depredador que generó estas acumulaciones. En la muestra actual esta relación está invertida y la frecuencia de elementos digeridos es mayor, particularmente en el fémur.

Debido a que se trata de un mismo proceso no hay motivos para mantener la cuantificación por separado de las frecuencias de digestión de ambos grupos, por lo que se combinan los datos cuantitativos de los tres estratos inferiores (Inf. supl., Tab. 4). En ambos casos se trató de niveles de corrosión digestiva compatibles con los modelos actuales de depredadores de la Categoría 1 (rapaces nocturnas) basados sobre elementos poscraneanos.

Estas categorías de digestión y el patrón de preservación esquelética permiten descartar la acción de depredadores más destructivos de sus presas como carnivoros (Andrews, 1990; Gómez, 2007; Gómez y Kaufmann, 2007; Montalvo et al., 2007; 2008, 2012b; Álvarez et al., 2012; Rafuse et al., 2014) o rapaces diurnas (Andrews, 1990; Gómez, 2007; Montalvo y Tallade, 2009; Montalvo et al., 2014) que

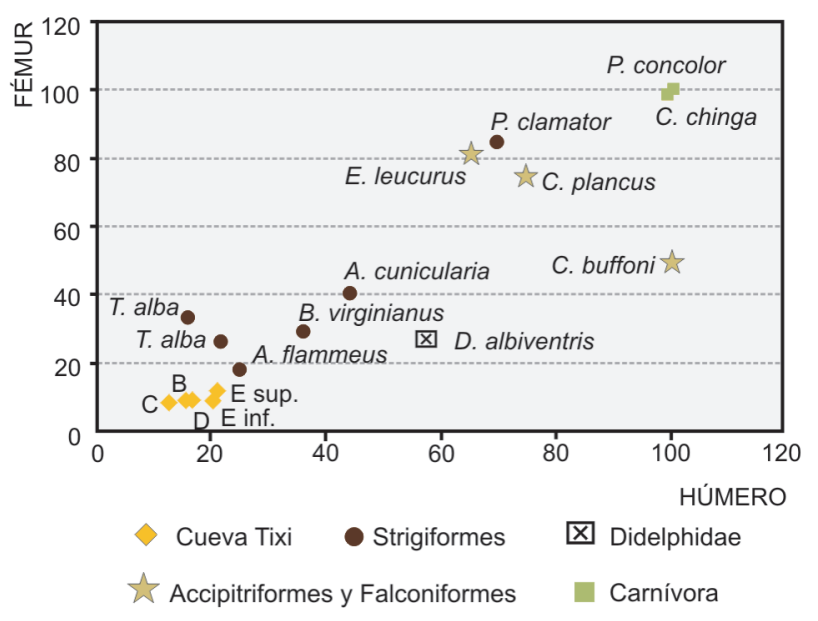

Figura 32. Frecuencias de corrosión digestiva en epífisis distales de húmeros y epífisis proximales de fémures de los micromamíferos de Cueva Tixi, comparado con aves rapaces y mamíferos depredadores. Fuente de datos: Tyto alba, Gómez (2007) y Quintana (2015b). Asio flammeus, Bubo virginianus, Athene cunicularia, Circus buffoni (Gmelin, 1788), Didelphis albiventris Lund, 1840, Gómez (2007). Pseudoscops clamator, Rudzik et al. (2015). Elanus leucurus (Vieillot, 1818), Montalvo et al. (2014). Caracara plancus (Miller, 1777), Montalvo y Tallade (2009). Puma concolor (Linnaeus, 1771), Montalvo et al. (2007) y Conepatus chinga (Molina, 1782), Montalvo et al. (2008).

ocasionan frecuencias más altas de corrosión digestiva de categorías fuertes y extremas (Fig. 32), proporciones mayores de fracturas, marcas de dientes o picos y abundancias relativas más bajas.

Las trazas de digestión sobre los restos de las aves se disponen principalmente en las epífisis de los huesos largos afectando áreas muy pequeñas. Los elementos del estrato E inferior tienen un porcentaje muy bajo debido a que se trata de una muestra chica (NEIT 36) con un solo elemento digerido. El resto de los niveles presenta proporciones variables de digestión del total de huesos largos (carpometacarpos, húmeros, ulnas, radios, fémures, tibiotarsos, tarsometatarsos). Considerando a estos elementos por separado se advierten valores elevados, lo cual es consecuencia de los pocos ejemplares registrados en cada categoría. Por ejemplo, los húmeros pueden representar proporciones muy altas, hasta el $42,8 \%$. Este sesgo se compensa parcialmente al cuantificar a los huesos largos como categoría única, lo cual resulta en proporciones más bajas y con valores similares a los micromamíferos. Las categorías bajas de alteración digestiva en las aves de Cueva Tixi también indican la intervención de un depredador del tipo de una rapaz nocturna. 
La muestra de microvertebrados actuales depositada por Tyto alba presenta trazas de digestión en proporciones algo mayores tanto en mamíferos como en aves y también de categorías ligera y moderada, mostrando un modelo característico de esa especie (Quintana, 2015b).

Los huesos largos de los anuros, excepto en los extremos distales de los húmeros y proximales de los radio-ulna, tienen los extremos articulares cartilaginosos, con tendencia a perderse en los registros fósiles. Así, la identificación de rasgos de digestión sobre esos extremos está subrepresentada en este tipo de muestras. Antes bien, los casos de elementos digeridos detectados también se corresponden con la categoría ligera y moderada. Los rasgos de digestión en los restos de anuros actuales también son de bajo impacto y parecen estar sub representados (Quintana 2015b).

Fracturas. Las fracturas más frecuentes en todos los grupos ocurrieron sobre el hueso seco durante la etapa posdepositacional y fueron generadas por agentes no determinados, aunque vinculables con la acción mecánica. Cueva Tixi es un refugio rocoso pequeño y con un gran bloque central que orienta la circulación de personas y de animales que pudieron afectar el depósito faunístico. Las fracturas sobre el hueso fresco son proporcionalmente mayores en los roedores cávidos de los estratos B y C que en el resto de los micromamíferos o que las aves.

Respecto de la frecuencia posdepositacional de las fracturas, resulta ilustrativa la muestra actual de microvertebrados depositada por Tyto alba. En este caso la incidencia de las fracturas sobre fémures de roedores fueron escasas (Quintana, 2015b), representando menos de la mitad del valor más bajo en Cueva Tixi. Del total de esas fracturas, las efectuadas sobre los fémures frescos duplicaron a las que sufrieron los huesos secos. Este patrón de pocas fracturas, con predominio de las frescas en un depósito de superficie es inverso al del caso de estudio que fue más afectado por los factores relacionados con el pisoteo y el entierro. Por ello, la fragmentación de la muestra fósil no es análoga a los casos actuales que no pasaron por procesos de pisoteo, enterramiento y excavación del material, que involucran a otras fuentes de formación de fracturas.

Las fracturas, particularmente las posdepositacionales, son la fuente principal de alteración de la muestra de aves, con el doble de elementos fracturados respecto de los mi- cromamíferos. Las fracturas en estado seco también son las más numerosas. Los planos de fractura fueron más afectados por ácidos radiculares en los estratos superiores, lo cual está vinculado con la mayor alteración radicular en general y la mayor cantidad de fracturas en esos niveles. Este patrón de mayor frecuencia de elementos fracturados de aves respecto de los mamíferos es similar a lo que ocurre en la muestra actual en la que, también, las fracturas frescas son más numerosas que las secas (Quintana, 2015a).

Los anuros presentan mayormente fracturas posdepositacionales, solo se registró un caso de fractura con el hueso en estado fresco de un ejemplar grande, similar a Leptodactylus Fitzinger, 1826, del estrato C.

Como en los otros microvertebrados el principal agente de modificación de los ofidios fueron las fracturas posdepositacionales. Esta situación puede ser tomada como una medida del bajo impacto sobre esta muestra como consecuencia de una muerte no violenta de los ejemplares y un enterramiento rápido. Las vértebras de estos reptiles presentan muchas partes frágiles salientes, como procesos articulares y espinas, que fueron las más expuestas a los daños.

Las alteraciones registradas en la superficie de los huesos de los microvertebrados analizados permiten reconocer una secuencia cronológica relativa de la formación de los distintos tipos de fracturas (Tab. 16). Las fracturas iniciales fueron las ocasionadas principalmente durante la captura y consumo de la presa y presentan atributos emergentes de transformaciones anteriores a su depósito en la superficie. Se trata de fracturas sobre el hueso en estado fresco que, en el caso de las aves, pueden tener bordes con evidencias de corrosión digestiva (adelgazamiento). Estas fracturas luego pueden ser alteradas en superficie por mordeduras de roedor, las cuales afectaron a las del tipo fresco (e.g., una diáfisis de fémur de ave del estrato $E$ inferior). En la muestra actual las fracturas frescas son preponderantes, lo que indica que las fracturas sobre el hueso seco comienzan a ocasionarse en superficie antes del enterramiento (Quintana, 2015b).

Las fracturas posenterramiento se pueden clasificar en tempranas y tardías. Las primeras presentan planos de fracturas afectados por raíces que, a su vez, pueden estar sobrepuestas a las de roedor (como en una ulna de ave del 
TABLA 16. Cronología relativa de las fracturas identificadas en microvertebrados de Cueva Tixi.

\begin{tabular}{|c|c|c|c|c|}
\hline Cronología & Origen & Ubicación del elemento & Tipo & Características del plano de fractura \\
\hline TO & Predepositacional & Indeterminado & Fresca & Puede tener bordes adelgazados \\
\hline$T 1$ & Bioestratinómica & Superficie & Seca & Puede tener bordes roídos \\
\hline$T 2$ & Posdepositacional Temprana & Enterrado & Seca & Afectado por raices, carbonatos o manganeso \\
\hline T3 & Posdepositacional Tardía & Enterrado & Seca & $\begin{array}{c}\text { Sin trazas radiculares. Alteran a carbonatos } \\
\text { y marcas de raíces previos }\end{array}$ \\
\hline
\end{tabular}

estrato E superior). Las tardías carecen de trazas radiculares pero interrumpen tanto a esa corrosión como a precipitaciones de minerales que se extienden en la superficie de las diáfisis. Fracturas con estas características no se formaron en la muestra actual.

Otras alteraciones. Alteraciones como disolución química, exfoliación o grietas superficiales son raras debido al reparo generado por el ambiente de cueva donde los factores ambientales que actúan en superficie tienen menos incidencia. Las patologías son proporcionalmente muy escasas (0,02\%) y no ocasionaron pérdida de información tafonómica.

\section{Causas de la formación de las acumulaciones de microvertebrados de Cueva Tixi}

Las alteraciones identificadas permiten proponer que los microvertebrados de Cueva Tixi fueron depositados por causas diferentes: muerte circunstancial en el sitio, acumulaciones antrópicas y por depredadores.

Los restos de ofidios de Cueva Tixi no presentan evidencias que los vinculan con depredadores o con la manipulación humana, como ocurre con los demás microvertebrados analizados. Algunas especies (Philodryas patagoniensis y Clelia rustica) pudieron ser depositadas por rapaces (Albino, 2001; Quintana, 2001b), mientras que Bothrops sp. fue citado como resto de presa del águila coronada Buteogallus coronatus (Vieillot, 1817) (Maceda et al., 2003). Sin embargo, ninguno de los elementos recuperados de ofidios tiene marcas de corrosión digestiva o de mordeduras. Por ello se sostiene que el ingreso de estos ofidios a Cueva Tixi habría sido por sus propios medios, posiblemente en busca de protección durante períodos de aletargamiento (Albino, 2001) y su muerte circunstancial dentro de la cueva. En el estrato C se registraron 31 vértebras y un pterigoides de
Bothrops alternatus en un metro cuadrado. Esta concentración alta representa un sesgo cuantitativo teniendo en cuenta el NEIT\% comparado con estratos, como el E superior, de mayor registro de microvertebrados pero menos restos de Bothrops. Esos restos del estrato C pueden estar vinculados a la presencia de uno o dos individuos que pudieron morir en el sitio durante el período de letargo (Albino, 2001), de hecho la mayoría de esas vértebras fueron halladas juntas y articuladas en medio de una estructura de piedra que pudo funcionar como refugio. Cueva El Abra presenta un patrón similar de registro de ofidios y se interpretaron las mismas causas de acumulación que en Cueva Tixi (Quintana, en prensa). La muestra actual no contiene ofidios.

Como se indicó, las acumulaciones producidas por acción humana involucraron solamente a los micromamíferos Cavia aperea y Galea tixiensis y posiblemente a peces de los estratos B y C.

Las frecuencias y categorías de corrosión digestiva y los patrones de preservación esquelética permiten plantear que un ave rapaz de la Categoría I (Andrews, 1990) fue el depredador que generó la mayor cantidad de aportes de elementos óseos en las tafocenosis de Cueva Tixi. Por esta causa ingresaron a la cueva los marsupiales didélfidos, los roedores (excepto los cávidos de los dos niveles superiores), las aves pequeñas, los anfibios y algunos peces. La poca frecuencia de elementos con patologías indica que la depredación sobre este tipo de individuos no fue intensa, a pesar de ser más vulnerables.

Entre las rapaces que ocasionan poca alteración al esqueleto de las presas se encuentran las familias Strigidae y Tytonidae, siendo las lechuzas Bubo virginianus (Gmelin, 1788) y Tyto alba las especies que más probablemente pu- 
dieron incorporar microvertebrados a Cueva Tixi. El comportamiento de esas rapaces coincide con el registro de las acumulaciones de este sitio ya que conforman el gremio de hábitos tróficos caracterizado por la preponderancia del consumo de mamíferos (Bó et al., 2007) y porque efectúan modificaciones bajas o moderadas sobre los esqueletos de las presas (Andrews, 1990; Gómez, 2005). Ambas estrigiformes, además, incorporan ocasionalmente micromamíferos grandes y otras presas como aves, murciélagos y anuros.

Bubo virginianus consume presas de hasta $326 \mathrm{~g}$ (Teta et al., 2006; Bó et al., 2007) aunque en Brasil se han informado masas de hasta $1000 \mathrm{~g}$ (Tomazzoni et al., 2004), por lo que selecciona las presas grandes del espectro de micromamíferos (Baladrón, 2010). El análisis de restos de egagrópilas de esta lechuza brindó frecuencias de digestión de huesos largos entre 33\% y 37\% de las categorías más bajas (Gómez, 2005, 2007).

Tyto alba presenta un rango de presas muy amplio dependiendo de la localidad y época del año (Bellocq, 1990, 2000). Esta rapaz captura presas de masas entre 12,6 g y $360 \mathrm{~g}$ (Bellocq, 2000), ocupa espacios cerrados como cuevas para regurgitar las egagrópilas y tiene un espectro de frecuencias de digestión de huesos largos entre 11\% y 35\% dentro de las categorías menos destructivas (Andrews, 1990; Gómez, 2007). A pesar de su tamaño Tyto alba consume con relativa frecuencia ejemplares grandes de micromamíferos (como Holochilus brasiliensis Desmarest, 1819 y Reithrodon auritus Fischer, 1814) y muy grandes como Cavia aperea (Bellocq, 2000).

Otras rapaces nocturnas que actualmente habitan en esta región pueden ser descartadas como protagonistas de las acumulaciones de Cueva Tixi por motivos diversos: Asio flammeus (Pontoppidan, 1763) selecciona presas muy pequeñas (hasta $24 \mathrm{~g}$ de masa promedio) (Bó et al., 2007) y ocasiona frecuencias de digestión muy bajas en los huesos largos (Andrews, 1990; Gómez, 2007); Pseudoscops clamator (Vieillot, 1807), incorpora micromamíferos grandes a su dieta (mayores de $150 \mathrm{~g}$ y hasta $630 \mathrm{~g}$ ) con alteraciones intensas en los esqueletos y frecuencias de digestión de huesos largos hasta de $88 \%$ con categorías fuertes y extremas (Isaach et al., 2000; Pautasso, 2006; Martínez et al., 1996; Rudzik et al., 2015) (Fig. 32); Athene cunicularia
(Molina, 1782), no usa reparos rocosos como perchas, presenta un tamaño corporal que orienta su caza a presas muy pequeñas, es consumidora principalmente de insectos (Bellocq, 1987; Bó et al., 2007) y ocasiona más del 40\% de alteraciones por digestión en los huesos largos (Gómez, 2007; Montalvo y Tejerina, 2009).

Como se señaló, los roedores cávidos de los estratos inferiores ( $D, E$ superior y $E$ inferior) presentan trazas de digestión y un patrón de preservación esquelética parecidos a los micromamíferos del Grupo 1 en diversos parámetros, lo cual es consistente con la depredación aviar (Quintana, 2015a). Este grupo depredado de roedores cávidos de Cueva Tixi se distribuye en el extremo superior de la diversidad de masas (> $300 \mathrm{~g}$ ) de los microvertebrados presentes en las tafocenosis de este sitio. El tamaño de estas presas, particularmente los individuos más grandes, parece incongruente con la depredación por las aves propuestas, lo que fue advertido en Quintana (2004C). Algunas rapaces ocasionalmente consumen carroña (Allen y Taylor, 2013; Mori et al., 2014) o cazan y seleccionan partes sin consumir los huesos (Bochenski y Tornberg, 2003; Montalvo y Tallade, 2009; Montalvo et al., 2011), de modo que los restos óseos presentan menos daños, relaciones de preservación esquelética propias y carecen de trazas de corrosión digestiva. Para poner a prueba si los restos de los cávidos más grandes pudieron tener otro agente de acumulación o haber ingresado como consecuencia de un comportamiento alimenticio alternativo, se analizaron los fémures y húmeros de mayor longitud. En los niveles inferiores de Cueva Tixi la proporción de los cávidos más grandes, estimada sobre la base de la longitud de fémures, es baja (del 3,16\% al 3,7\%) debido a que los adultos están subrepresentados. Algunos de los fémures correspondientes a los individuos de mayor masa (entre 35 mm y 4,60 mm) (los menos probables de ser consumidos enteros por rapaces nocturnas) presentan trazas de digestión (Fig. 33) y carecen de marcas de carnívoros o producidas por picos, lo mismo ocurre con los húmeros más grandes (> $30 \mathrm{~mm}$ ). En consecuencia, en los estratos inferiores, los cávidos de mayor masa también fueron tragados enteros por rapaces y trasladados al sitio junto a los cávidos más pequeños y al resto de los microvertebrados depredados. El consumo de cávidos grandes en Cueva Tixi es consistente con que adultos de Cavia aperea fueron re- 

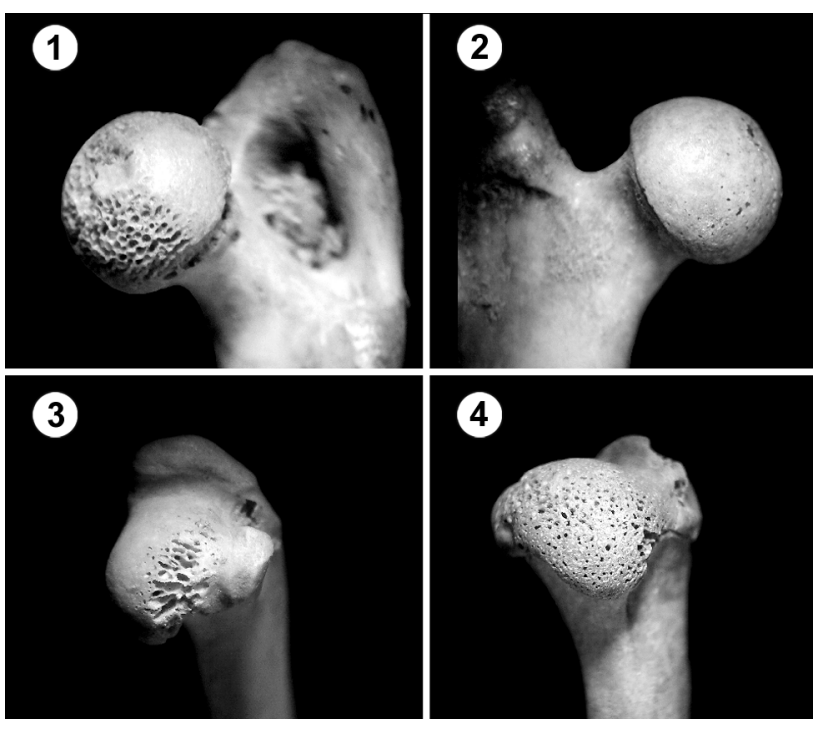

Figura 33. Elementos de roedores cávidos adultos grandes con trazas de digestión. 1-2, Fémures del estrato $D$; 3-4, húmeros del estrato E superior.

portados en egagrópilas de B. virginianus (Bó et al., 2007) y T. alba (Bellocq, 2000). En dos localidades de Bolivia los contenidos de egagrópilas de $T$. alba presentaron frecuencias altas de C. aperea (hasta 56\%) con promedios de masas de presas entre $136 \mathrm{~g}$ y $340 \mathrm{~g}$ (Aliaga-Rossel y Tarifa, 2005; Vargas et al., 2002).

Con el didélfido Lutreolina crassicaudata (Desmarest, 1804) ocurre una situación similar de equifinalidad de ingreso al sitio, debido a que la masa de los adultos oscila entre $490 \mathrm{~g}$ y $737 \mathrm{~g}$ (Muschetto et al., 2011). Sin embargo, los ejemplares de este didélfido son muy escasos y casi todos corresponden a individuos juveniles, con molares poco gastados o sin erupcionar. Esta situación fue advertida por Goin (2001) lo que le permitió plantear su posible acumulación por Strigiformes en Cueva Tixi. A partir de egagrópilas actuales Rudzik et al. (2015) también discuten el consumo de los juveniles de esta comadreja.

En los micromamíferos la alta frecuencia de fracturas es incongruente con el bajo impacto de la corrosión digestiva, pero la evaluación del origen de las fracturas permite interpretar mejor a esta relación. Las fracturas posdepositacionales fueron preponderantes sobre las ocasionadas sobre el hueso en estado fresco. De este modo la mayor proporción de la fragmentación de las acumulaciones de Cueva Tixi no es consecuencia de la actividad del depredador sino de procesos causados durante su depósito en la superficie y el enterramiento. Esta situación fue señalada en otros registros fósiles de microvertebrados (Montalvo et al., 2012a; Fernández y De Santis, 2013; Scheifler, 2014; Quintana, en prensa).

El promedio de la abundancia relativa de los elementos de micromamíferos es bajo en comparación con los evaluados en acumulaciones de microvertebrados ocasionadas por Strigiformes (Gómez, 2007), pero este parámetro está influenciado fuertemente por los agentes posdepositacionales que alteran la muestra, principalmente a los elementos esqueléticos más frágiles (Quintana, 2015b). Sin embargo los valores de abundancias relativas se disponen dentro del modelo de lechuzas planteado por Andrews (1990).

La cuantificación de la corrosión digestiva en el esqueleto de las aves presentó frecuencias similares a los mamíferos, a diferencia de otros registros fósiles (Fernández et al., 2009) y actuales (Quintana, 2015b). Las aves pequeñas de Cueva Tixi se distribuyen en toda la secuencia junto a los micromamíferos por lo que no hay evidencias que tuvieran un agente de transporte diferente. La estructura ósea de este grupo pudo favorecer la presencia de planos de fractura adelgazados por ácidos digestivos, como en las aves de la muestra actual, lo cual no se presentó en el resto de los microvertebrados analizados. Las aves son un componente poco frecuente (menos del 1\%) en la dietas de los depredadores de Cueva Tixi debido a que estos enfatizaron la selección sobre otros tipos de presas. En consecuencia, se cuenta con una muestra relativamente poco numerosa cuya preservación esquelética entre estratos se caracteriza por su diversidad y por valores extremos (altos o bajos). La frecuencia de aves registrada es consistente con que en este sitio los depredadores que efectuaron las acumulaciones son del gremio trófico de consumidores de mamíferos (Bó et al., 2007). Las rapaces especializadas en el consumo de aves, como gavilanes y halcones (Bó et al., 2007), ocasionan daños más profundos en los esqueletos (Andrews, 1990) que los determinados en este sitio.

La poca abundancia registrada de anuros en Cueva Tixi puede estar relacionada con que los depredadores los cazaron de modo extremadamente esporádico y, posiblemente, solo durante las estaciones cálidas.

La causa del ingreso de los peces a Cueva Tixi de los es- 
tratos inferiores no es clara. Solamente en el estrato E superior hay un ejemplar con trazas atribuibles a la digestión (Fig. 11). En casos excepcionales se registraron consumos de peces por parte de T. alba (Taylor, 1994; Bogiatto et al., 2006), en B. virginianus (Tomazzoni et al., 2004) y algo más frecuente en B. bubo (Linnaeus, 1758) (Pérez Mellado, 1980), otras rapaces también consumen peces (Bó et al., 2007). Los casos de registros fósiles de peces consumidos por rapaces son todavía más raros, aunque pueden generar grandes tafocenosis producto de la caza o del carroñeo (Broughton et al., 2000, 2006). La muestra analizada es muy chica como para referir esas trazas de digestión a algún depredador específico, ya sean aves diurnas, nocturnas o mamíferos carnívoros. De todos modos, la posición en el paisaje de Cueva Tixi no permite plantear el ingreso de peces sin la participación de un agente que los transporte, aun desde el cauce del manantial que forma un pequeño espejo de agua a pocos metros de la entrada de la cueva.

\section{CONCLUSIONES}

El registro de microvertebrados de Cueva Tixi comprende a toda la secuencia estratigráfica, excepto a los estratos $A$ y $F$.

Los principales cambios del contenido taxonómico ocurrieron durante el Holoceno tardío y fueron asociados con variaciones climáticas (Quintana, 2001c). Se registró por primera vez el roedor cricétido Scapteromys sp.

Los elementos esqueléticos de los microvertebrados analizados presentan evidencias de alteraciones durante las etapas previas a su depósito por fenómenos ocurridos en la superficie y durante el enterramiento. Las alteraciones analizadas permiten proponer tres causas de ingreso de restos óseos de microvertebrados a Cueva Tixi: muerte natural en el sitio, caza antrópica y depredación de rapaces. La ausencia de evidencias de marcas de depredadores, la concentración de vértebras y el comportamiento estacional sugieren que los ofidios murieron en el sitio durante la etapa de letargo. La acumulación antrópica de roedores cávidos en los estratos C y B está indicada por las huellas de filos de instrumental lítico, la preponderancia de ejemplares adultos, el aumento de fracturas de huesos en estado fresco y las proporciones esqueléticas diferentes a los cávidos de los estratos inferiores. Las marcas de corrosión digestiva y el patrón de preservación esquelética de los microvertebrados depredados (cricétidos, cávidos de los estratos D, E superior y E inferior, aves, anuros y peces del estrato E superior) son compatibles con la Categoría I (rapaces Strigiformes). La estabilidad de indicadores tafonómicos en los huesos de los microvertebrados denota que un mismo tipo de ave (posiblemente Tyto alba) regurgitó egagrópilas en Cueva Tixi durante toda la secuencia cronológica. Los procesos de superficie fueron de poca magnitud indicando la poca modificación de la muestra y que los huesos fueron enterrados rápidamente, o estuvieron expuestos a meteorización ligera. Algunos procesos fosildiagenéticos de largo plazo presentaron tendencias estratigráficas, como la disminución proporcional de corrosión radicular y el aumento de las impregnaciones de minerales hacia la base de la secuencia. Las fracturas posdepositacionales fueron la causa principal de pérdida de información, siendo preponderantes las ocasionadas sobre el hueso seco. La relación de las fracturas con otros procesos tafonómicos permitió plantear una cronología relativa de su formación. La preservación esquelética del Grupo 1 se presenta relativamente uniforme entre las muestras de cada estrato. La preservación esquelética del Grupo 2 es menos uniforme debido a la acción de dos agentes diferentes de depositación, en los tres niveles inferiores es similar a la preservación esquelética del Grupo 1. Las aves presentan una preservación del esqueleto caracterizada por la preponderancia del poscráneo y la baja abundancia relativa promediada. Los ofidios y los anuros conservaron principalmente elementos poscraneanos, mientras que la baja frecuencia de los peces no muestra una tendencia clara.

\section{AGRADECIMIENTOS}

A Claudia Montalvo por sus valiosas sugerencias en las distintas versiones de este manuscrito. A María Susana Bó, Juan Pablo Isaach y Alejandro Baladrón por su orientación sobre los hábitos tróficos de aves rapaces. A Luciana Stoessel por su ayuda en la identificación de restos de peces. A los evaluadores cuyas sugerencias permitieron mejorar el manuscrito. Estas investigaciones son parte de proyectos financiados por la Secretaría de Investigación de la Universidad Nacional de Mar del Plata y por el PICT 20131979 de la Agencia Nacional de Promoción Científica y Tecnológica.

\section{REFERENCIAS}

Albino, A. 1994. Estado actual del registro de los escamados extinguidos de América del Sur y sus implicancias paleoambientales. Cuadernos de Herpetología 8: 146-154. 
Albino, A. 1999. Serpientes del sitio arqueológico Cueva Tixi (Pleistoceno tardío-Holoceno), provincia de Buenos Aires, Argentina. Ameghiniana 36: 269-274.

Albino, A. 2001. Reptiles. En: D. Mazzanti y C. Quintana (Eds.), Cueva Tixi: Cazadores y recolectores de las sierras de Tandilia Oriental. I. Geología, Paleontología y Zooarqueología, Publicación Especial 1, Laboratorio de Arqueología, Universidad Nacional de Mar del Plata, Mar del Plata, p. 65-74.

Albino, A., Quintana, C. y Valverde, F. 2002. La fauna herpetológica de los sitios arqueológicos de Argentina, con énfasis en la Región Pampeana. En: D. Mazzanti, M. Berón y F. Oliva (Eds.), Del Mar a los Salitrales. Diez mil Años de Historia Pampeana en el Umbral del Tercer Milenio, Universidad Nacional de Mar del Plata y Sociedad Argentina de Antropología, Mar del Plata, p. 411-417.

Alcántara García, V., Barba Egido, R., Barral del Pino, J.M., Crespo Ruíz, A.B., Eiriz Vidal, A.I., Falquina Aparicio, Á., Herrero Calleja, S., Ibarra Jiménez, A., Megías González, M., Pérez Gil, M., Pérez Tello, V., Rolland Calvo, J., Yravedra Sáinz, J., Vidal, A. y Domínguez-Rodrigo, M. 2006. Determinación de procesos de fractura sobre huesos frescos: un sistema de análisis de los ángulos de los planos de fracturación como discriminador de agentes bióticos. Trabajos de prehistoria 63: 37-45.

Aliaga-Rossel, E. y Tarifa, T. 2005. Cavia sp. como principal presa de la lechuza de campanario (Tyto alba) al final de la estación seca en una zona intervenida al norte del Departamento de La Paz, Bolivia. Ecología en Bolivia 40: 35-42.

Allen, M. y Taylor, A. 2013. First Record of Scavenging by a Western Screech-Owl (Megascops kennicotti). The Wilson Journal of Ornithology 125: 417-419.

Álvarez, M., Kaufmann, C., Massigoge, A., Gutiérrez, M., Rafuse, D., Scheifler, N. y González, M. 2012. Bone modification and destruction patterns of leporid carcasses by Geoffroy's cat (Leopardus geoffroyi): An experimental study. Quaternary International 278: 71-80.

Andrews, P. 1990. Ow/s, caves and fossils. The University of Chicago Press, Chicago, $231 \mathrm{p}$.

Baladrón, A. 2010. [Impacto de la depredación de aves rapaces sobre micromamíferos en el sudeste bonaerense. Tesis doctoral, Facultad de Ciencias Exactas y Naturales, Universidad Nacional de Mar del Plata, Mar del Plata, 162 p. Inédita.].

Bellocq, M.I. 1987. Selección de hábitat de caza y depredación diferencial de Athene cunicularia sobre roedores en ecosistemas agrarios. Revista Chilena de Historia Natural 60: 81-86.

Bellocq, M.l. 1990. Composición y variación temporal de la dieta de Tyto alba en ecosistemas agrarios pampeanos, Argentina. Vida Silvestre Neotropical 2: 32-35.

Bellocq, M.I. 2000. A review of the trophic ecology of the Barn Owl in Argentina. Journalof Raptor Research 34: 108-119.

Binford, L. 1984. Faunal remains from Klasies River Mouth. Studies in Archaeology, Academic Press, Londres, 283 p.

Bó, M., Baladrón, A. y Biondi, L. 2007. Ecología trófica de Falconiformes y Strigiformes: tiempo de síntesis. El Hornero 22: 97115.

Bochenski, Z. 1997. Preliminary taphonomic studies on damage to bird bones by Snowy Owls Nyctea scandiaca, with comments on the survival of bones in palaeontological sites. Acta Zoologica Cracoviensia 40: 279-292.

Bochenski, Z. 2005. Owls, diurnal raptors and humans: signature on avian bones. En: T. O־Connor (Ed.), Biosphere and Lithosphere. New studies in vertebrate taphonomy, Oxbow Books, Oxford, p. 31-45.

Bochenski, Z. y Tornberg, R. 2003. Fragmentation and preservation of bird bones in uneaten food remains of the Gyrfalcon Falco rusticolus. Journal of Archaeological Science 30: 1665-1671.

Bogiatto, R., Broughton, J., Cannon, V., Dalton, K. y Arnold, S. 2006. Fish remains dominate barn owl pellets in northwestern $\mathrm{Ne}$ vada. Western North American Naturalist 66: 395-396.

Bramwell, D., Yalden, D. y Yalden, P. 1987. Black grouse as the prey of the golden eagle at an archaeological site. Journal of Archaeological Science 14: 195-200.

Brea, M. y Mazzanti, D. 2014. Selección y uso de los recursos madereros en cazadores-recolectores de la transición Pleistoceno-Holoceno y Holoceno medio, sierras de Tandilia oriental, Argentina. Revista del Museo Argentino de Ciencias Naturales 16 : 129-141.

Broughton, J., Cannon, V., Arnold, S., Bogiatto, R. y Dalton, K. 2006. The taphonomy of owl-deposited fish remains and the origin of the Homestead Cave ichthyofauna. Journal of Taphonomy 4: 69-95.

Broughton, J., Madsen, D. y Quade, J. 2000. Fish Remains from Homestead Cave and Lake Levels of the Past 13,000 Years in the Bonneville Basin. Quaternary Research 53: 392-401.

Cione, A. y Barla, M. 2001. Peces. En: D. Mazzanti y C. Quintana (Eds.), Cueva Tixi: Cazadores y recolectores de las sierras de Tandilia Oriental. l. Geología, Paleontología y Zooarqueología, Publicación Especial 1, Laboratorio de Arqueología, Universidad Nacional de Mar del Plata, Mar del Plata, p. 115-118.

Ericson, P. 1987. Interpretations of archaeological birds remains a taphonomic approach. Journal of Archaeological Science 14: 65-75.

Fernández, F. y De Santis, L. 2013. Tafonomía de restos de micromamíferos recuperados del sitio arqueológico Agua de la Mula (Mendoza, Argentina) y su implicancia en la subsistencia humana. Cuadernos del Instituto Nacional de Antropología y Pensamiento Latinoamericano-Series Especiales 1: 181-195.

Fernández, F., Moreira, G., Ballejo, F. y De Santis, L. 2009. Novedosos registros de aves exhumadas del sitio arqueológico Laguna El Sosneado (LS-3) para el Holoceno tardío en el sur de Mendoza: aspectos tafonómicos. Intersecciones en Antropología 10: 327-342.

Figini, A., Huarte, R., Carbonari, J., Gómez, G., Zubiaga, A., Tonni, E. y Fidalgo, F., 1985. Edad isotópica de los carbonatos de la Cueva Tixi, partido de Gral. Alvarado provincia de Buenos Aires. $1^{a s}$ Jornadas Geológicas Bonaerenses (Tandil), Actas 128-130.

Goin, F. 2001. Marsupiales (Didelphidae: Marmosinae y Didelphinae). En: D. Mazzanti y C. Quintana (Eds.), Cueva Tixi: Cazadores y recolectores de las sierras de Tandilia Oriental. I. Geología, Paleontología y Zooarqueología, Publicación Especial 1, Laboratorio de Arqueología, Universidad Nacional de Mar del Plata, Mar del Plata, p. 75-114.

Gómez, G. 2005. Analysis of bone modification of Bubo virginianus pellets from Argentina. Journal of Taphonomy 3: 1-16.

Gómez, G. 2007. Predators categorizations based on taphonomic analysis of micromammals bones: a comparison to proposed models. En: M. A. Gutierrez, L. Miotti, G. Barrientos, G. Mengoni Goñalons y M. Salemme (Eds.), Taphonomy and Zooarqueology in Argentina, British Archaelogical Reports, International Series 1601, Oxford, p. 89-103.

Gómez, G. y Kaufmann, C. 2007. Taphonomic analysis of Pseudalopex griseus (Gray, 1837) scat assemblages and their archaeological implications. Journal of Taphonomy 5: 59-70.

Isacch, J.P., Bó, M.S. y Martínez, M. 2000. Food habits of the Striped Owl (Asio clamator) in Buenos Aires Province, Argentina. Journal of Raptor Research 34: 235-237.

Imbellone, P. y Zárate M. 1983. Glébulas sesquioxídicas en un Argial- 
bol. General Mansilla, prov. Bs.As. Ciencia del Suelo 1: 173-181.

Laza, J. 2001. Nidos de Scarabaeinae. Significación paleoclimática y cronológica. En: D. Mazzanti y C. Quintana (Eds.), Cueva Tixi: Cazadores y recolectores de las sierras de Tandilia Oriental. I. Geología, Paleontología y Zooarqueología, Publicación Especial 1, Laboratorio de Arqueología, Universidad Nacional de Mar del Plata, Mar del Plata, p. 119-122.

Lyman, R. 1994. Vertebrate Taphonomy. Cambridge University Press, Cambridge, $524 \mathrm{p}$.

Maceda, J., Sarasola, J. y Pessino, M. 2003. Presas consumidas por el águila coronada (Harpyhaliaetus coronatus) en el límite sur de su rango de distribución en Argentina. Ornitología Neotropical 14: 419-422.

Martínez, G.A. 2007. Procesos de formación de sitios en reparos rocosos de Tandilia. Cazadores-Recolectores del Cono Sur. Revista de Arqueología 3: 105-127.

Martínez, G. y Gutiérrez, M.A. 2004. Tendencias en la explotación humana de la fauna durante el Pleistoceno final y Holoceno en la Región Pampeana (Argentina). En: G. L. Mengoni Goñalons (Ed.), Zooarchaeology of South America, Archaeopress, Oxford, 1298: 81-98.

Martínez, M., Isacch, J.P. y Donatti, F. 1996. Aspectos de la distribución y biología reproductiva de Asio clamator en la provincia de Buenos Aires, Argentina. Ornitología Neotropical 7: 157-161.

Martínez, G., Mazzanti, D., Quintana, C., Zucol, A., Colobig, M., Hassan, G., Brea, M. y Passegi, E. 2013. Geoarchaeological and Paleoenvironmental context of the human settlement in the Eastern Tandilia Range, Argentina. Quaternary International 299: 23-37.

Martínez, G.A. y Osterrieth, M. 2001. Estratigrafía, Procesos formadores y Paleoambientes. En: D. Mazzanti y C. Quintana (Eds.), Cueva Tixi: Cazadores y recolectores de las sierras de Tandilia Oriental. I. Geología, Paleontología y Zooarqueología, Publicación Especial 1, Laboratorio de Arqueología, Universidad Nacional de Mar del Plata, Mar del Plata, p. 19-34.

Martínez, G. y Osterrieth, M. 2004. The Pleistocene-Holocene stratigraphical record from early archaeological sites in caves and rockshelters of eastern Tandilia, Pampean Region, Argentina. En: L. Miotti, M. Salemme y N. Flegenheimer (Eds.), Where the south winds blow: Ancient evidences for Paleo South Americans, Center for the Studies of the First Americans y Texas A\&M University Press, Texas, p. 63-68.

Martínez, G., Osterrieth, M., y Borelli, N. 2000. Registro de la Pequeña Edad de Hielo en ambientes sedimentarios del sudeste bonaerense, Argentina. $2^{\circ}$ Congreso Latinoamericano de Sedimentología (Mar del Plata), Actas 113-114.

Martínez, G., Osterrieth, M. y Mazzanti, D. 1999. Estratigrafía de sitios arqueológicos en reparos rocosos en las sierras de La Vigilancia y Valdés, sistema de Tandilia, provincia de Buenos Aires. $12^{\circ}$ Congreso Nacional de Arqueología Argentina (La Plata), Actas 3: $139-144$.

Mazzanti, D. 1993. Investigaciones arqueológicas en el sitio Cueva Tixi (provincia de Buenos Aires). Etnia 38-39: 125-163.

Mazzanti, D. 1994. Archaeology of the Eastern edge of the Tandilia Range (Buenos Aires, Argentina). Quaternary of South America and Antarctic Peninsula 10: 211-227.

Mazzanti, D. 1995-1996. Arqueología del Borde Oriental de las Sierras de Tandilia. Cambios y Continuidades en el uso del espacio. Shincal 5: 7-25.

Mazzanti, D. 1997a. Excavaciones arqueológicas en el sitio Cueva Tixi, Buenos Aires, Argentina. Latin American Antiquity 8: 55-62. Mazzanti, D. 1997b. Secuencia arqueológica del sitio Cueva Tixi (Pdo. de Gral. Alvarado. Pcia. de Buenos Aires). En: M. Berón y G. Politis (Eds.), Arqueología Pampeana en la década de los '90, Museo de Historia Natural, Santa Fe, p. 127-135.

Mazzanti, D. 1997c. An archaeological sequence of hunter-gatherers in the Tandilia Range: Cueva Tixi, Buenos Aires, Argentina. Antiquity 71: 450-452.

Mazzanti, D. 2001. Las Investigaciones en Cueva Tixi. En: D. Mazzanti y C. Quintana (Eds.), Cueva Tixi: Cazadores y recolectores de las sierras de Tandilia Oriental. I. Geología, Paleontología y Zooarqueología, Publicación Especial 1, Laboratorio de Arqueología, Universidad Nacional de Mar del Plata, Mar del Plata, p. 3-7.

Mazzanti, D. y Bonnat, G. 2013. Paisajes arqueológicos y cazadores-recolectores de la transición Pleistoceno-Holoceno. Análisis de las cuencas de ocupación en Tandilia oriental, provincia de Buenos Aires, Argentina. Relaciones de la Sociedad Argentina de Antropología 38: 521-541.

Mazzanti, D., Martínez, G., y Quintana, C. 2012. Early settlements in eastern Tandilia, Buenos Aires Province, Argentina: archaeological contexts and site-formation processes. En: L. Miotti, M. Salemme, N. Flegenheimer y T. Goebel (Eds.), Southbound: Late Pleistocene Peopling of Latin America, Current Research in the Pleistocene, Texas A\&M University press, Texas, p. 99-103.

Mazzanti, D. y Porto López, J. 2007 Caracterización petrográfica y estructural de cerámicas arqueológicas de las sierras de Tandilia. En: M. Cremonte y N. Ratto (Eds.), Cerámicas arqueológicas. Perspectivas arqueométricas para su análisis e interpretación, Universidad Nacional de Jujuy, San Salvador de Jujuy, p. 97-122.

Mazzanti, D. y Quintana, C. 1997. Asociación cultural con fauna extinguida en el sitio arqueológico Cueva Tixi, provincia de Buenos Aires, Argentina. Revista Española de Antropología Americana 27: 11-21.

Mazzanti, D. y Quintana, C. 2001. Comentarios al Artículo "Tafonomía de microvertebrados en yacimientos arqueológicos de Patagonia (Argentina)". Pardiñas (1999). Arqueología 11: 271-277.

Mazzanti, D. y Quintana, C. 2002. Réplica a: "Micromamíferos y paleoambientes del Holoceno en el Sudeste de la provincia de Buenos Aires (Argentina): el caso de Cueva Tixi". Publicación Especial 2, Laboratorio de Arqueología, Universidad Nacional de Mar del Plata, 1-10.

Mazzanti, D. y Valverde, F. 2001. Artefactos sobre hueso, asta y valva. En: D. Mazzanti y C. Quintana (Eds.), Cueva Tixi: Cazadores y recolectores de las sierras de Tandilia Oriental. I. Geología, Paleontología y Zooarqueología, Publicación Especial 1, Laboratorio de Arqueología, Universidad Nacional de Mar del Plata, Mar del Plata, p. 157-180.

Medina, M., Rivero, D. y Teta, P. 2011. Consumo antrópico de pequeños mamíferos en el Holoceno de Argentina central: perspectivas desde el Abrigo Rocoso Quebrada del Real 1 (Pampa de Achala, Córdoba). Latin American Antiquity 22: 615-628.

Medina, M., Teta, P. y Rivero, D. 2012. Burning damage and smallmammal human consumption in Quebrada del Real 1 (Córdoba, Argentina): an experimental approach. Journal of Archaeological Science 39: 737-743.

Mikuláš, R. 1999. Notes on the concept of plant trace fossils related to plant-generated sedimentary structures. Bulletin of the Czech Geological Survey 74: 39-42.

Montalvo, C., Bisceglia, S., Kin, M. y Sosa, R.A. 2012b. Taphonomic analysis of rodent bone accumulations produced by Geoffroy's cat (Leopardus geoffroyi, Carnivora, Felidae) in Central Argentina. Journal of Archaeological Science 39: 1933-1941.

Montalvo, C.I., Fernández, F., Liébana, M., Santillán, M. y Sarasola, J. 2014. Taphonomic analysis of rodent bone accumulations 
produced by the White-tailed Kite (Elanus leucurus, Accipitriformes) in Central Argentina. Journal of Archaeological Science 52: 354-362.

Montalvo, C.I., Pessino, M. y Bagato, F.C. 2008. Taphonomy of the bones of rodents consumed by Andean hog-nosed Skunks (Conepatus chinga, Carnivora, Mephitidae) in central Argentina. Journal of Archaeological Science 35: 1481-1488.

Montalvo, C.I., Pessino, M. y González, V. 2007. Taphonomic analysis of mammals remains eaten by pumas (Puma concolor Carnivora, Felidae) in central Argentina. Journal of Archaeological Science 34: 2151-2160.

Montalvo, C. y Tallade, P. 2009. Taphonomy of the accumulations produced by Caracara plancus (Falconidae). Analysis of prey remains and pellets. Journal of Taphonomy 7: 235-248.

Montalvo, C.I., Tallade, P., Fernández, F.J., Moreira, G.J. y De Santis, L. 2011. Pattern of damage done by Caracara plancus (Aves, Falconiformes) on bird bones. Journal of Archaeological Science 38: 3541-3548.

Montalvo, C. y Tejerina, P. 2009. Análisis tafonómico de los huesos de anfibios y roedores depredados por Athene cunicularia (Strigiformes, Strigidae) en La Pampa, Argentina. En: M. Berón, L. Luna, M. Bonomo, C. Montalvo, C. Aranda y M. Carrera Aizpitarte (Eds.), Mamül Mapu: pasado y presente desde la arqueología pampeana, Libros del Espinillo, Ayacucho, p. 323-334.

Montalvo, C.I., Tomassini, R.L., Visconti, G. y Tiranti, S. 2012a. Análisis tafonómico de micromamíferos del Pleistoceno Superior del Quequén Salado, Provincia de Buenos Aires, Argentina. Revista Brasileira de Paleontologia 15: 345-358.

Mori, E., Menchetti, M. y Dartora, F. 2014. Evidence of carrion consumption behaviour in the long-eared owl Asio otus (Linnaeus, 1758) (Aves: Strigiformes: Strigidae). Italian Journal of Zoology 81: 471-475.

Muschetto, E., Cueto, G. y Suárez, O. 2011. New data on the natural history and morphometrics of Lutreolina crassicaudata (Didelphimorphia) from central-eastern Argentina. Mastozoología Neotropical 18: 73-79.

Pardiñas, U. 1995. Novedosos cricétidos (Mammalia, Rodentia) en el Holoceno Tardío del sudeste de la provincia de Buenos Aires, Argentina. Ameghiniana 32: 197-203.

Pardiñas, U. 1999a. Tafonomía de microvertebrados en yacimientos arqueológicos de Patagonia (Argentina). Arqueología 9: 265-340.

Pardiñas, U. 1999b. [Los roedores muroideos del Pleistoceno tardioHoloceno en la región pampeana (sector este) y Patagonia (República Argentina): aspectos taxonómicos, importancia bioestratigráfica y significación paleoambiental. Tesis doctoral, Facultad de Ciencias Naturales y Museo, Universidad Nacional La Plata, La Plata, 283 p. Inédita.].

Pardiñas, U. 2000 Micromamíferos y paleoambientes del Holoceno en el sudeste de la provincia de Buenos Aires (Argentina): el caso de Cueva Tixi. Revista Cuaternario y Ciencias Ambientales 1: 31-36.

Pautasso, A. 2006. Dieta del lechuzón orejudo (Asio clamator) en el centro y este de la provincia de Santa Fe, Argentina. Ornitología Neotropical 17: 289-293.

Payne, S. 1975. Partial recovery and simple bias. En: E. S. Higgs (Ed.), Archaeological studies, North-Holland Publishing Company, Amsterdam, $17 \mathrm{p}$.

Pérez Mellado, V. 1980. Alimentación del búho real (Bubo bubo) en España central. Ardeola 25: 93-112.

Pinto Llona, A. y Andrews, P. 1999. Amphibian taphonomy and its application to the fossil record of Dolina (middle Pleistocene,
Atapuerca, Spain). Palaeogeography, Palaeoclimatology, Palaeoecology 149: 411-429.

Politis, G. y Gutiérrez, M. 1998. Gliptodontes y cazadores-recolectores de la región pampeana (Argentina). Latin American Antiquity 9: 111-134.

Porto López, J. y Mazzanti, D. 2009. Pigmentos minerales arqueológicos y fuentes de aprovisionamiento del sudeste bonaerense: Análisis arqueométrico comparativo. $2^{\circ}$ Congreso Argentino y $1^{\circ}$ Latinoamericano de Arqueometría Latinoamericana (San Martín), Actas 1: 215-220.

Porto López, J.M. y Mazzanti, D. 2010. Análisis arqueométrico de sustancias colorantes provenientes de contextos tempranos de las sierras de Tandilia oriental. En: S. Bertolino, R. Cattaneo, y A. D. Izeta (Eds.), La Arqueometría en Argentina y Latinoamérica, Editorial de la FFyH, Córdoba, p. 337-342.

Prado, J., Goin, F. y Tonni, E. 1985. Lestodelphys halli (Mammalia, Didelphidae) in Holocene sediments of Southearstern Buenos Aires Province (Argentina): Morphological and palaeoenviromental considerations. Quaternary South America and Antarctic Peninsula 3: 93-107.

Quintana, C. 2001a. Composición y cambios en la secuencia faunística. En: D. Mazzanti y C. Quintana (Eds.), Cueva Tixi: Cazadores y recolectores de las sierras de Tandilia Oriental. I. Geología, Paleontología y Zooarqueología, Publicación Especial 1, Laboratorio de Arqueología, Universidad Nacional de Mar del Plata, Mar del Plata, p. 37-64.

Quintana, C. 2001b. Formación del depósito faunístico. En: D. Mazzanti y C. Quintana (Eds.), Cueva Tixi: Cazadores y recolectores de las sierras de Tandilia Oriental. I. Geología, Paleontología y Zooarqueología, Publicación Especial 1, Laboratorio de Arqueología, Universidad Nacional de Mar del Plata, Mar del Plata, p. $123-133$.

Quintana, C. 2001c. Galea (Rodentia, Caviidae) del Pleistoceno Superior y Holoceno de las sierras de Tandilia Oriental, Provincia de Buenos Aires, Argentina. Ameghiniana 38: 399-408.

Quintana, C. 2004a. Zooarchaeological Record in Early Sediments of Caves from Tandilia Range, Argentina. Current Research in the Pleistocene 21: 19-20.

Quintana, C. 2004b. El registro de Ctenomys talarum durante el Pleistoceno Tardío-Holoceno de las Sierras de Tandilia Oriental. Mastozoología Neotropical 11: 45-63.

Quintana, C. 2004c. Acumulaciones de restos óseos en reparos rocosos de las Sierras de Tandilia Oriental, Argentina. Estudios Geológicos 60: 37-47.

Quintana, C. 2005. Despiece de micro roedores en el Holoceno Tardío de las sierras de Tandilia, Argentina. Archaeofauna 217: 227-241.

Quintana, C. 2007. Marcas de dientes de roedores en huesos de sitios arqueológicos de las sierras de Tandilia, Argentina. Archaeofauna 16: 185-191.

Quintana, C. 2015a. Patrón esquelético de roedores Cávidos en la secuencia arqueológica de Cueva Tixi, Tandilia Oriental (Pleistoceno Tardío-Holoceno Tardío) Argentina. Archaeofauna 24: $173-185$.

Quintana, C. 2015b. Tafonomía de contenidos dispersos de egagrópilas de Tyto alba en un ambiente serrano. Historia Natural 5: 29-47.

Quintana, C. en prensa. Tafonomía de los microvertebrados del sitio arqueológico Cueva El Abra, Tandilia Oriental. Comechingonia Revista de Arqueología 20.

Quintana, C. y Mazzanti, D. 1996. Secuencia faunística del sitio arqueológico Cueva Tixi (Pleistoceno tardío- Holoceno), provincia 
de Buenos Aires. $6^{\circ}$ Jornadas Pampeanas de Ciencias Naturales (Santa Rosa), Actas: 187-194.

Quintana, C. y Mazzanti, D. 2001. Selección y aprovechamiento de recursos faunísticos. En: D. Mazzanti y C. Quintana (Eds.), Cueva Tixi: Cazadores y recolectores de las sierras de Tandilia Oriental. I. Geología, Paleontología y Zooarqueología, Publicación Especial 1, Laboratorio de Arqueología, Universidad Nacional de Mar del Plata, Mar del Plata, p. 181-209.

Quintana, C. y Mazzanti, D. 2010. Caza menor en sitios arqueológicos de Tandilia Oriental. En: M. Gutiérrez, M. De Nigris, P. Fernández, M. Giardina, A. Gil, A. Izeta, G. Neme y H. Yacobaccio (Eds), Zooarqueología a principios del siglo XXI. Aportes teóricos, metodológicos y casos de estudio, Ediciones del Espinillo, Buenos Aires, p. 307-319.

Quintana, C. y Mazzanti, D. 2011. Las vizcachas pampeanas (Lagostomus maximus, Rodentia) en la subsistencia indígena del Holoceno tardío de las sierras de Tandilia oriental (Argentina). Latin American Antiquity 22: 253-270.

Quintana, C. y Mazzanti, D. 2014. La emergencia de la diversificación de la caza en las sierras de Tandilia Oriental durante el Holoceno tardío final. Comechingonia. Revista de Arqueología 18: 41-64.

Quintana, C., Mazzanti, D. y Valverde, F. 2004. El Lagarto Overo como recurso faunístico durante el Holoceno de las sierras de Tandilia Oriental Provincia de Buenos Aires. En: C. Gradín y F. Oliva (Eds.), La Región Pampeana, su pasado Arqueológico, Laborde Editor, Buenos Aires p. 347-353.

Quintana, C., Valverde, F. y Mazzanti, D. 2002. Roedores y lagartos como emergentes de la diversificación de la subsistencia durante el Holoceno tardío en sierras de la región Pampeana Argentina. Latin American Antiquity 13: 455-473.

Rafuse, D., González, M., Kaufmann, C., Álvarez, M., Gutiérrez, M. y Massigoge, A. 2014. Análisis Comparativo de los Patrones de Modificaciones Óseas de Dos Carnívoros Sudamericanos: El Gato Montés (Leopardus geoffroyi) y el Zorro Pampeano (Lycalopex gymnocercus). Aportes para la Identificación de la Acción de Pequeños Carnívoros en el Registro Arqueológico. Magallania 42: 165-184.

Rudzik, S., Fernández, F. y Carrera, J. 2015. Taphonomic Analysis of Micromammal Remains from Striped Owl (Pseudoscops clamator) Pellets in Northeastern Buenos Aires Province, Argentina: Implications for Archaeological Sites Formation. International Journal of Osteoarchaeology 25: 550-563.

Scheifler, N. 2014. Zooarqueología de los pequeños vertebrados del sitio Calera (cuenca superior del arroyo Tapalqué, provincia de Buenos Aires). Relaciones de la Sociedad Argentina de Antropología 39: 145-173.

Shipman, P., Foster, G. y Schoeninger, M. 1984. Burnt bones and teeth: an experimental study of colour, morphology, crystal structure and shrinkage. Journal of Archaeological Science 11: 307-325.
Taylor, I. 1994. Barn Ow/s, predator-prey relationship and conservation. Cambridge University Press, Cambridge, $324 \mathrm{p}$.

Teta, P., Malzof, S., Quintana, R. y Pereira, J. 2006. Presas del Ñacurutú (Bubo virginianus) en el bajo delta del Río Paraná (Buenos Aires, Argentina). Ornitología Neotropical 17: 441-444.

Tomazzoni, A., Pedó, E. y Hartz, S.M. 2004. Food habits of Great Horned Owls (Bubo virginianus) in Lami Biological Reserve, southern Brazil. Ornitología Neotropical 15: 279-282.

Tonni, E., Bargo, M. y Prado, J. 1988. Los cambios ambientales en el Pleistoceno tardío y Holoceno del S.E. de la Prov. de Buenos Aires a través de una secuencia de mamíferos. Ameghiniana 25: 99-110.

Valverde, F. 2001. Huellas y marcas sobre restos óseos. En: D. Mazzanti y C. Quintana (Eds.), Cueva Tixi: Cazadores y recolectores de las sierras de Tandilia Oriental. I. Geología, Paleontología y Zooarqueología, Publicación Especial 1, Laboratorio de Arqueología, Universidad Nacional de Mar del Plata, Mar del Plata, p. 137-156.

Valverde, F. 2003. Análisis de desechos líticos de la ocupación inicial del sitio Cueva Tixi (provincia de Buenos Aires): cadena operativa de producción y técnicas de talla tempranas. Relaciones de la Sociedad Argentina de Antropología 28: 185-202.

Vargas, J., Landaeta, C. y Simonetti, J. 2002. Bats as prey of barn owls (Tyto alba) in a tropical savanna in Bolivia. Journal of Raptor Research 36: 146-148.

White, T. 1953. A method of calculating the dietary percentage of various food animals utilized by aboriginal peoples. American Antiquity 19: 396-398.

Zucol, A., Brea, M. y Mazzanti, D. 2008. Análisis de restos orgánicos presentes en cerámicas arqueológicas de las sierras de Tandilia (provincia de Buenos Aires, Argentina). En: M.A. Korstanje y M. del P. Babot (Eds.), Matices Interdisciplinarios en Estudios Fitolíticos y de Otros Microfósiles, John and Erica Hedges Ltd, Oxford, p. 201-208.

Doi: 10.5710/PEAPA.06.04.2016.87

Recibido: 22 de Octubre de 2015

Aceptado: 6 de Abril de 2016 